\title{
Survey of Degradation Modes of Candidate Materials for High-Level Radioactive-Waste Disposal Containers
}

\section{Volume 7}

Weldability of Austenitic Alloys

\author{
M. J. Strum, H. Weiss, and J. C. Farmer
}

Lawrence Livermore National Laboratory

Livermore, Calif.

D. B. Bullen

Science \& Engineering Associates, Inc.

Pleasanton, Calif.

June 1988

\section{DISCLAIMER}

\begin{abstract}
This repon was prepared as an account of work sponsored by an agency of the United States Government. Neither the United States Gnvernment nor any agency thereor, not any of their employees, makes any warranty, express or impljed, or assumes any legal liability or responsibility for the accuracy, completeness, or usefulness of any information, apparatus, product, or process disclosed, or represents that its use would not infringe privately owned rights. Reference herejn to any specific commercial product, process, or service by trade name, tradertark, mantufacturer, of otherwise does not necessarily constitute or imply its endorsement, recommendation, or favoring by the Unitod States Government or any agency thereof. The vicws and opinions of authors expressed herein do not necessarily state or rellect those of the United States Government or any agency thercof.
\end{abstract}

\section{LAWRENCE LIVERMORE NATIONAL LABORATORY University of California - Livermore, California - 94550}




\section{Contents}

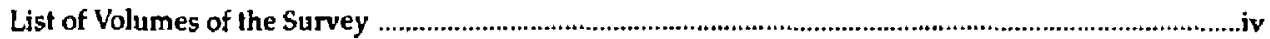

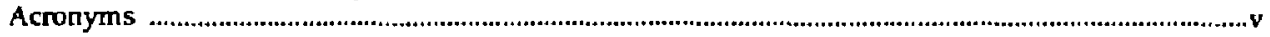

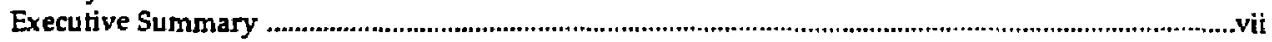

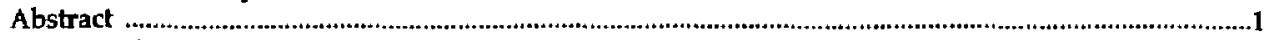

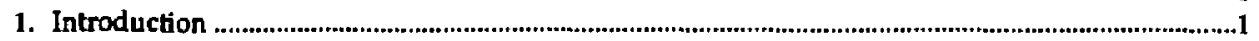

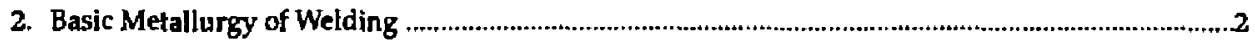

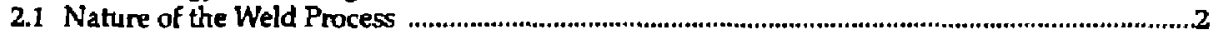

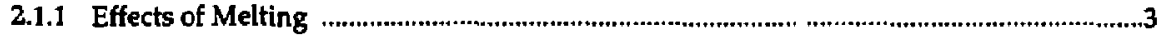

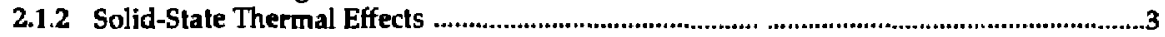

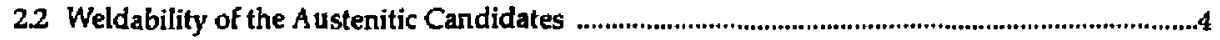

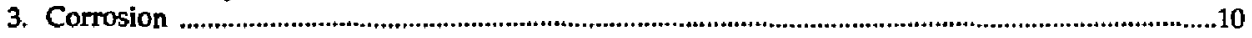

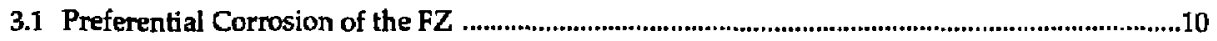

32 Sensitization of Iron- and Nickel-Based Austenitic Alloys ..........................................................11

3.2.1 Effects of Alloying Elements .........................................................................................14

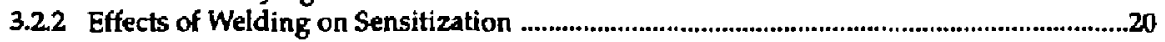

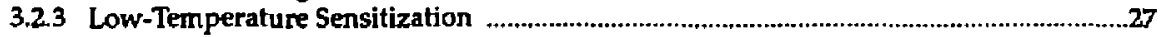

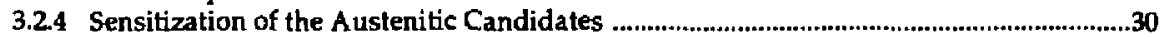

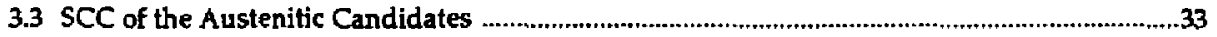

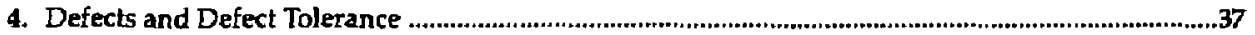

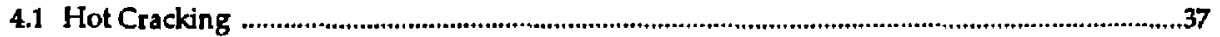

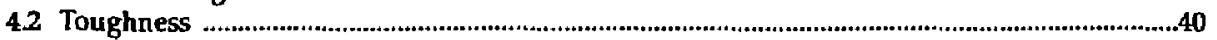

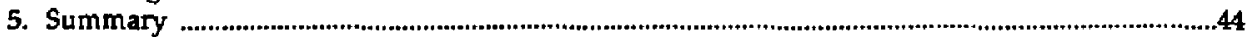

6. Acknowledgments .........................................................................................................................4

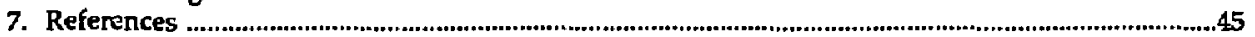




\title{
List of Volumes of the Survey
}

This is Volume 7 of the repurt Survey of Degradation Modes of Candidate Materials for High-Level Radioactive-Wasle Disposal Containers. The titles of all of the volumes are as follows:

\author{
Overview \\ Volume 1: Phase Stability \\ Volume 2: Oxidation and Corrosion \\ Volume 3: Localized Corrosion and Stress Corrosion Cracking of Austenitic Alloys \\ Volume 4: Stress Corrosion Cracking of Copper-Based Alloys \\ Volume 5: Localized Cornosion of Copper-Based Alloys \\ Volume 6: Effects of Hydrogen in Austenitic and Copper-Based Alloys \\ Volume 7: Weldability of Austenitic Alloys \\ Volume 8: Weldability of Copper-Based Alloys
}




\section{Acronyms}

\begin{tabular}{ll} 
AISI & American Iron and Steel Institute \\
ASME & American Society of Mechanical Engineers \\
ASTM & American Society for Testing and Materials \\
bcc & body-centered cubic \\
CDA & Copper Development Association \\
CERT & constant extension rate test \\
CHLW & commercial high-Jevel waste \\
DHLW & defense high-Jevel waste \\
DOS & degree of sensitization \\
EPR & electrochemical potentiokinetic reactivation \\
fcc & face-centered cubic \\
FZ & fusion zone \\
GMAW & gas metal-arc welding \\
GTAW & gas tungsten-arc welding \\
HAZ & heat-affected zone \\
IGSCC & intergranular stress corrosion cracking \\
INCO & International Nickel Company \\
LTS & low-temperature sensitization \\
MIG & metal inert gas \\
MMA & manual metal arc \\
NNWSI & Nevada Nuclear Waste Storage Investigations Project \\
NRC & Nuclear Regulatory Commission \\
NWMP & Nuclear Waste Management Program \\
SAW & submerged arc welding \\
SCC & stress corrosion cracking \\
SEM & scanning electron microscopy \\
SMAW & shielded metal-arc welding \\
TEM & transmission electron microscopy \\
TGSCC & transgranular stress corrosion cracking \\
TIG & tungsten inert gas \\
TTS & time-temperature sensitization \\
WZ & weld zone \\
\hline
\end{tabular}




\section{Executive Summary}

The candidate materials for the fabrication of containers for storing high-level nuclear waste include three austenitic alloys: Types $304 \mathrm{~L}$ and 316L stainless steels and Alloy 825. The nuclear waste will be stored in containers at the prospective repository at Yucca Mountain, Nevada. This volume reviews the degradation modes that result from welding the austenitic candidates. Three specific arcas of concern are discussed in depth: (1) resistance to corrosion, (2) hot cracking, and (3) formation of intermetallic phascs. Corrosion resistance can decrease in weldments because of preferential corrosion, sensitization to intergranular corrosion, and susceptibility to stress corrosion cracking (SCC). Sensitization due to preferential grain-boundary precipitation of $\mathrm{M}_{23} \mathrm{C}_{6}$ carbides within the heat-affected zone (HAZ) of the weld decreases resistance to intergranular corrosion. It also increases susceptibility to intergranular stress corrosion cracking (ICSCC).

The formation of carbides is a nucleation and growth phenomenon affected by time, temperature, chemical composition, and thermal strain. We review models for intergranular corrosion based on localized chromium depletion due to precipitation of carbides at grain boundaries. A compositional model for sensitization is discussed that defines an effective chromium content. The effective chromium content accourits for the beneficial effect of elements such as chromium and molybdenum as well as the detrimental influence of carbon and nickel. Other elements such as silicon, nitrogen, sulfur, manganese, and phosphorus are reviewed with respect to their effects on carbide formation.

Of major interest to the Nevada Nuclear Waste Storage Investigations (NNWSI) Project is the effect of long storage times on nucleated carbides. This effect is typically described as low-temperature sensitization (LTS), i.e., service temperatures are below $400^{\circ} \mathrm{C}$. Although some data are available on Type 304L stainless steel showing a loss of resistance to corrosion, there is a general lack of information on Type 316L stainless steel. The problem in prediction lies in the lack of available data on the long-term growth of the carbides at relatively low temperatures. Even less information is available on the LTS of Alloy 825; it would appear, however, that the high-nickel alloys are not subject to LTS.

Minimizing the carbon content is the most effective means of preventing sensitization. With proper welding procedures, neither of the low-carbon grades of austenitic stainless steels, Type $304 \mathrm{~L}$ or Type 316L stainless steel, will sensitize as a result of weld fabrication. According to the compositional model and confirmations by available data, Type $316 \mathrm{~L}$ stainless steel is more resistant to sensitization than Type 304L stainless steel. While Alloy 825 can be stabilized to impart immunity from traditional sensitization, there is a potential for sensitization after dissolution of the stabilized carbides in multipass welds. Specification of low carbon cantents will prevent this susceptibility. [n addition to the resistance of Alloy 825 to sensitization, jts high nickel content and fully austenitic structure make it the least susceptible to SCC.

The susceptibilities of the weldment to cracking are reviewed with an emphasis on microfissuring of the HAZ. The formation of ferrite in the fusion zone (FZ) is discussed, and theories as to why ferrite provides such a positive countermeasure against grain-boundary cracking are presented. Basically, the ferrite serves to decrease the sensitivity to impurity contents. In terms of resistance of the weldment to cracking, Type 304L stainless steel is best, followed by Type 316L stainless steel and Alloy 825. As in the case of sensitization, there are very few data in the open literature on the causes of hot cracking in Alloy 825 weldments. Much of the reported information was obtained from private communications with individuals having experience in the nickel industry. The most generally accepted method of preventing hot cracking in Alloy 825 is to substitute a weld filler material of a different composition, namely Alloy 625 .

The formation of intermetallic sigma phase $(\sigma)$ can occur at elevated temperatures in austenitic stainless steels, and under certain conditions, it can remain stable at room temperature. Sigma, a hard, brittle, nonmagnetic phase, can result in the reduction of some mechanical properties, namely fracture toughness or impact resistance. Data are presented suggesting that the tate of formation of $\sigma$ and its effects on mechanical properties are inereased by the presence of $\delta$ ferrite in the FZ. Sigma phase is more likely to form in the molybdenum-containing Type 316L stain[ess steel than in Type 304L stainless steel. Although no mention was found of immunity from formation of $\sigma$ in Alloy 825 , its formation is considered highly unlikely on the basis of existing phase diagrams.

On the basis of resistance to corrosion-assisted degradation, the austenitic candidate materials are ranked as follows in terms of weldability: Alloy 825 (best) > Type 316L stainless steel > Type 304L stainless steel (worst). 


\title{
Survey of Degradation Modes of Candidate Materials for High-Level Radioactive-Waste Disposal Containers
}

\author{
Volume 7: Weldability of Austenitic Alloys
}

\begin{abstract}
This volume surveys the effects of welding on the degradation modes of three austenitic alloys: Types 304L and 316L stainless steels and Alloy 825. These materials are candidates for the fabrication of containers for the long-term storage of high-level nuclear waste. The metallurgical characteristics of fusion welds are reviewed here and related to potential degradation modes of the containers. Three specific areas are discussed in depth: (1) decreased resistance to corrcsion in the forms of preferential corrosion, sensitization, and susceptibility to stress corrosion cracking, (2) hot cracking in the heat-affected zone and the weld zone, and (3) formation of intermetallic phases. The austenitic alloys are ranked as follows in terms of overall weldability: Alloy 825 (best) > Type 316L stainless steel > Type 304L stainless steel (worst).
\end{abstract}

\section{Introduction}

The Nuclear Waste Management Program (NWMP) at Lawrence Livermore National Laboratory is responsible for developing the engineered barrier design to meet the Nuclear Regulatory Commission licensing requirements for the permanent disposal of high-level nuclear waste. This waste will include (1) spent fuel from civilian nuclear power plants (fuel assemblies from pressu:ized-water reactors and boilingwater reactors, and consolidated fuel pins; (2) commercial high-isvel waste (CHLW) in the form of spent-fuel reprocessing wastes contained in borosilicate glass, and (3) defense high-level waste (DHLW) contained in borosilicate glass. The waste package is being designed for emplacement in a geologic repository at a site at Yucca Mountain, Nevada. The reference horizon is located in the Topopah Spring Member of the Paintbrush Tuff, $350 \mathrm{~m}$ below the ground surface and $200 \mathrm{~m}$ above the static water table. The composition of the vadose water results in slightly oxidizing conditions in the repository:

The Metal Barrier Selection and Testing Task of the Nevada Nuclear Waste Storage Investigations (NNWSI) Project has as its objective the selection of a candidate material to be used in the waste-package container that will meet the requirements set forth in the relevant federal regulations $[1,2]$. Six candidate materials are currently under consideration, including these austenitic materials: Types 304L and 316L stainless steels and Alloy 825 . The austenitic materials have been selected as a result of their relatively high strength and good corrosion resistance. The specified ranges of composition of these alloys are presented in Table 1 . The remaining materials under consideration are three copper-based alloys: CDA 102 (oxygen-free copper), CDA 613 (Cu-7Al), and CDA 715 (Cu-30Ni).

The design criteria for the metal barrier require that the waste container maintain chemical and mechanical integrity for a period of about $50 \mathrm{yr}$ after emplacement to permit the nuclear waste to be retrieved during the preclosure phase of repository operation $[1,2]$. The engineered barrier system must provide substantially complete containment for at least $300 \mathrm{yr}$ and perhaps as long as 1000 yr. During the containment period, the metal barrier will be exposed to a changing environment. Radioactive decay of the stored waste will result in substantial heat generation. Initially, many of the waste packages will be at a temperature of about $250^{\circ} \mathrm{C}\left(482^{\circ} \mathrm{F}\right)$. After $100 \mathrm{yr}$ of storage, the temperature will drop to about $150^{\circ} \mathrm{C}\left(302^{\circ} \mathrm{F}\right)$. The resistance of the container material to corrosion over these time periods will have an impact on the mechanical behavior of the metal barrier. Degradation modes include 
Table 1. Elemental compositions of the austenitic candidate alloys (wt \%).

\begin{tabular}{|c|c|c|c|c|c|}
\hline \multirow[b]{2}{*}{ Element } & \multicolumn{4}{|c|}{ Stainless steels } & \multirow[b]{2}{*}{ Alloy 825} \\
\hline & 304 & $304 \mathrm{~L}$ & 316 & $316 \mathrm{~L}$ & \\
\hline C & 0.08 & $0.03 \max$ & 0.08 & $0.03 \mathrm{max}$ & $0.05 \max$ \\
\hline Mn & 2.00 & $2.00 \max$ & 2.00 & $2.00 \max$ & $1.0 \max$ \\
\hline Si & 1.00 & $1,00 \max$ & 1.00 & $1.00 \max$ & $0.5 \max$ \\
\hline Cr & $18.0-20.0$ & $18.0-20.0$ & $16.0-18.0$ & $16.0-18.0$ & $19.5-23.5$ \\
\hline $\mathrm{Ni}$ & $8.0-10.5$ & $8.0-12.0$ & $10.0-14.0$ & $10.0-14.0$ & $38.0-46.0$ \\
\hline $\mathbf{P}$ & 0.045 & $0.045 \max$ & 0.045 & $0.045 \max$ & - \\
\hline s & 0.03 & $0.03 \max$ & 0.03 & $0.03 \max$ & $0.03 \max$ \\
\hline $\mathrm{Cu}$ & - & - & - & - & $1.5-3.0$ \\
\hline $\mathrm{Ti}$ & - & - & - & - & $0.6-1.2$ \\
\hline $\mathbf{N}$ & 0.10 & 0.10 & 0.10 & 0.10 & - \\
\hline Mo & - & - & $2.0-3.0$ & $2.0-3.0$ & 3.0 \\
\hline $\mathrm{Fe}$ & Bal. & Bal. & Bal. & Bal. & Bal. \\
\hline
\end{tabular}

uniform aqueous phase corrosion and various torms of localized corrosion. Precipitation of carbides at grain boundaries can modify the local alloy composition, resulting in conditions favorable to intergranular stress corrosion cracking (IGSCC). The formation of sigma phase $(\sigma)$ and the development of microcracks during the welding process can potentially reduce the fracture properties of the material.

This volume on the austenitic candidate materials reviews the basic metallurgy of the austenitic alloy system, discusses the effects of welding on corrosion, and examines the potential loss of toughness in weldments. Areas are highlighted in which significant data and results exist in the literature, and areas are identified in which very little data is found. The effects of welding on the copper-based candidates are surveyed in Vol.8.

A discussion on the methodology and extent of the literature search can be found in the Overview.*

\section{Basic Metallurgy of Welding}

\subsection{Nature of the Weld Process}

From the viewpoint of the metallurgical effects of welding, the welding processes can be divided into fusion and solid-state techniques. Fusion welding involves heating the surfaces to be joined to above the melting point and, if necessary, adding filler metal to fill the joint gap.

Solid-state joining processes require only the creation of clean surfaces and subsequent contact to allow formation of a metallic bond. Because fusion processes are nomally required for joining large structures, and because fusion processes encompass more of the pertinent metallurgical concerns, this discussion will focus on the effects of fusion welding.

A fusion weld has been termed a microcosm that involves melting, solidification, and virtually every microstructural change that can be produced by thermal treatments [3]. The metallurgical effects of the welding process are heterogeneous, and it is therefore useful to describe discrete zones within a weldment. The fusion zone (FZ) consists of a composite of filler metal diluted by the surrounding base metal. This zone is surrounded by an unmixed zone consisting of base metal melted without mixing. Its outer edge defines the weld interface

- j. C. Farmer, R. D. McCright, J. N. Kass, Survey of Degradation Modes of Candidate Materials for HighLecel Radioactive-Write Disposal Containers, Oventiew, Lawrence Livermore National Laboratory, Livermore, California, UCID-21362 Overview (1988). 
(or fusion line). Further from the FZ exists the partially melted zone, where localized liquid films may form at low solidus regions such as segregated grain boundaries. Beyond this region is the true heat-affected zone (HAZ), where all microstructural changes are restricted to the solid state. The fusion-welding process and process variables influence the extent and morphology of these zones. The widths of the partially melted zone and $H A Z$ are inversely related to the sleepness of the thermal gradient, which increases with the power density of the heat source. The extent of the unmixed zone decreases in processes that permit uniform melting and mixing of the filler metal. Processes such as cold-wire-feed gas tungsten-arc welding (GTAW) minimize the formation of unmixed zones, while more erratic weld-pool mixing, as in gas metal-arc welding (GMAW) or shielded metal-arc welding (SMAW), is more likely to produce unmixed zones [4].

\subsection{Effects of Melling}

Melting and subsequent resolidification in weldments result in significant compositional and microstructural changes relative to the wrought parent metal. A number of reactions can occur in the liquid metal. Protection of the molten surface from atmospheric oxygen and nitrogen is accomplished through the use of flux and/or protective atmospheres. Oxygen pickup and the content of oxide inclusions are minimized through the exclusive use of protective atmospheres, which may consist of inert-gas shielding or evacuation. Because the maximum temperatures in the $\mathrm{FZ}$ can approach the boiling point, vapoization losses may also occur. Elements with low vapor pressure will be preferentialiy depleted from the FZ and may necessitate the use of overalloyed filler metal to compensale for these losses.

Another means through which compositional heterogeneity occurs in weldments is by solidification segregation. Solidification in welds requires the redistribution of composition between the solid and liquid phases. The first solid to form is either enriched or depleted in alloying elements relative to the remaining liquid. This phenomenon leads to the formation of a concentration gradient at the solid-liquid interface. The rapid cooling rates characteristic of weldments limit compositional homogenization during solidification to the liquid phase and only by diffusion (mechanical mixing in the liquid and diffusion in the solid are not significant) [3]. In highly alloyed materials such as the austenitic alloys, these restrictions typically result in a cellular-dendritic mode of solidification and microsegregation. The solidification fronts grow epitaxially from the equiaxed parent metal grains as spikes along the major dirertion of heat extraction. The surrounding liquid is later consumed by lateral growth. Because of solute rejection at the solid-liquid interface, both the initial and final liquids to solidify can be of a significantly different composition than that of the average $F Z$. The extent of microsegregation is dependent on the equilibrium distribution coefficients of the solute species between the solid and liquid phases.

The last liquid to solidify is typically enriched in low-melting solutes and solidifies at a temperature well below the equilibrium (bulk) solidus. This has a marked influence on the resistance of the weldment to hot cracking. Solute elements that severely depress the effective solidus (temperature at which the last liquid aciually solidifies) have the largest negative impact on resistance to hot cracking and microfissuring. Hot cracks are believed to initiate at liquated grain boundaries in the $F Z$ and partially melted zone. Microfissuring accurs during reheating of underlying weld beads in multipass welds. The region of partial melting in the underlying weld bead is extended by the presence of microsegregation. The driving force for hot cracking and microfissuring is the tensile stress produced by the shrinkage strains during weld solidification and cooling. The residual stresses in a weld generally increase with increased restraint, as in thick-section welds, and can reach the ambirnttemperature yield strength of the weldment.

\subsection{Solid-State Thermal Effects}

The thermal cycles in the HAZ vary with location and reach peak temperatures ranging from near-ambient to near the melting point. The cooling rates in the HAZ are dependent on factors such as the physical properties of the material, section sizes, ambient temperatures (or interpass temperatures), the power density of the heat source, and the heat input. The thermal history of a particular $H A Z$ region is dependent on the total number of weld passes as well as geometric factors such as the width of the HAZ relative to the size of the weld beads. The width of the HAZ and the extent of thermal exposure above a criti. cal temperature or within an elevated temperature range is dependent on the selection of the weld process and fabrication technique. 
Exposure to elevated temperatures in the $\mathrm{HAZ}$ is limited by the use of a high-power-density process, low heat inputs, and low preheat and interpass temperatures.

In solid-solution alloys, the effect of $\mathrm{HAZ}$ thermal cycles is small. The most significant effect is grain growth at the regions of highest peak temperature near the partially melted zone. In previously cold-worked material, HAZ temperatures can also cause recrystallization. The effects on the HAZ in precipitation-hardened alloys or alloys subject to solute precipitation are more complex. The welding heat will re-solutionize the precipitates in regions of high peak temperature, and enhance precipitation or cause overaging at intermediate peak temperatures. Carbide precipitation in the HAZs of welds is a common concern in austenitic alloy weldments.

\subsection{Weldability of the Austenitic Candidates}

Several general review articles on the constitution and struclure of stainless steels and austenitic alloys have been identified in the technical literature [e.g., 5-7]. A summary of these articles is provided here.

The austenitic candidate materials are all derived from the ternary iron-chromium-nickel system. The most basic phases encountered in this ternary system are dictated by the allotropic forms of iron, which can be identified in the chromium-iron binary phase diagram shown in Fig. 1 [8]. Between the melting point of $1539^{\circ} \mathrm{C}$ $\left(2800^{\circ} \mathrm{F}\right)$ and about $1390^{\circ} \mathrm{C}\left(2558^{\circ} \mathrm{F}\right)$, pure iron exists as a body-centered cubic (bec) structure that is usually called delta $(\delta)$ ferrite. From about

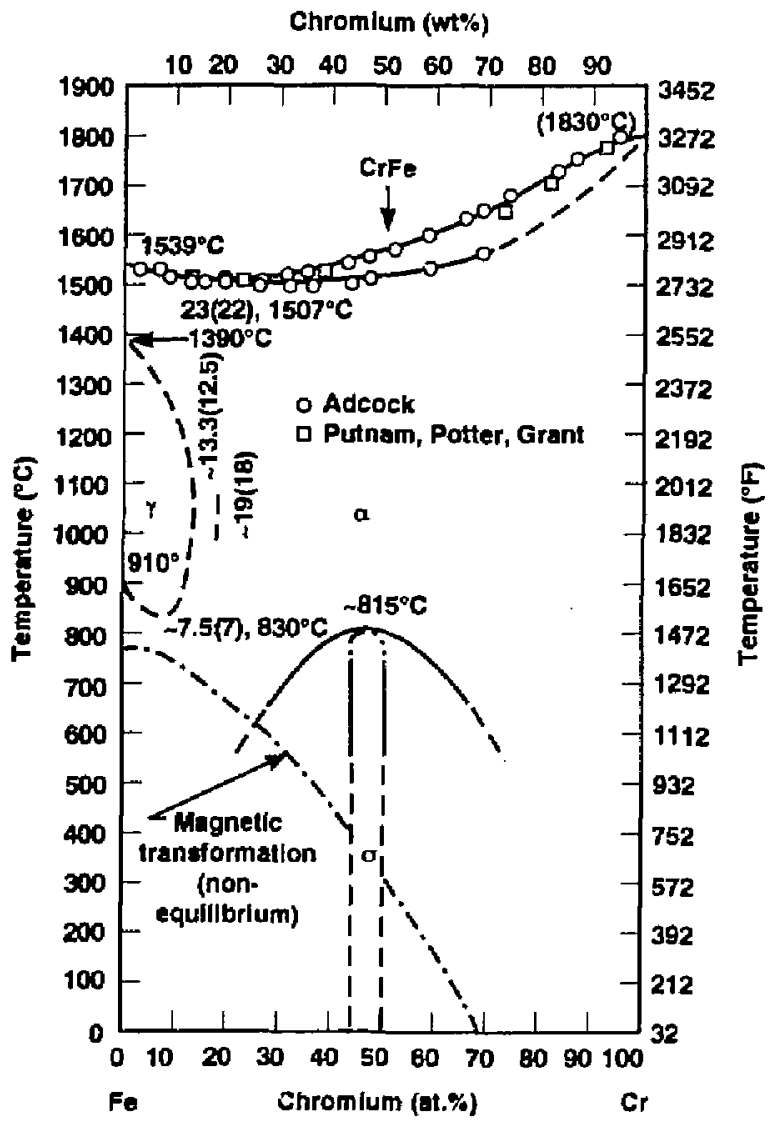

Figure 1. Chromium-iron binary equilibrium phase diagram [8]. 
1390 to $910^{\circ} \mathrm{C}\left(2550-1670^{\circ} \mathrm{F}\right)$, the structure of iron is face-centered cubic ( $\mathrm{fcc}$ ) and is called austenite or gamma phase $(\gamma)$. Below $910^{\circ} \mathrm{C}\left(1670^{\circ} \mathrm{F}\right)$, iron again becomes bcc, with a structure identified as alpha $(\alpha)$ ferrite. There is no obvious microstructural difference between $\delta$ and $\alpha$ ferrite. This nomenclature has been adopied to provide a distinction between the conditions of formation of the ferrite.

The addition of chromium (up to about $7 \mathrm{wt} \%$ ) to iron lowers the austenite temperature range, as indicated on the left side of Fig. 1.

Above $7 \mathrm{wt} \%$ chromium, the temperature range over which austenite exists is gradually reduced. Above 13 wt\% chromium, no $\alpha$ to $\gamma$ transformation occurs, and ferrite is stable at all temperatures. Hence, chromium is said to be a ferriteforming element. Other elements commonly used in stainless steels that behave similarly to chromium are molybdenum, silicon, aluminum, titanium, and niobium.

Austenitic alloys all contain more than $\mathbf{1 6}$ wt\% chromium, which should produce an entirely ferritic material (Fig. 1). The effect of chromium is counteracted, however, by the addition of nickel. Figure 2 shows the equilibrium phase diagram for the iron-nickel system [8]. The austenite phase region is significantly increased by the addition of nickel to iron. Therefore, nickel is called an austenite-forming element. Manganese and cobalt are other examples of austenite-forming elements.

The effect of the balance of chromium and nickel additions on phase equilibria is shown in the pseudobinary-alloy phase diagrams for $63.5 \%$ iron alloys in Fig. 3, and for 50, 60, 70, and 80\% iron alloys in Fig. 4. The iron-nickel-chromium ternary alloy phase diagram at $650^{\circ} \mathrm{C}\left(1202^{\circ} \mathrm{F}\right)$ is

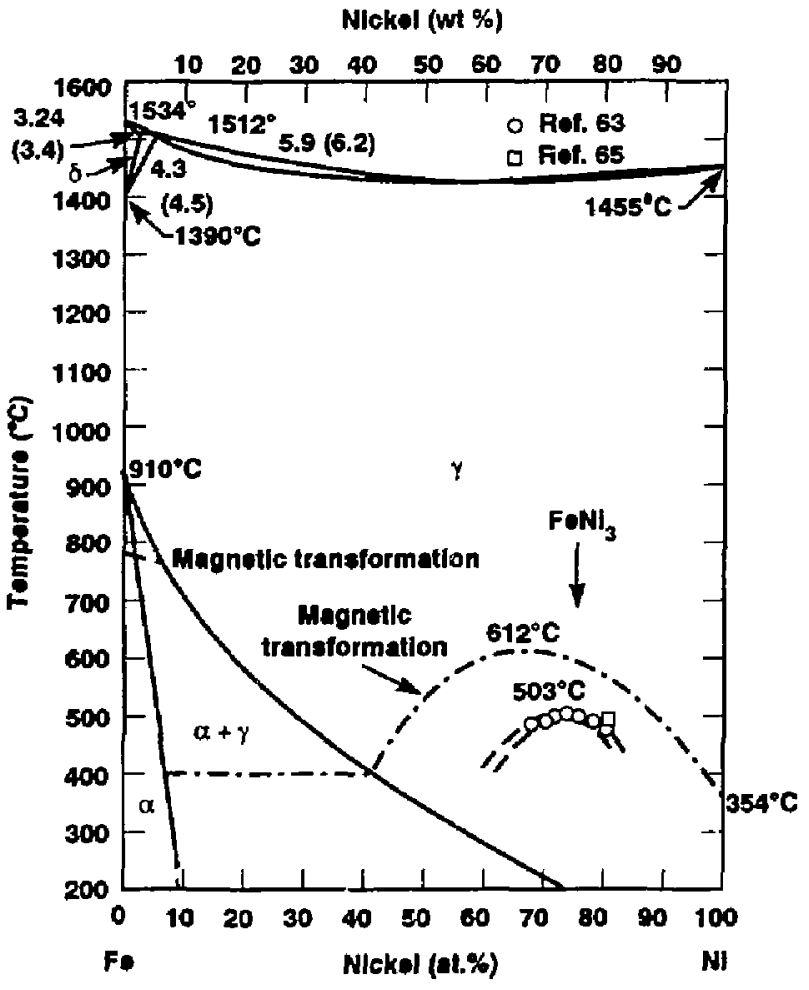

Figure 2. Iron-nickel binary equilibrium phase diagram [8]. 


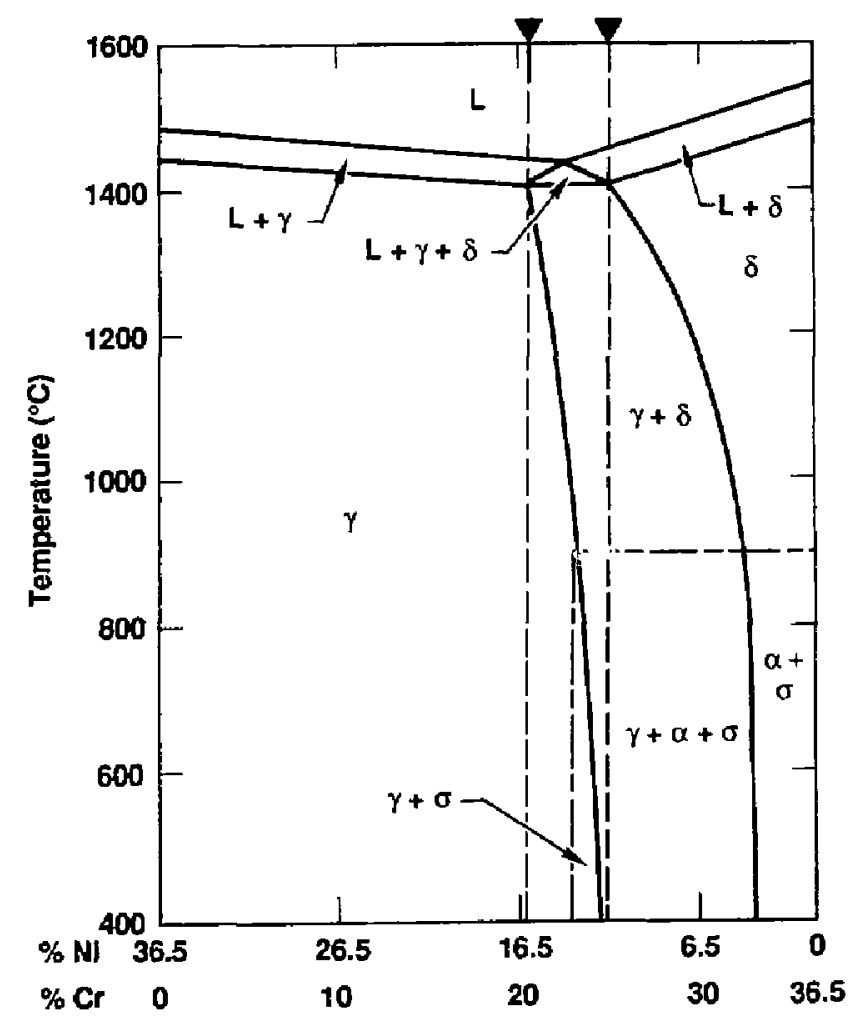

3i;ure 3. Vertical section of the ternary iron-chromium-nickel pnase diagram at $63.5 \mathrm{wt} \%$. The dotted lines define typical alloy ranges for duplex weld metals [98].

shown in Fig. 5. The primary mode of solidification in austenitic welds and the resulting ferrite content are very important for the control of microfissuring and other second-phase concerns. Therefore, the concepts of chromium equivalent and nickel equivalent were developed. These values incorporate the tendency of additional alloying elements to stabilize either the austenite phase (as does nickel) or the ferrite phase (as does chromium). From these equivalent compositional values, a constitution plot mapping the amount of retained ferrite in weld FZs can be derived, as determined by Schaeffler (Fig. 6) and also by DeLong (Fig. 7).

As a class of materials, the austenitic alloys are considered the most weldable of any of the high-alloy steels. This is due to the good toughness of austenitic alloy weldments, even in the as-welded condition. Even so, there are three general concerns with respect to the weldability of these materials. These concerns are:

(1) preservation of the corrosion resistance,

(2) prevention of cracking and (3) avoidance of harmful effects from intermetallic formation. The principal concern with respect to corrosion resistance of the weldment is prevention of sensitization to intergranular corrosion and intergranular stress corrosion cracking (IGSCC). Sensitization is basically a result of chromium depletion surrounding chromium-rich carbide precipitales in the HAZ. The susceptibility to sensitization can be reduced through compositional control of alloying-element additions and by limiting the extent of thermal excursions within the sensitization temperature range. Limitation of carbon contents, as in Types 
Chromlum (\%)

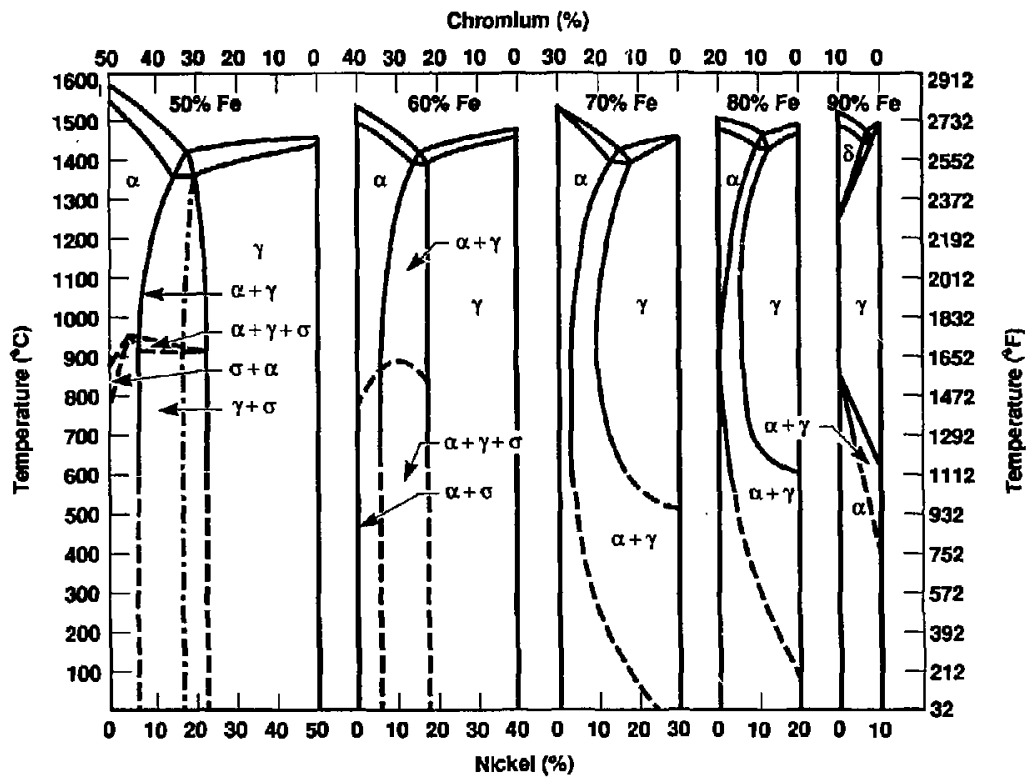

Fig. 4. Cross sections of iron-chromium-nickel temary phase diagram [101]. 


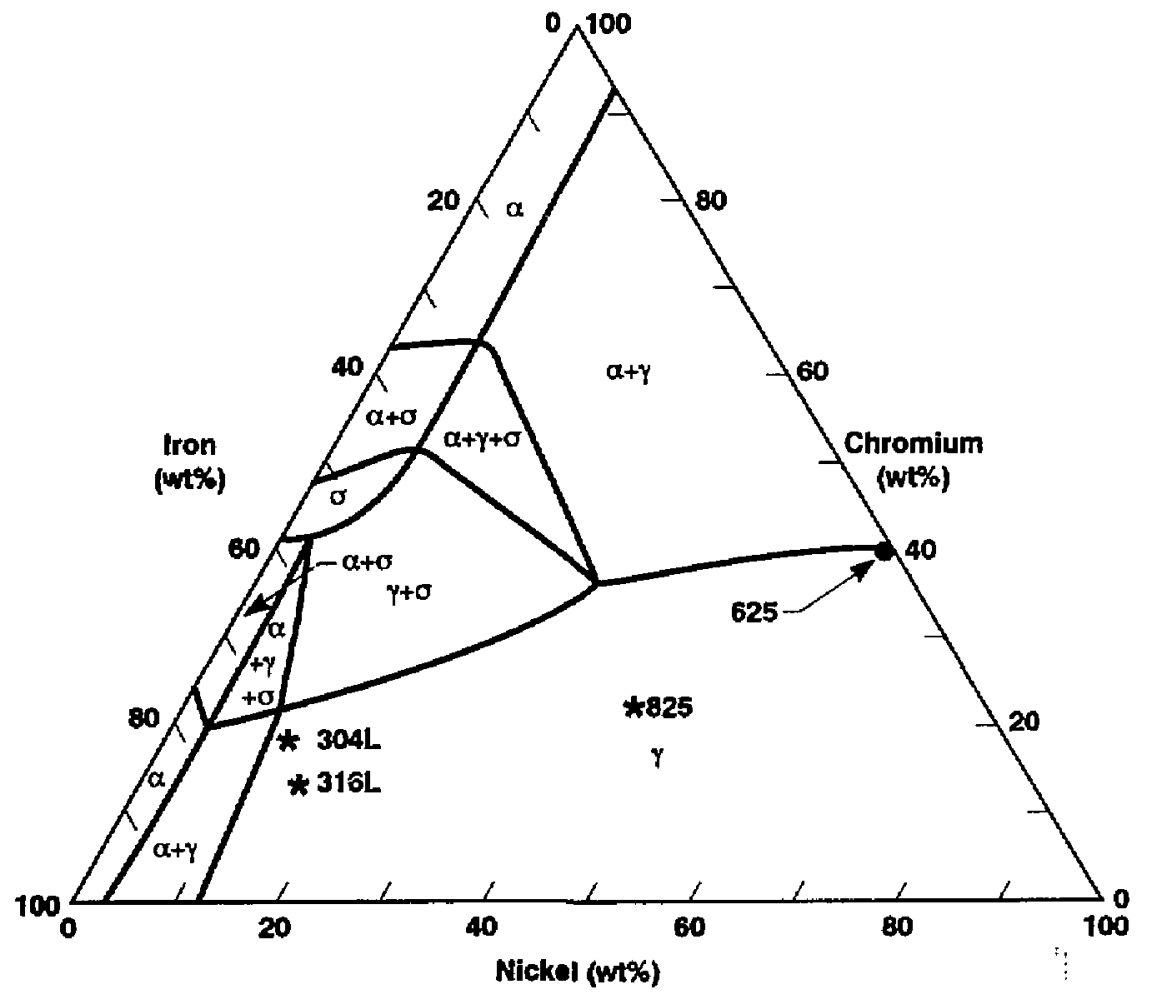

Figure 5. Iron-chromium-nickel equilibrium phase diagram at $650^{\circ} \mathrm{C}\left(1202^{\circ} \mathrm{F}\right)$. Nole the location of Types 304L and 316L stainless steels and Alloy 825, plotled using nickel and chromium equivalent values [4].

304L and 316L stainless sleels, is the most effective means of decreasing the susceptibility to sensitization.

Cracking during solidification and reheating is also strongly dependent on alloy and impurity contents but is most easily avoided by an indirect effect of chemistry on solidification behavior. Solidification as primary ferrite or insurance of at least 3 to $5 \%$ residual ferrite in the final microstructure avoids most cracking concerns in these alloys. The precipitation of intermetallics such as o phase can embrittle austenitic steels. Such embrittlement is dependent on the extent and distribution of intermetallic formation as determined $b_{y}$, the composition, thermal history, and ferrite content (which can accelerate o formation).

The high-nickel alloys such as A!loy 825 possess welding characteristics somewhat different from those of the austenitic stainless steels. In addition to the welding conc:rns for Types $304 \mathrm{~L}$ and $316 \mathrm{~L}$ stainless steels, three concerns can be listed. These are: (1) an increased necessity for cleanliness, (2) the inherently viscous weld metal, and (3) the characteristically low penetration. As pointed out by Kaiser [9], these concerns make the welding of high-nickel alloys different but not necessarily difficult. The necessity for increased cleanliness is twofold. First, unlike iron oxide, nickel oxide melts at temperatures above the typical temperature in the $\mathrm{FZ}$ and must be avoided to prevent lack-of-fusion or trapped oxide defects. Second, the sensitivity to cracking increases with nickel content, and deleterious impurities such as sulfur, lead, phosphorus, zirconium, and boron must be avoided [4]. Alloy 825 is fully austenitic and more susceptible to microfissuring than Type 304L stainless steel, especially in thick sections. Filler melals 


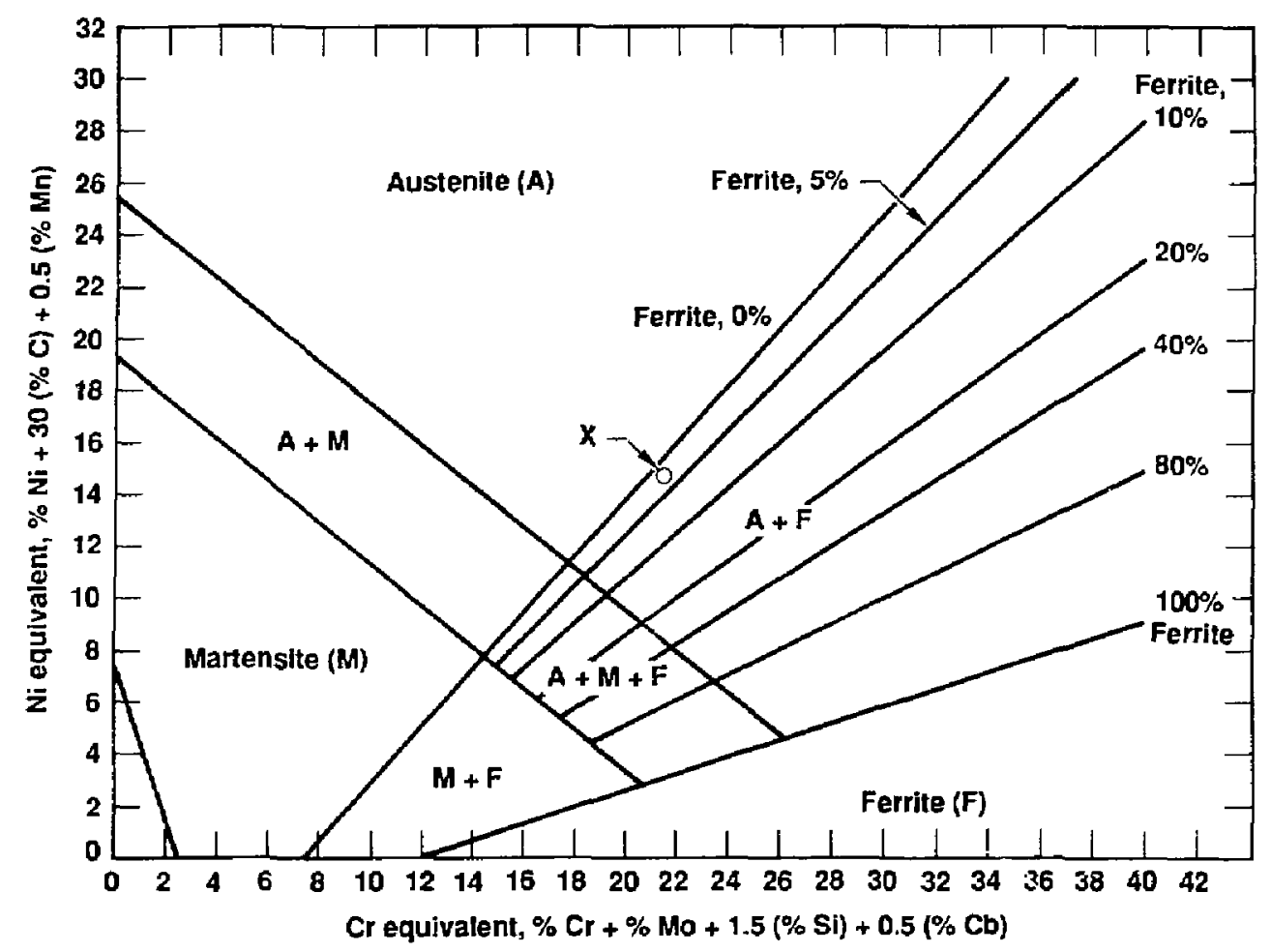

Figure 6. A Scheeffler diagram [78].

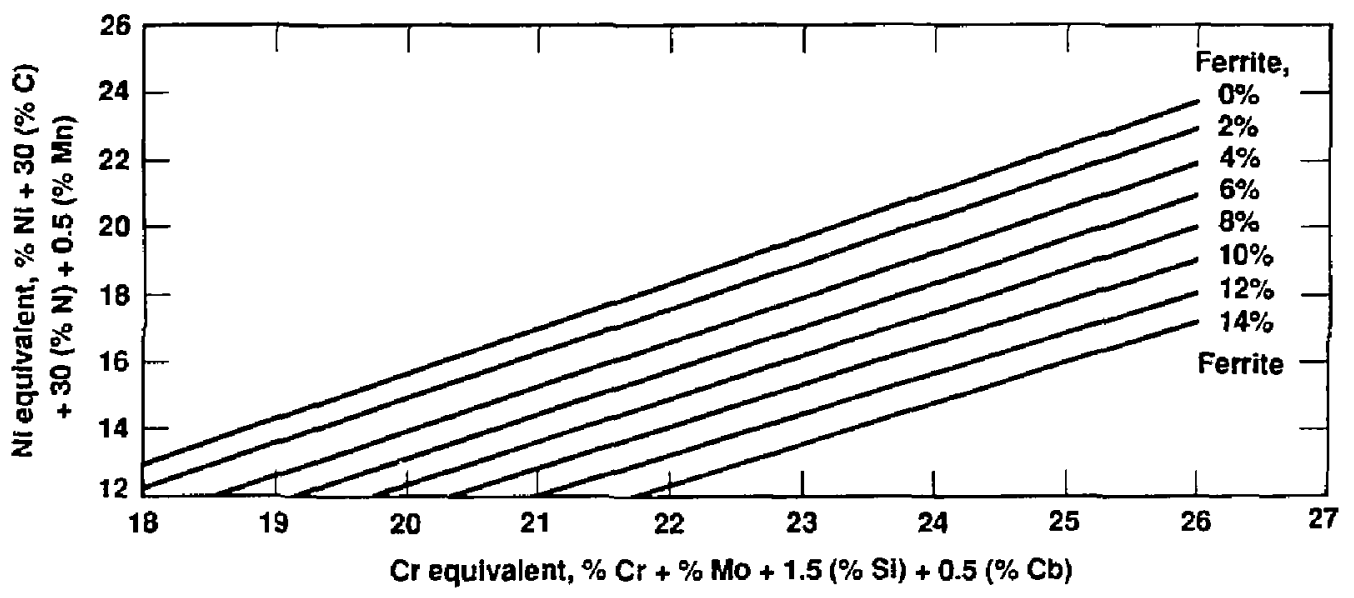

Figure 7. A DeLong diagram [79]. 
designed for improved resistance to cracking. such as Alloy 625 , reduce this concern. The viscous nature of high-nickel alloys requires special attention to are manipulation to ensure complete fusion with the sides of the joint. This is typically achieved with proper weld pracedures. Last, the characteristically low penetration of high-nickel alloys must simply be accepted to avoid overheating.

\section{Corrosion}

The resistance of the austenitic candidates to corrosion can be significantly altered by the welding process. Attention must be given to the potential for preferential corrosion in the FZ, sensitization in the HAZ, and enhanced susceptibility to stress corrosion cracking (SCC). Both the potential causes of weld-induced decreases in corrosion resistance and preventive procedures are discussed here. Corrosion resistance of the weldment equivalent to that of the parent metal can be achieved through control of parent-metal chemistry and the use of proper welding procedures. Proper welding procedures include the maintenance of cleanliness, selection of appropriate filler metals, and limitation of weld heat inputs, preheat, and interpass temperatures.

\section{I Preferential Corrosion of the FZ}

Relative to the wrought parent metal, the $\mathrm{FZ}$ of a weldment is inhomogeneous in composition and microstruciure. Because corrosive processes are selective, choosing the most susceptible region for attack, this inhomogeneous nature of the $\mathrm{FZ}$ can lead to preferential corrosive attack. Inhomogeneities may arise from the localized depletion of alloying elements by either alloy segregation during solidification or by sublimation during melting. This can result in preferentia] corrosive attack of these regions. Therefore, filler metals are often designed to compensate for these effects through overalloying. Microstructural differences in the $\mathrm{FZ}$ can also alter the corrosion resistance. Solidification segregation can enhance the formation of second phases such as intermetallics and stabilize the hightemperature ferrite. Weld filler metals for the austenitic alloys are commonly designed to initially solidify as $\delta$ ferrite to reduce susceptibility to microfissuring. This results in duplex austenitic/ferritic microstructures in the rapidly cooled $\mathrm{FZ}$.
Lacalized depletion of alloying elements responsible for good corrosion resistance can result in accelerated corrosion within the $\mathrm{FZ}$. Garner [10] has shown that molybdenum- and chromium-dejleted regions in the dendritic structure of the $F Z$ undergo preferential attack over a wide range of oxidizing conditions. This preferential attack is considered to be more of a problem in primary austenitic solidification, which leaves the dendrite cores depleted in molybdenum and chromium. Primary of ferrite solidification results in molybdenum and chromium enrichment at the dendrite cores, with depletion of these elements in the interdendritic regions. David et al. [11] have shown that the retained ferrite is depleted in nickel as well as being enriched in chromium.

The influence of autogenous welding on resistance to pitting in the FZ has been quantified for several high-alloy stainless steels by Garner $[10,12]$. Both potentiostatic and isothermal immersion tests in $10 \% \mathrm{FeCl}_{3}$ show reductions in the resistance of austenitic alloys to pitting after autogenous welding. The loss of pitting resistance relative to the unwelded parent metal increases with increasing molybdenum content in the high-alloy steels. A roughly linear relationship is observed between the critical pitting temperature and the molybdenum content for both parent and weld metal. The improvement in the pitting resistance in the weld metal, however, increases more gradually with increasing molybdenum content than in the parent metal. Because of this relationship, the pitting resistance of the parent metal can be achieved in the weld through the use of overalloyed filler metals enriched in molybdenum. For example, the pitting protection of the $3.2 \%$ molybdenum Type 317L stainless steel parent metal is achieved using a $3.8 \%$ molybdenum Type 317L stainless steel or higher-alloy filler metal. Alloys such as Type 304 stainless steel without molybdenum additions are typically welded with a filler metal of higher nickel and 
chromium content (such as Type 308 filler, which is used for welding Type 304 stainless steel parent metal) [13].

While the use of overalloyed filler metals increases the corrosion resistance of the $\mathrm{FZ}$, unmixed zones may also exist. Unmixed zones are essentially very thin autogenous welds with a chemistry similar to the parent metal. These unmixed zones are expected to possess the corrosion resistance of the welded parent metal. Skillful welding can avoid surface unmixed zones and prevent associated preferential corrosion in welds with enriched filler metals.

Preferential corrosion may also occur in the FZ due to the presence of second phases.

Austenitic alloys commonly contain 5 to $10 \%$ retained $\delta$ ferrite in the $\mathrm{FZ}$. This ferrite is present in the form of a continuous or nearly continuous dendritic network at these levels. As in the case of solidification segregation discussed above, compositional partitioning between the ferrite and austenite exists but with a sharp discontinuity in composition at the austenite / ferrite interface. This can result in galvanic coupling, and preferential attack of the ferrite has been observed $[11,14]$. Preferential attack of the ferrite may occur in strong mineral acids and in strongly reducing media such as ammonium carbamate [14]. For this reason, ferrite levels may be limited to less than $2 \%$ (to ensure discontinuous networks) and special precautions taken to avoid the greater susceptibility to microfissuring. The influence of ferrite on SCC will be discussed below. Ferrite, and molybdenum- and chromium-rich regions, can also provide a fast transformation path for intermetallics enriched in these elements. At temperatures above $600^{\circ} \mathrm{C}$, ferrite has been observed to transform to $a$ or $\chi$ phases $[10,15,16]$. These molybdenum-and chromium-rich precipitates are not attacked under mild or moderate oxidizing conditions but are susceptible to attack in reducing acids or highly oxidizing acids [12]. Sensitization of weld microstructures to localized corrosive attack by the precipitation of semicontinuous chromiumrich carbides will be discussed below.

\subsection{Sensitization of Iron- and Nickel- Based Austenitic Alloys}

Sensitization due to welding is the most common cause of weld-related intergranular corrosion in austenitic alloy components of the chemical and power industries [17]. Sensitization describes a metallurgical condition in which the material is rendered susceptible to localized corrosive attack at the grain boundaries. The loss of corrosion resistance is generally a result of slow cooling through a particular temperature regime [18], within which chromium-rich carbide precipitation occurs. When weld sensitization occurs, it is associated with the HAZ of the weld.

Three theories have been proposed to explain the intergranular corrosion of sensitized austenitic steels: Bain et al.'s chromium depletion theory [19], the noble carbide theory [20], and the segregation theory [21]. Bain et al.'s classical chromium depletion theory seems to be the most credible. The noble carbide theory argues that intergranular corrosion is brought about by an electrochemical reaction between the carbide particles and the matrix and proceeds along a continuous path of connected carbide particles. The segregation theory described by Aust [21] explains intergranular corrosion as a result of a continuous grain-boundary path of either second-phase or soluble segregate resulting from solute-vacancy interactions. Some evidence exists supporting the role of grainboundary segregation of phosphorus in accelerating grain-boundary conrosion in material without grain-boundary carbide precipitation [22].

The chromium depletion theory is based on two main assumptions: (1) the bulk material contains sufficient chromium to provide a protective passive film (generally agreed to be 13-15 wt\% chromium), and (2) the material adjacent to a chromium-rich carbide particle precipitated in the sensitization range will have a chromium content below that required for passivation. Bain and his co-workers theorized that, during sensitizing heat treatro $\in$ nts, cilromiurr:-rich carbides preferentially precipitate along grain boundaries. Chromium, having a much slower diffusion rate than carbon, is initially drawn from the surrounding grain-boundary regions. At sensitizing temperatures, the replenishment of chromium from the surrounding matrix is prevented by the slow matrix diffusivity of chromium. The chromium deficiency in the grain-boundary area surrounding the carbide creates a grain boundary susceptible to localized intergranular attack.

A susceptible microstructure results when chromium carbide precipitation at the grain boundaries depletes the chromium content of the surrounding grain-boundary area below the critical level required for passivity (Fig. 8). In the 


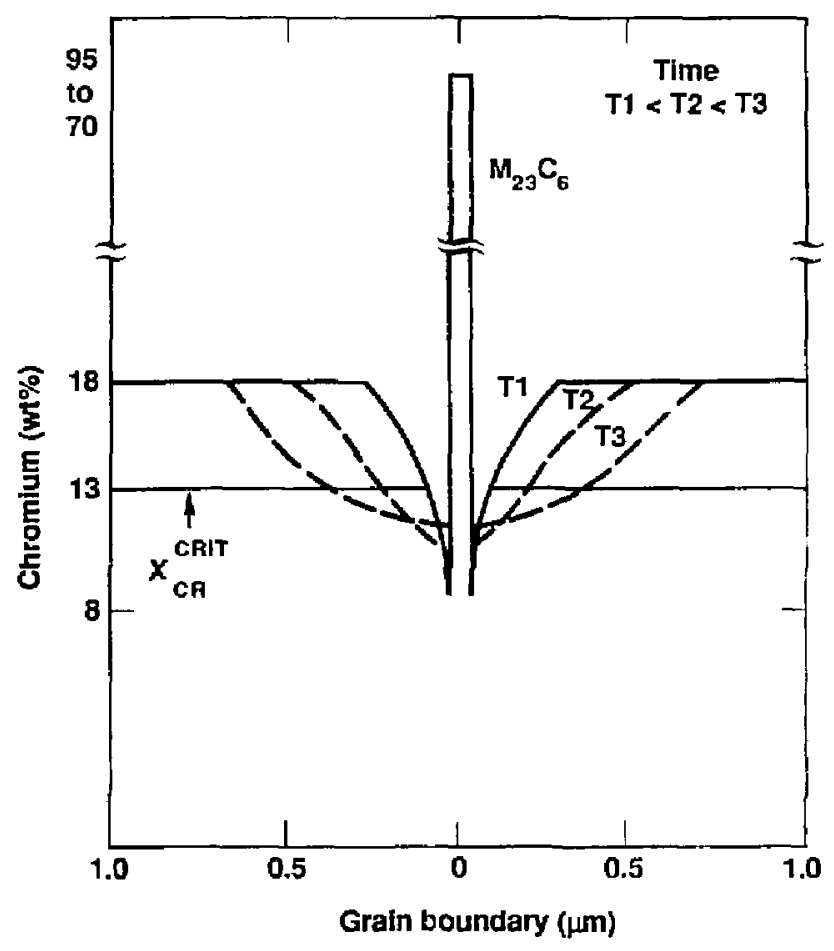

Figure 8. Diagram of the chromium profile in the vicinity of a grain boundary as a function of time (chromium depletion theory) [52].

absence of any strong carbiđe-forming element, the principal carbide formed is $\mathrm{M}_{23} \mathrm{C}_{6}$, where $\mathrm{M}$ is primarily chromium, although other elements such as iron and molybdenum can partially substitute fer the chromium. Precipitation of $\mathrm{M}_{23} \mathrm{C}_{6}$ takes place in the approximate temperature range of 450 to $950^{\circ} \mathrm{C}\left(842\right.$ to $1742^{\circ} \mathrm{F}$ ) [23]. However, weld sensitization is only observed in a more limited temperature range, typically between $\mathbf{5 5 0}$ and $800^{\circ} \mathrm{C}\left(1022\right.$ to $\left.1472^{\circ} \mathrm{F}\right)$, and is strongly dependent on composition as well as the strain state and thermal history $[18,24]$.

More recent theoretical and experimental studies $[23,25]$ have provided a more quantitative approach to the local chromium-carboncarbide equilibrium at the grain boundary. The studies assumed that the local concentration of chromium immediately adjacent to a carbide particle could be calculated from the equilibrium constant for the solubility of chromium carbide in an austenite matrix:

$$
23 \mathrm{Cr}+6 \mathrm{C} \leftrightarrow \mathrm{Cr}_{23} \mathrm{C}_{6}
$$

The equilibrium constant is given by:

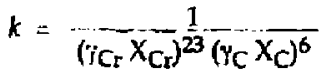

The activity coefficients of carbon, $\gamma_{C}$, and of chromium, ${ }_{\mathrm{C}_{r}}$ were oblained from available experimental data combined with a Wagner analysis [26], while unit activity is assumed for the carbide. With the determination of ${ }^{\gamma} \mathrm{C}$ and ${ }_{\mathrm{Cr}}$ the chromium composition at the grain boundary, $X_{C_{r}}$, in equilibrium with the carbide can be calculated from Eq. (2), assuming that the carbon activity, ${ }_{C} X_{C}$ is fixed by the bulk chromium composition. This calculation seems reasonable since carbon has a much higher diffusion rate than chromium at sensitizing temperatures.

Figure 9 gives the calculated values for the chromium concentration in the grain boundary 


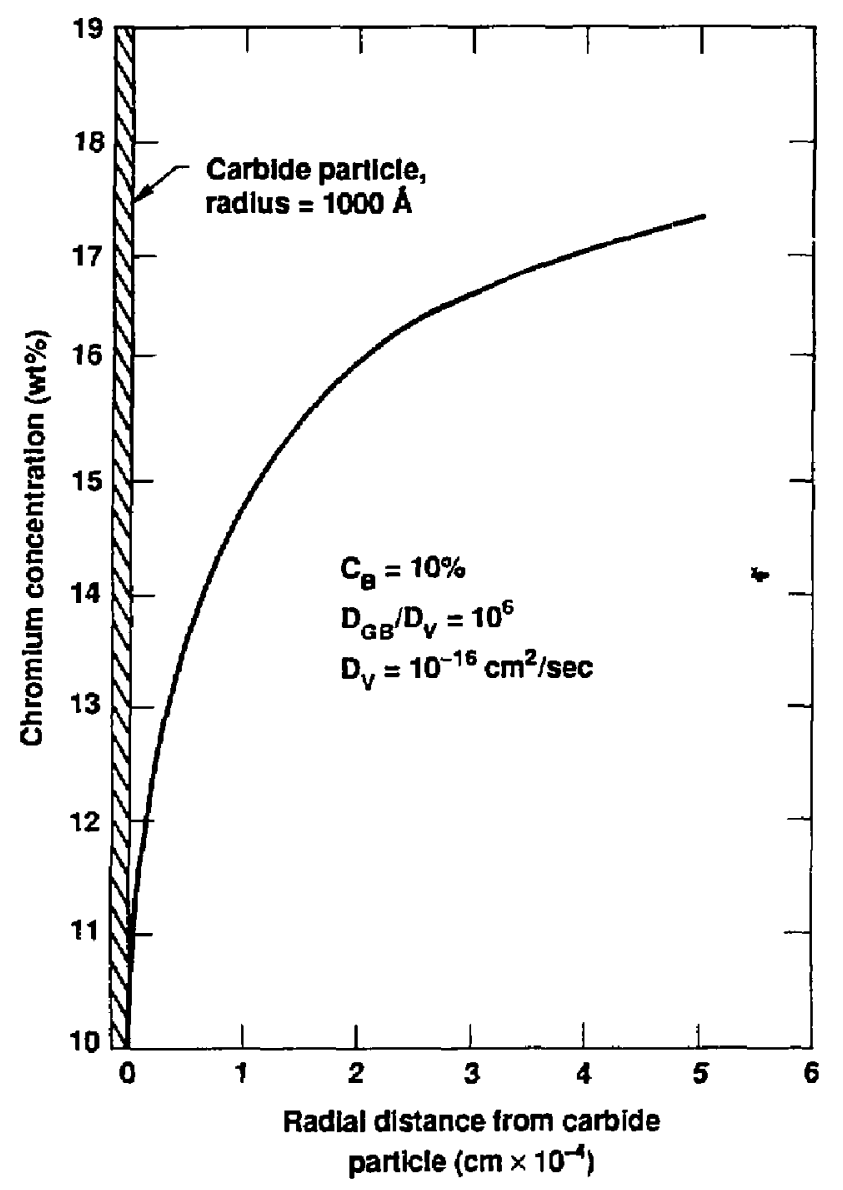

Figure 9. Chromium concentration in the grain boundary vs radial distance from a carbide particle having a radius of $1000 \AA$. Data appropriate to $600^{\circ} \mathrm{C}\left(1112^{\circ} \mathrm{F}\right)$ were used [25].

near the carbide particle. For the particular condition of a $1000-\AA$ carbide particle, the figure shows that the grain boundary is depleted to a distance of $1 \mathrm{~mm}$, assuming that a passive film requires a minimum of 14 wt\% chromium. The figure also shows that it is not necessary to have a continuous carbide in the grain boundary for the boundary to be continuously sensitized. Grain-boundary carbide particles separated by about $2 \mathrm{~mm}$ will create a continuous depleted boundary. Figure 10 shows the very rapid increase in chromium concentration away from the grain boundary compared with the more gradual change within the boundary.
Sensitization in the HAZ of the weld is an important determinant of the weldability of austenitic alloys for use in corrosive environments. The degree of sensitization (DOS) after welding is strongly dependent on both the composition and the thermal history of the HAZ. Strains due to prestrain or cooling strains during welding, as well as the microstructural characteristics of the weld, affect the kinetics of sensitization. These important factors in the control of sensitization and the resulting susceptibility to intergranular corrosion and IGSCC are discussed below. 


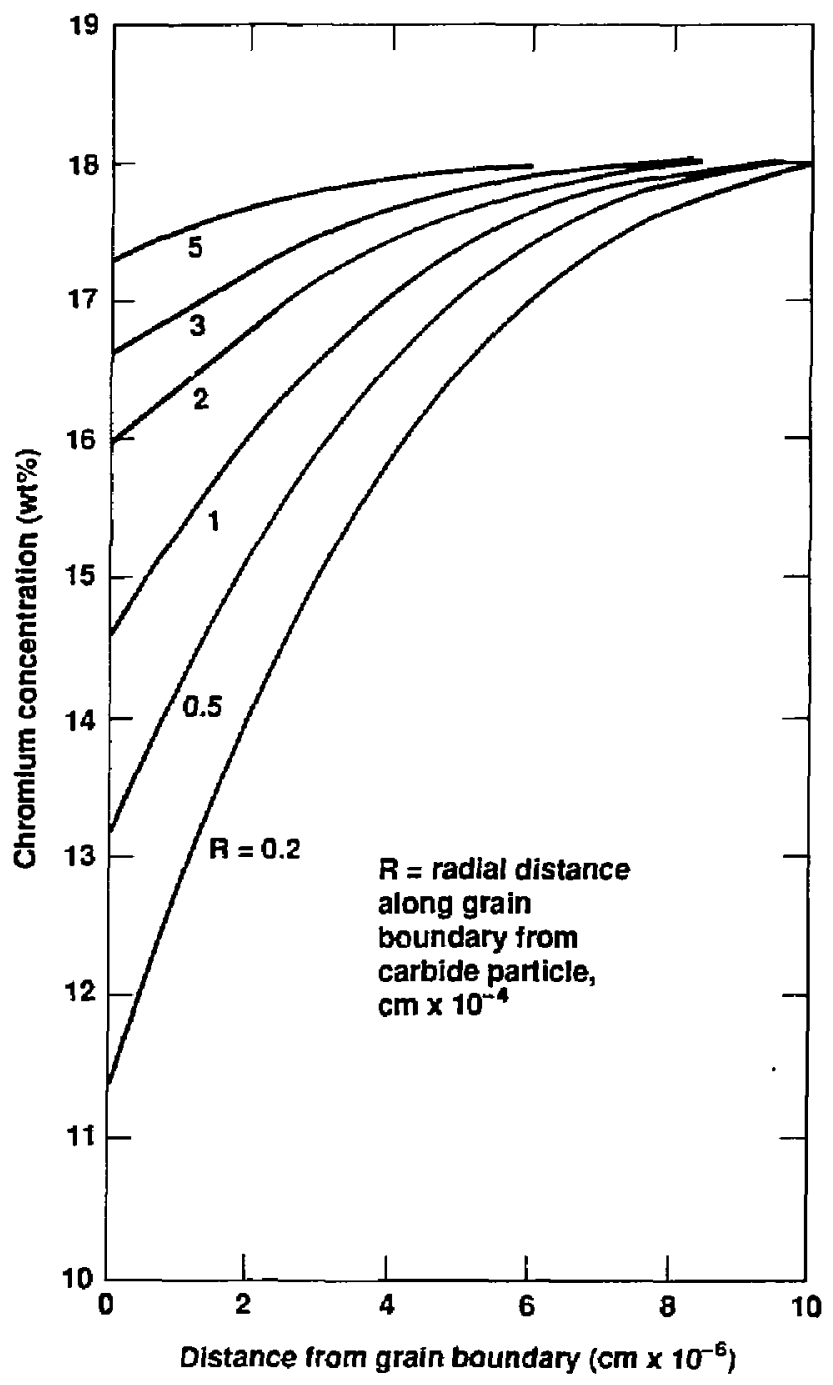

Figure 10. Chromium concentration as a function of distance perpendicular to the grain boundary for varying distances from the carbide particle. Data appropriate to $600^{\circ} \mathrm{C}\left(1112^{\circ} \mathrm{F}\right)$ were used [25].

\subsubsection{Effects of Alloying Elements}

Although chromium and carbon contents are both critical to sensitization of the grain boundaries by carbide precipitation, carbon content is the principal compositional variable determining the rate and extent of precipitation. Carbon has a wide range of acceptable composition in austenitic alloys (0.01 to 0.08 wt\%) compared with the acceptable range for chromium of 18 to $20 \mathrm{wt} \%$ in Type 304 stainless steel and 16 to $18 \mathrm{wl} \%$ in Type 316 stainless steel. The reduction in time required for sensitization at $650^{\circ} \mathrm{C}$ with increased bulk carbon content in Type 304 stainless steel is 


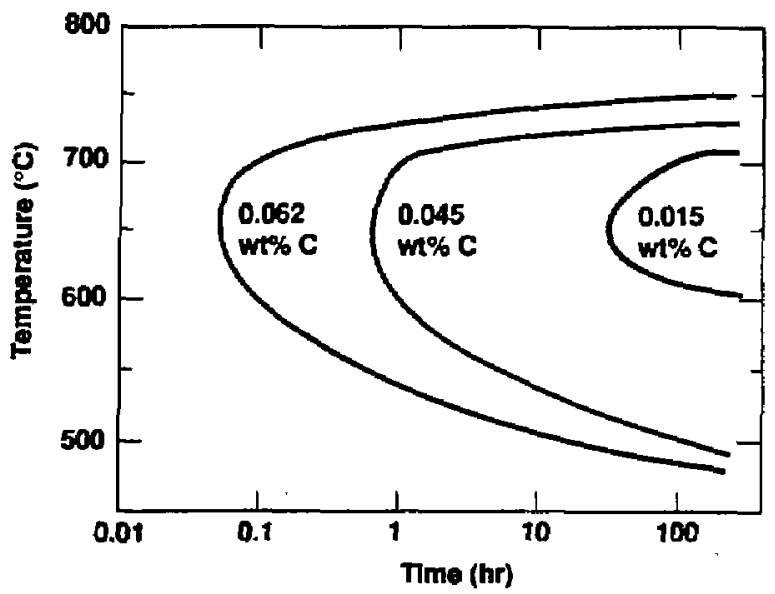

Figure 11. Time-temperature-sensitization curves determined by EPR tests on Type 304 stainless steel alloys of variable carbon contents [18].

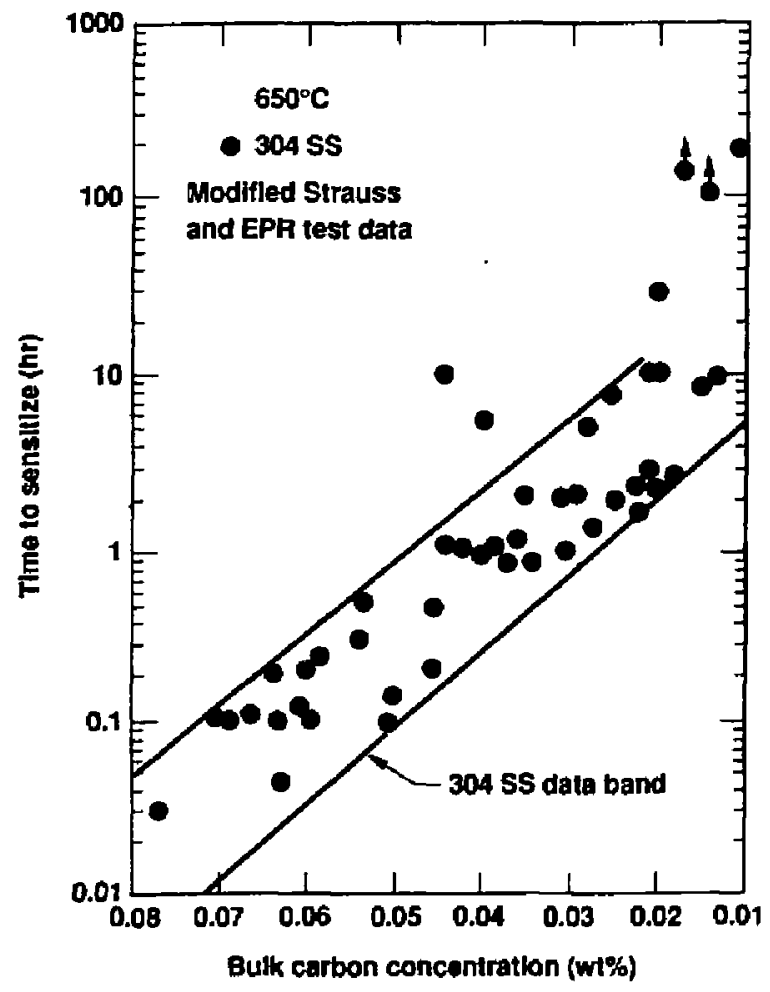

Figure 12. Time-to-sensitization data as determined by modified Strauss or EPR tests at $650^{\circ} \mathrm{C}\left(1202^{\circ} \mathrm{F}\right)$, plotted as a function of bulk carbon content for Type 304 stainless steel [33]. 


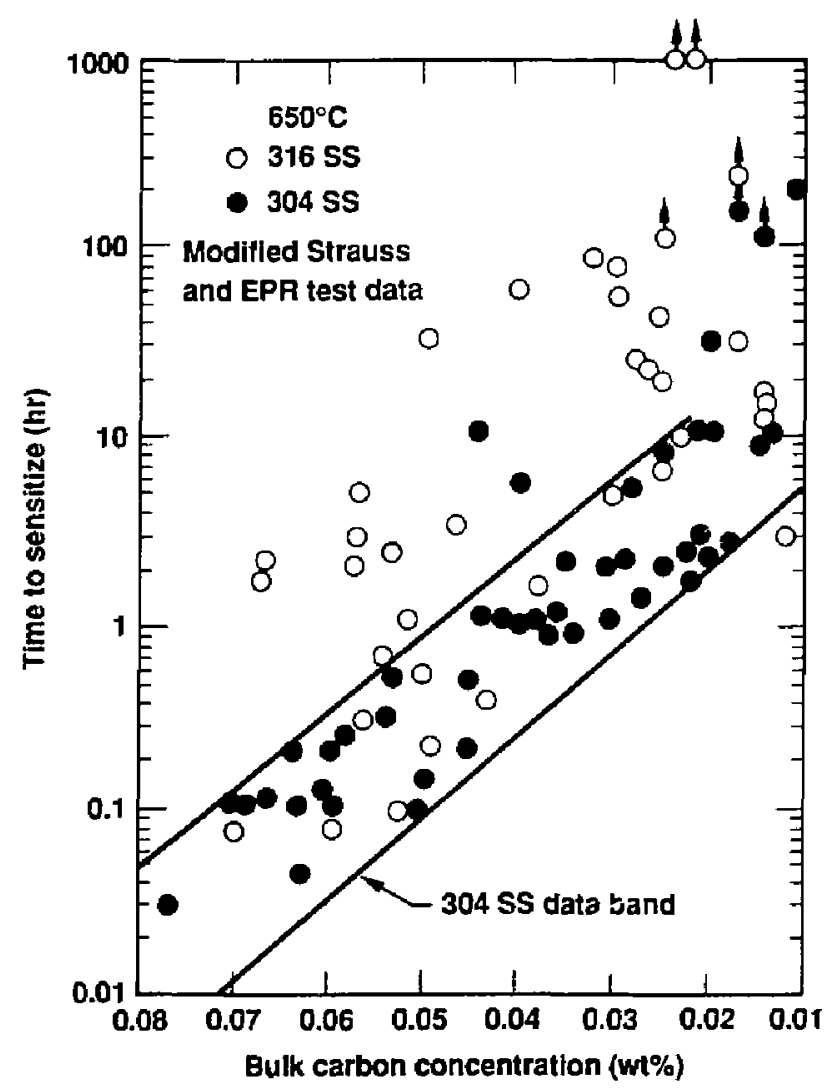

Figure 13. Time-to-sensitization data as determined by modifled Strauss or EPR tests at $650^{\circ} \mathrm{C}\left(1202^{\circ} \mathrm{F}\right)$, plotted with data for Type 316 stainless steel included [33].

shown in Figs. 11 and 12. Data on time for sensitization of Type 316 stainless steel al $650^{\circ} \mathrm{C}$ are included in Fig. 13. The scatter in the data can be partially attributed to differences in other elements affecting sensitization such as the chromium, molybdenum, and nickel concentrations of individual heats of Types 304 and 316 stainless steels.

Alloying elements can affect the process of sensitization and the susceptibility to intergranular corrosion and IGSCC in several ways. While carbon content is the dominant element controlling sensitization, the rate and extent of $\mathrm{M}_{23} \mathrm{C}_{6}$ carbide precipitation are altered by alloy and impurity additions. Composition also influences the corrosion/passivation properties of chromium-depleted zones. In addition, alloy elements can stabilize the alloy against sensitization by altering the chromium content of precipitated carbides. The alloying elements chromium, inolybdenum, nitrogen, niobium, titanium, and manganese can be classified as beneficial in decreasing susceptibility to sensitization; carbon, nickel, sulfur, and phosphorus are detrimental.

Results of work by Briant et al. [27] on several different compositions with and withoul molybdenum and with varying amounts of chromium show that in a Strauss test [28], the alloys containing molybdenum required only $11 \mathrm{wt} \%$ chromium to prevent corrosion, whereas alloys without molybdenum required $15 \mathrm{wt} \%$ chromium to prevent corrosion. Consequently, a greater amount of chromium depletion is required before sensitization of the molybdenumcontaining alloys is observed. A molybdenum 


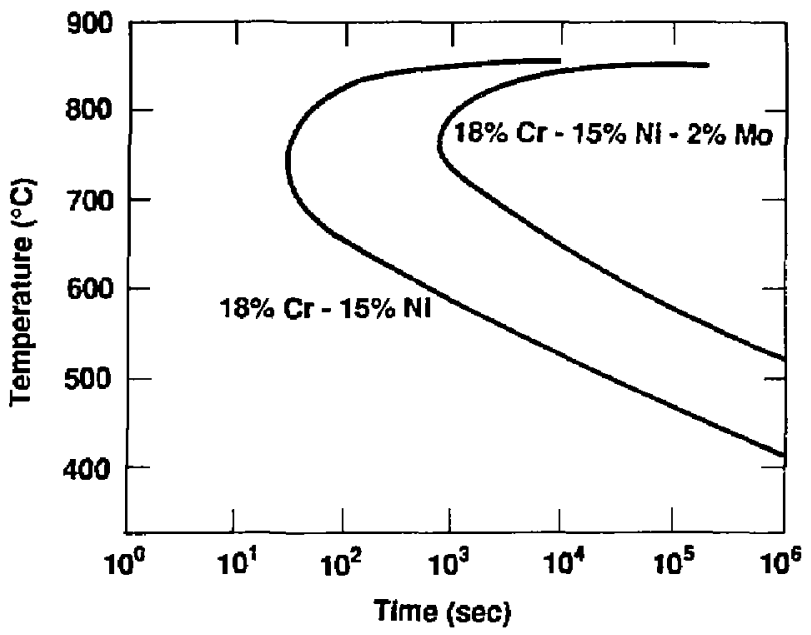

Figure 14. Effect of molybdenum on reducing the sensitization of $18 \mathrm{wt} \%$ chromium- $15 \mathrm{wt} \%$ nickel stainless steels tested in acid copper sulfate solution [29].

addition of $2 \%$ in an $18 \mathrm{Cr}-15 \mathrm{Ni}$ steel increased the critical time required for sensitization at all temperatures tested (approximately $400-850^{\circ} \mathrm{C}$; $752-1562^{\circ} \mathrm{F}$ ) in an acid copper sulfate solution [29], as shown in Fig. 14. Hall et al. [30] noted that no martensite was evident in molybdenumcontaining alloys even after straining, which suggests that molybdenum also tends to prevent the formation of martensite in Type 316 Ltainless steel.

Tedmon et al. [25] studied the carbon activity coefficient in austenitic steel vs nickel content at $600^{\circ} \mathrm{C}\left(1112^{\circ} \mathrm{F}\right)$ for various chromium levels. From this work, nickel appears to increase the activity coefficient of carbon and thus the susceptibility toward sensitization, as shown Fig. 15. This increase in the activity coefficient caused by nickel is not totally unexpected because there is such a low solubility of carbon in nickel and because stable carbides of nickel are absent.

ithe concept of an empirical equation to include the variations in chromium, nickel, and molybdenum into an effective chromium content was developed by Cihal [31] and expanded by Fullman [32]. The equation is based on the concept that the important variable in determining the time required for sensitization of an alloy is the local chromium activity at the interface. The chromium activity at this interface depends not only on the chromium concentration but also on the concentration of the other elements, especially carbon. The effective chromium content, $\mathrm{Cr}_{\text {eff }}$ is a reflection of the change in the chromium activity as a result of the presence of these other elements. Several such empirical relations have been proposed $[27,31,33,34]$. The effective chromium relation given by Kass et al. [34], which accounts for the variability in carbon, molybdenum, and nickel may be written as:

$\mathrm{Cr}_{\mathrm{eff}}=\mathrm{Cr}+1.7 \mathrm{Mo}-100 \mathrm{C}-0.2(\mathrm{Ni}-10)$

Three observations can be made from Eq. (3): (1) carbon content is of principal importance, (2) an increase in molybdenum can be almost twice as effective as chromium in preventing sensitization, and (3) the contribution of nickel in lowalloy stainless steels to the degradation of chromium is small. Kass et al. [34] report that a $\mathrm{Cr}_{\text {eff }}$ of 16.2 or greater has been shown to confer immunity from intergranular cracking in boilingwater reactor environments after an isothermal treatment of $620^{\circ} \mathrm{C}$ for $24 \mathrm{hr}$. They also point out that a $\mathrm{Cr}_{\text {eff }}$ of $\mathbf{1 5 . 7}$ is more appropriate for the less severe thermal cycle due to welding.

Figure 16 shows tl e time-temperature susceptibility range for $18 \mathrm{wt} \%$ chromium austenitic stainless steels and alloys to intergranular corrosion for carbon contents between 0.005 and 0.087 wt $\%$ and nickel contents between 9 and $40 \mathrm{wt} \%$. 


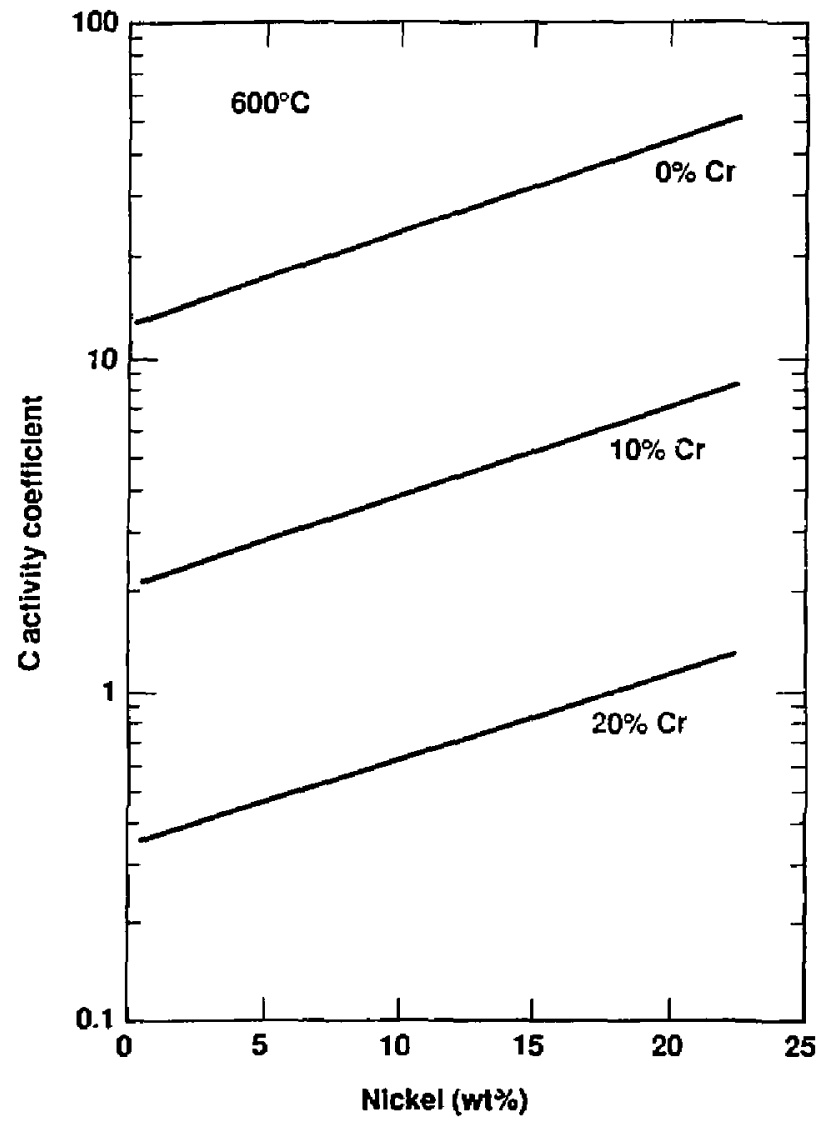

Figure 15. Carbon activity coefficient in austenitic steel vs nickel content at $600^{\circ} \mathrm{C}\left(1112^{\circ} \mathrm{F}\right)$ for various chromium levels [25].

At a carbon level of 0.005 wt $\%$, a change in nickel content from 9 to 40 wt $\%$ barely affects the susceptibility to intergranular corrosion, but at a carbon level of $0.021 \mathrm{wt} \%$, a change in nickel content from 9 to $40 \mathrm{wt} \%$ significantly decreases the time required for sensitization. At $0.087 \mathrm{wt} \%$ carbon, the influence of nickel content on the timetemperature susceptibility range again diminishes.

Nitrogen can have a positive influence on the reduction of intergranular corrosion since it tends to retard the nucleation and growth of carbides at the grain boundaries $[27,35]$. The response of Type $304 \mathrm{~L}$ stainless steel to two levels of nitrogen is shown in Fig. 17. This figure shows that the addition of $0.13 \mathrm{w} / \%$ nitrogen increased the time necessary for sensitization at most temperatures although little effect is observed near $600^{\circ} \mathrm{C}\left(1110^{\circ} \mathrm{F}\right)$. In contrast to the above, some researchers have reported that perhaps nitrogen does not have such a positive effect on preventing sensitization. Cowan and Tedmon [24] postulated that nitrogen might play a role similar to carbon, causing the precipitation of chromium-nitrogen compounds and inducing grain-boundary chromium depletion. An investigation by Mulford et al. [35] found that in Type 316L stainless steel with high levels of nitrogen $(0.16 \mathrm{wt} \%)$, many phases are found at the grain boundaries, including Laves phase $\mathrm{Cr}_{2} \mathrm{~N}$ as well as $\mathrm{M}_{23} \mathrm{C}_{6}$. The presence of these additional phases, however, did not appear to adversely affect the resistance to sensitization. 


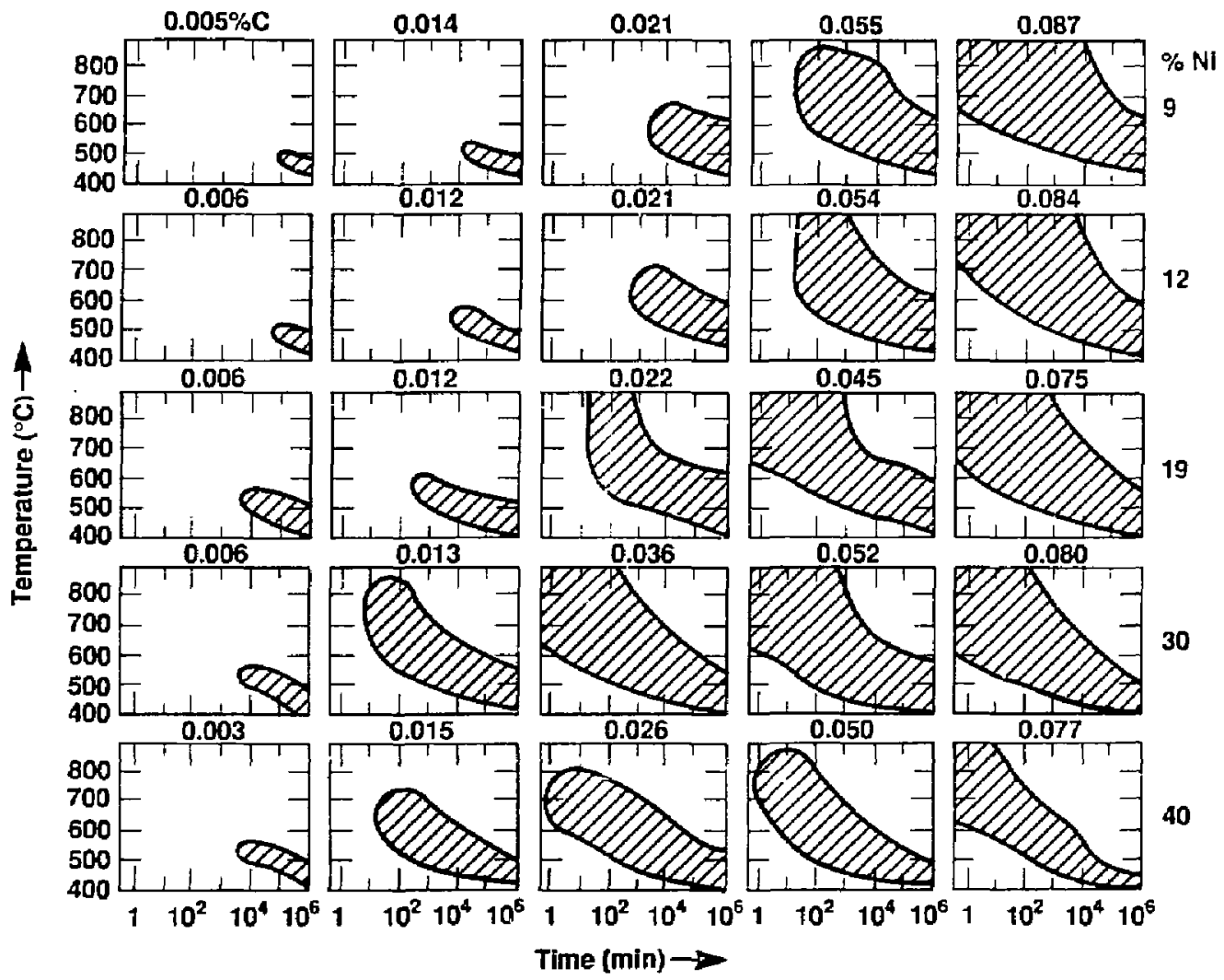

Figure 16. The effect of nickel content $(9-40 \mathrm{wt} \%)$ and carbon content $(0.003-0.087 \mathrm{wt} \%)$ on the susceptibility to intergranular corrosion (Rollason curve) in austenitic steels and alloys containing 18 wt\% chromium, as found after testing in standard solution [31].

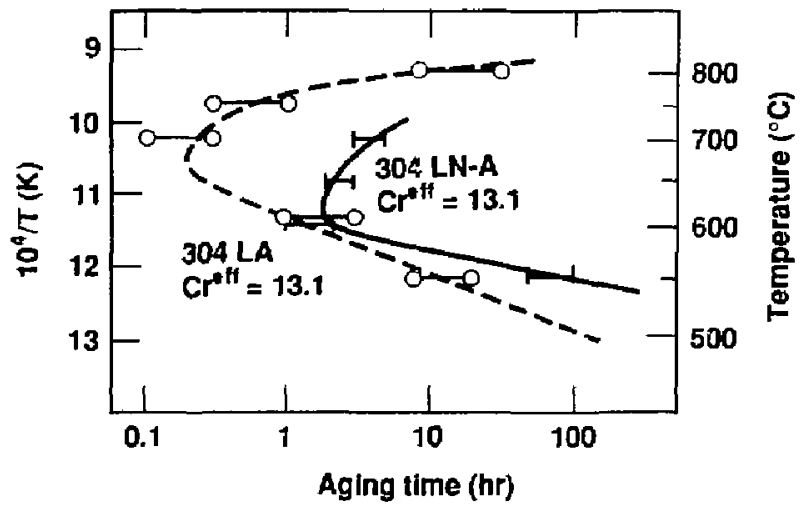

Pigure 17. Response of Types 304LA $(0.002 w 1 \%$ nitrogen) and 304LN-A (0.13 wt\% nitrogen) slainless steels to the modified Strauss lest [35]. 


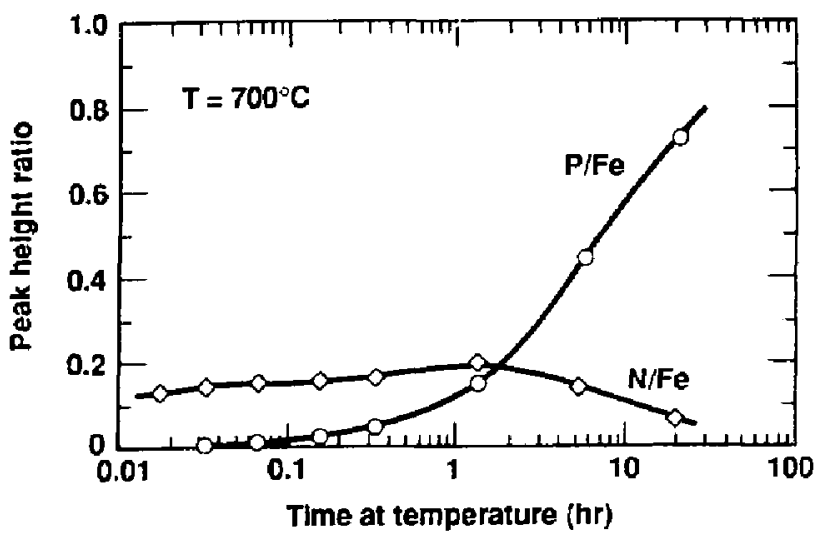

Figure 18. Results of isothermal heating experiments on a Type 316LN-3 sample, plotted as the Auger peak-height ratio vs time for phosphorus and nitrogen at $700^{\circ} \mathrm{C}\left(1292^{\circ} \mathrm{F}\right)$. In this figure, the peak-height ruwu reters to the phosphorus 120eV or nitrogen $380-\mathrm{eV}$ peak normalized by the iron $703-\mathrm{eV}$ peak [35].

Auger spectroscopy has shown that both nitrogen and phosphorus have a tendency to segregate to grain boundaries in the sensitization temperature range [35]. Such impurity segregants can compete for grain-boundary sites [36], decreasing nitrogen levels (see Fig. 18). They may also independently increase the susceptibility of the steel to corrosion. Phosphorus segregation has been associated with accelerated intergranular corrosion in highly oxidizing solutions $[22,37]$. Although sulfur can also segregate to grain boundaries, its effect on corrosion and SCC is small [37]. This may be due in part to the precipitation of most of the sulfur as manganese sulphides.

Although manganese does not appear to have any detrimental effects on passivation, its beneficial effects are small. Briant et al. [27] showed that manganese retarded carbide precipitation in a specially prepared Type 304L stainless steel containing nitrogen at $600^{\circ} \mathrm{C}\left(1112^{\circ} \mathrm{F}\right)$.

However, this effect was not observed at 650 and $700^{\circ} \mathrm{C}\left(1202\right.$ and $\left.1292^{\circ} \mathrm{F}\right)$, the other temperatures tested.

The addition of stabilizing elements, such as niobium and titanium, can prevent chromium depietion by forming carbides that are thermodynamically more stable than chromium. The stabilized grades are essentially immune to isothermal sensitization when properly heat-(reated, but can leave areas susceptible to subseguent sensitization, as in the "knife-line" corrosjve attack in the HAZ of the weld. Dissolution of the niobium or titanium carbide in the HAZ occurs at sufficiently high $\mathrm{HAZ}$ temperatures, typically above $1205^{\circ} \mathrm{C}$ $\left(2200^{\circ} \mathrm{F}\right)$ for niobium carbide. Subsequent rapid cooling can leave the carbon in solstion, unstabi.lized and susceptible to sensitization. While large additions of stabilizer decrease the tendency for chromium-rich carbide co-precipitation, additions are limited by the corresponding increase in susceptibility to cracking in the HAZ.

\subsubsection{Effects of Welding on Sensitization}

Sensitization of weldments can result during fabrication or postweld heat treatments. The effects of thermal history, strain, and microstructure on the DOS are discussed individually below, fnllowing a description of techniques used to evaluate the DOS.

Techniques for Evaluating Sensitization. The accepted practices for determining the susceptibility to intergranular attack as recommended by ASTM are A 262, practices A-E [28]. Practice $A$ is the oxalic acid etch test for classification of etch structures of austenitic steels. Practice B is the ferric sulfate-sulfuric acid test for detecting susceptibility to intergranular attack in austenitic stainless steeis. Practice $C$ is the nitric acid test 
for detecting susceptibility to intergranular attack in austenitic stainless steels. Practice $D$ is the nitric-hydrofluoric acid test for detecting susceptibility to intergranular attack in molybdenum-bearing austenitic stainless steels, and Practice E is the copper-copper sulfatesulfuric acid test for detecting susceptibility to intergranular ałtack in austenitic stainless steels.

The simplest and least time-consuming is practice $A$ (oxalic acid test), which is primarily considered to be a screening device; that is, specimens passing the oxalic acid test can be eliminated from further testing. Practices B, C, and $D$ all use a weight-loss determination and therefore can provide a quantitative measure of the relative performance of specimens tested. Practice $E$ is based on a visual examination of bend specimens and therefore is used to classify the specimen only as acceptable or unacceptable. Practice $C$ is sometimes referred to as the Huey test and practice $E$ as the Strauss test.

Some reports $[33,38,39]$ that evaluate and discuss sensitization and DOS seem to indicate that, although ASTM A 262 [28] could provide the qualitative information as to whether or not a material was sensitized, it should not be used as a quantitative lool to determine the DOS. One of the quantitative techniques available is electrochemical potentiodynamic reactivation (EPR), as described by Clarke et al. [39]. This is basically a nondestructive electrochemical technique wherein a specimen is subjected to two potential sweeps in a de-aerated solution of sulfuric acid and KCNS. A reactivation peak is formed on the

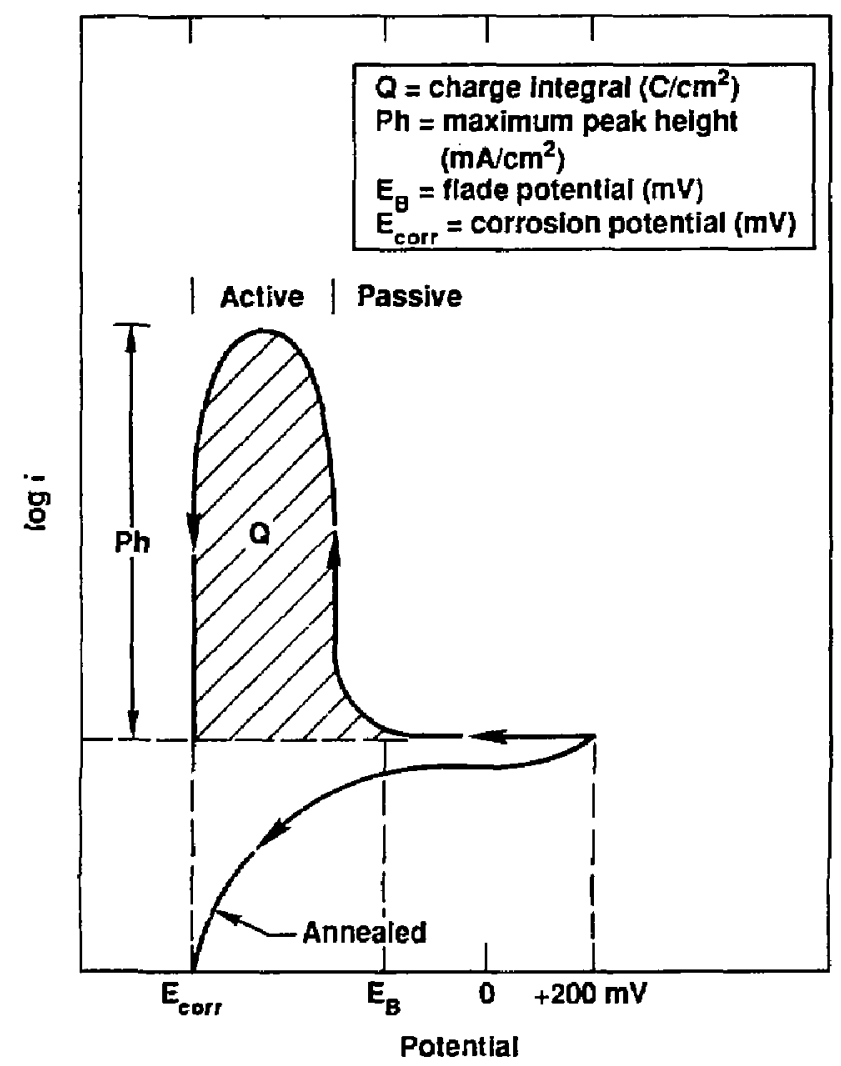

Figure 19. Schematic of the reactivation polarization curve, showing parameters of interest for EPR testing [39]. 
reverse current-potential sweep, and the area under the curve is proportional to the DOS.

The criteria used to distinguish between annealed and sensitized materials include the activation charge ( $Q$ ), shown by the shaded area below the reaction peak of the curve in Fig. 19. Sensitized steels are easily activated and show high $Q$ values compared with annealed steels.

Another quantitative technique is the constant extension rate test (CERT) [40]. This technique acts as a screening test if the test envinonment is suspected to accelerate SCC. A specimen is pulled at a constant strain rate in a test environment, and the results are compared with those of annealed material and test material exposed to a potential sensitizing thermal history.

Thermal Effects. In studying the response to isothermal heat treatments, time-temperature sensitization (TTS) curves, such as those in Fig. 11, have been used for many years to predict the susceptibility of a particular composition to IGSCC. The nose of each TTS curve indicates the minimum time required for sensitization. This minimum time is dependent on material composition. Displacing the nose to longer times decreases the probability that sensitization will occur during a welding process. Direct correlations between time-to-sensitize measurements and composition allow us to evaluate the effect of specific elements on sensitization. A large data base can enable us to make some appropriate comparisons. However, because the measurements are dependent on both the thermodynamics and kinetics of the grainboundary depletion phenomena, some scatter occurs as a result of the microstructural differences between the data on the many heats that are available.

Sensitization in the $\mathrm{HAZ}$ of the weld results from heating and cooling through the sensitization temperature range. Thus, the thermal cycles in the HAZs of weldments are better approximated by continuous cooling treatments than by isothermal treatments. Peak temperatures in the $\mathrm{HAZ}$ range from near-ambient to near the melting point, resulting in highly localized sensitization. The specific thermal cycle in the weld or HAZ is dependent on weld fabrication techniques including heat input, number of weld passes, and overlap of $\mathrm{H} / 2 \mathrm{Z}$ thermal profiles in multipass welds.

One technique useful for determining the dependence of sensitization on the location and thermal history of the HAZ is EPR profiling. The
EPR technique is valuable in its capability of measuring and distinguishing between the low levels of sensitization in the HAZ. Using a bead-on-edge welding technique, samples are sectioned from several predetermined distances from the fusion line. Placement of thermocouples at these locations prior to welding allows recording of the weld thermal cycles. The normalized reactivation charge, $\mathrm{Pa}$ (coulombs per square centimeter of grain-boundary area) in the EPR test gives a measure of the DOS. A surface with a Pa number of 2.0 was determined by Lundin et al. [17] to correspond to the DOS at which the dual structure starts to occur in the oxalic acid test (ASTM A262-A). The test material was 0.06 wt\% carbon Type 304 stainless steel.

Several test welds in Types $304 \mathrm{LN}$ and 316NG stainless steels were examined by Lundin [17] using EPR profiling. Autogenous gas tungsten-arc (GTA) edge-welds were produced using a heat input of $40 \mathrm{~kJ} / \mathrm{in}$. (1.57 kJ/mm) and preheat and interpass temperatures of $427^{\circ} \mathrm{C}$ $\left(800^{\circ} \mathrm{F}\right)$. This is considered equivalent to welding a plate 1.5 in. $(38 \mathrm{~mm})$ thick with a heat input of $80 \mathrm{~kJ} / \mathrm{in}$. $(3.15 \mathrm{~kJ} / \mathrm{mm})$ at $316^{\circ} \mathrm{C}\left(600^{\circ} \mathrm{F}\right)$. Such tests show a strong dependence of the DOS on the peak temperature. In a Type $304 \mathrm{LN}$ stainless steel single-cycle weld, the $\mathrm{Pa}$ number increases from a value of 0.1 at the fusion line to 0.6 at a distance of $0.17 \mathrm{in} .(4.3 \mathrm{~mm})$ from the fusion line. This increase corresponds to a peak temperature of $925^{\circ} \mathrm{C}\left(1700^{\circ} \mathrm{F}\right)$. The Pa number then decreases with distance to a value of 0.15 at a peak temperature of $705^{\circ} \mathrm{C}\left(1300^{\circ} \mathrm{F}\right)$ or lower. The same tests on Type 316NG stainless steel resulted in virtually no change in $\mathrm{Pa}$ number from the fusion line to the unaffected base metal.

The effect of multiple thermal cycles may be most simply treated as additive. Sensitization should be related to the time spent within the sensitization range. The effect of five thermal cycles (by the same GTA edge passes above) in Type 304LN stainless steel increases the maximum Pa number from 0.6 to 0.9 . The peak temperature at maximum DOS remains near $925^{\circ} \mathrm{C}\left(1700^{\circ} \mathrm{F}\right)$, but the shape of the curve changes because of smaller increases in $\mathrm{Pa}$ number at higher and lower peak temperatures. Solomon [41] has poinied out that the effects of multiple cycles are not necessarily additive. Partial or complete dissolution of the carbides at high peak temperatures replenishes chromiumdepleted regions and can wipe out the effects of previous cycles. There appears to be a general 
shortage of data in the literature on the effects of multiple thermal cycles, especially on the effects of overlapping HAZs.

Heat input in welding influences the cooling rates and times within the sensitization range. $A$ heat input threshold for sensitization has been established through research by Gooch (see [13]). This threshold was measured to decrease with increasing carbon content from $68 \mathrm{~kJ} / \mathrm{in}$. at 0.06 wt\% carbon to $40 \mathrm{~kJ} /$ in. at $0.08 \mathrm{wt} \%$ carbon. It was recommended that in common practice the weld heat input should be limited to a maximum of 30 to $35 \mathrm{~kJ} / \mathrm{in}$. for unstabilized alloys.

Strain Effects. Strain effects that can affect sensitization can be developed in two ways: (1) through the process of welding, and (2) through cold work before a thermal heat treatment or welding process. The weld-induced strain effect is developed during the welding process when a cold region surrounds the warmer $\mathrm{HAZ}$ and the molten fusion zone $(\mathrm{FZ})$; the HAZ goes through a sequence of both lension and compression. The final stress state of the HAZ is dependent on the joint geometry and the welding process used. Unless some type of stress relief is applied, some part of the HAZ will contain stresses as high as the yield values at ambient temperature [42]. Very little data has been published on the effects of strain during exposure to sensitization temperatures $[43,44]$, but the limited data agrees with the significantly large amount of published data on cold work before isothermal heat treatments.

Pednekar et al. [64] studied the effect of prior strain (cold work) on sensitization. They used anodic polarization scans to determine sensitization, using varying amounts of prior strain at a sensitization temperature of $660^{\circ} \mathrm{C}\left(1220^{\circ} \mathrm{F}\right)$. Their results show that, with increasing amounts of prior cold work, the rate of carbide precipitation increased, first along the grain boundaries. Then, as the amount of prior cold work increased, the carbides preferentially precipitated within the grains. The DOS increases with initial cold work but then decreases with additional cold work as more and more carbides precipitate within the grains. This can be explained qualitatively using a dislocation model. With small amounts of cold work (less than 10\%), one would expect a large increase in dislocation density in the grainboundary region, which would result in the observed ease of precipitation and growth of carbides at the grain boundaries when the material is heated in the sensitizing temperature range. At the same time, the bulk diffusion rate for chromium would remain unchanged, resulting in chromium depletion in the vicinity of the carbide network. With increased cold work, the low stacking-fault energies typical of stainless steels result in dislocation pileups at slip-plane intersections. Consequently, as the amount of cold work increases, the carbide nucleation and precipitation process is increasingly favored within the grains. Bain et al. [19] and Tedmon et al. [25] also noted that a more uniform carbide distribution is developed. As explained by Bain el al. [19], this would shorten the diffusion path for chromium and ultimately result in quicker homogenization of the chromium content in the matrix between the bands of precipitated carbides within the grains.

The presence of martensite can also influence sensitization. Briant and Ritter [46] found that the temperature needed to cause sensitization is much lower in a material that contains some martensite than in a purely austenitic material. The time required for sensitization is also greatly reduced. They suggested that these effects were the result of higher diffusion rates of carbon and chromium in body-centered tetragonal martensite than in fcc austenite [46-49]. The solubility of carbon is also lower in martensite than in austenite. A comparison of sensitization in a Type 304 stainless steel with and without martensite is shown in Fig. 20. Even though martensite appears to have a negative effect on corrosion resistance, an increased resistance to susceptibility to $S C C$ was observed when Types $304 \mathrm{~L}$ and $316 \mathrm{~L}$ stainless steels were coldworked (10-15\%) prior to heat treatment at $400^{\circ} \mathrm{C}\left(752^{\circ} \mathrm{F}\right)[45]$.

Solomon and Lord [44] modeled fusionwelding thermal cycles on Type 304 stainless steel to observe the effects of strain in conjunction with continuous cooling on sensitization. Figure 21 indicates that strain increases the propensity for sensitization as long as the strain is on the order of $5 \%$ or greater. Solomon and Lord also considered the effect of multiple welding passes and found that as little as $0.8 \%$ strain per pass can enhance sensitization, provided that multiple cycles are used with this strain, for peak temperatures of $800^{\circ} \mathrm{C}\left(1472^{\circ} \mathrm{F}\right)$ (Fig. 22). Solomon and Lord further postulated that dislocations generated as a result of strain increase the carbide nucleation and diffusion rates. The more carbon present, the greater the amount of carbide precipitated and the greater the influence of strain on sensitization. 

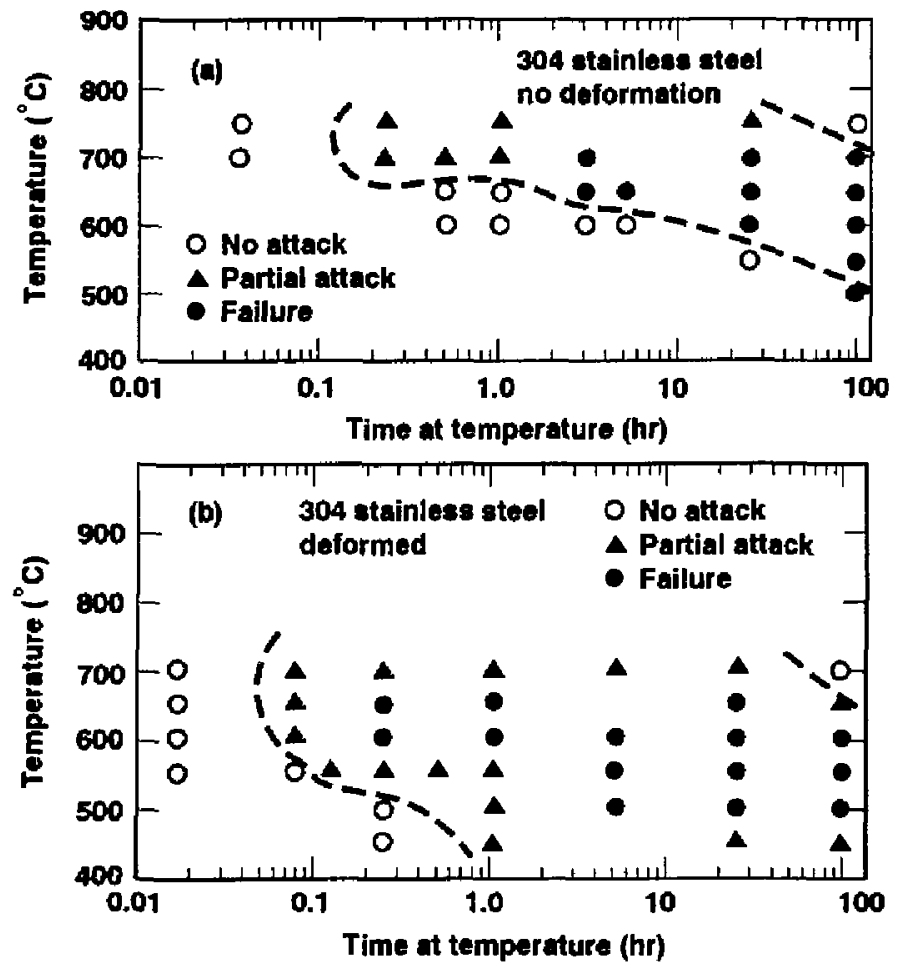

Figure 20. Comparison of sensitization in a Type 304 stainless steel (a) with, and (b) without martensite [47].

Microstructural Effects. Microstructural characteristics that strongly influence sensitization include the presence of $\delta$ ferrite, differences in grain size, and carbide morphologies.

The presence of $\delta$ ferrite in the austenitic structure provides additional nucleation sites for $\mathrm{M}_{23} \mathrm{C}_{6}$ carbide precipitation. The ferrite-austenite interface is favored over austenite grain boundaries and twin boundaries as nucleation siles for precipitation [50]. Devine and Drummon [100] have shown that the resistance of two-phase austenite-plus-ferrite alloys lo intergranular corrosion is related to the amount of the ferriteaustenite interfacial area. While small amounts of ferrite (1 to $2 \%$ ) have only small effects on the DOS and susceptibility to intergranular corrosion, large amounts of ferrite (8 to 15\%) decrease the susceptibility to intergranular corrosion.

While not subject to intergranular attack, quantities of ferrite that form a nearly continuous network can also provide a nearly continuous sensitized path. Devine and Drummon [100] have shown, however, that immunity to corrosion in these alloys can occur quite rapidly by replenishment of the relatively narrow depleted zone in the austenite. This phenome non is due to the capability of the ferrite, which is enriched in chromium, to provide the principal source of chromium for carbide precipitation. They also point out that this ferrite is metastable in the sensitization range and will decompcise. If the carbon has not consumed all of the ferrite, the rejection of chromium into the remaining ferrite as the ferrite decomposes into austenite can result in o formation. The influence of ferrite on preferential corrosion has been discussed earlier. Grain size can also affect sensitization and SCC through its effect on grain-boundary area, and it influences SCC through its effect on the material's strength. Bain et al. [19] observed that 


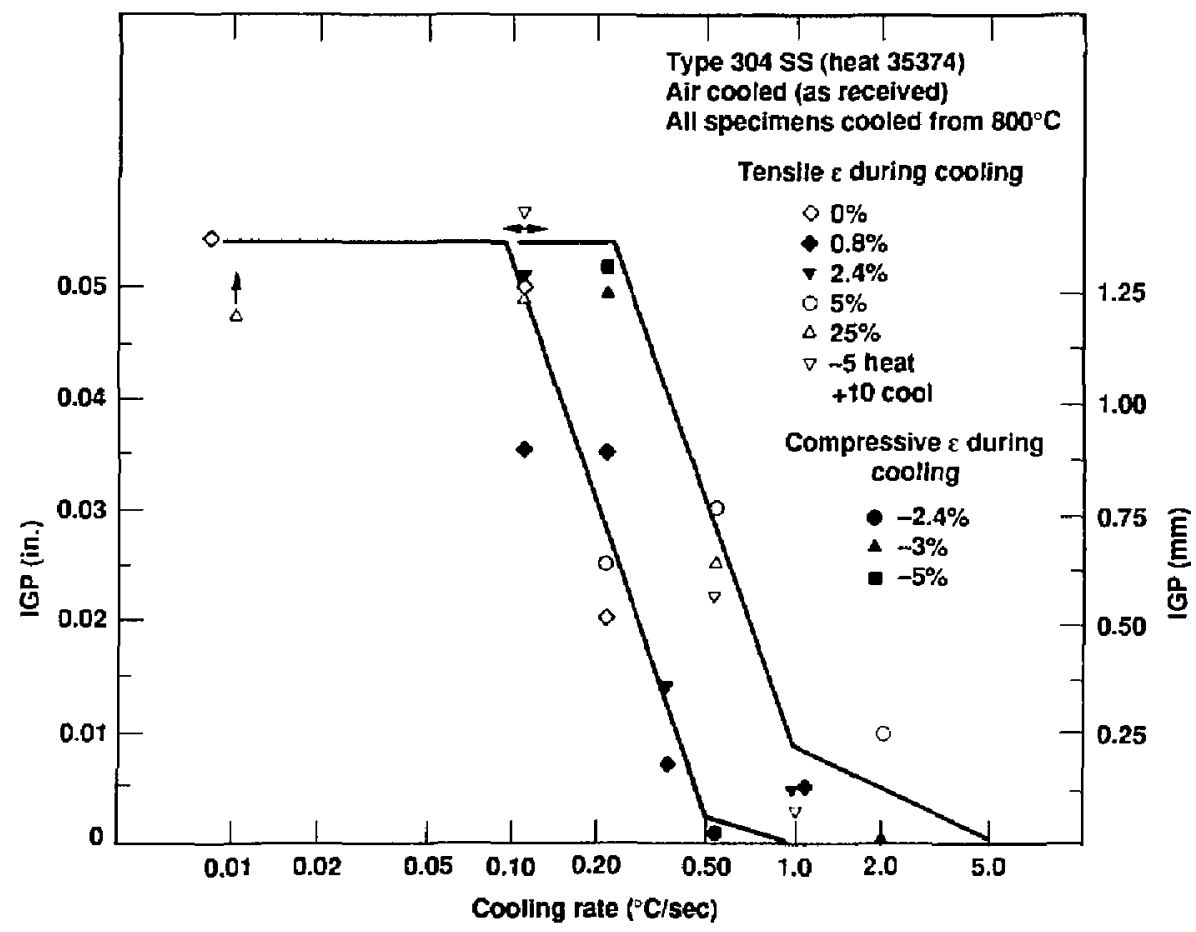

Figure 21. Intergranular penetration (IGP) in an ASTM A 262, practice $E$ test as a function of cooling rate for air-cooled (as-received) specimens cooled from $800^{\circ} \mathrm{C}\left(\mathbf{1 4 7 2}^{\circ} \mathrm{F}\right.$ ) [44].

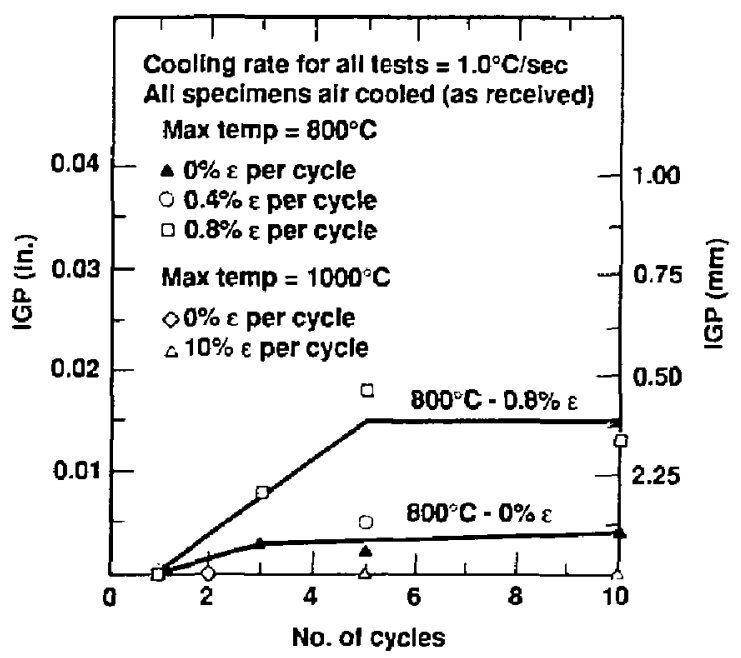

Figure 22. Intergranular penetration in an ASTM A 262, practice $E$ test as a function of the number of cycles of heating and cooling from 800 and $1000^{\circ} \mathrm{C}\left(1472\right.$ and $\left.1832^{\circ} \mathrm{F}\right)$ [44]. 


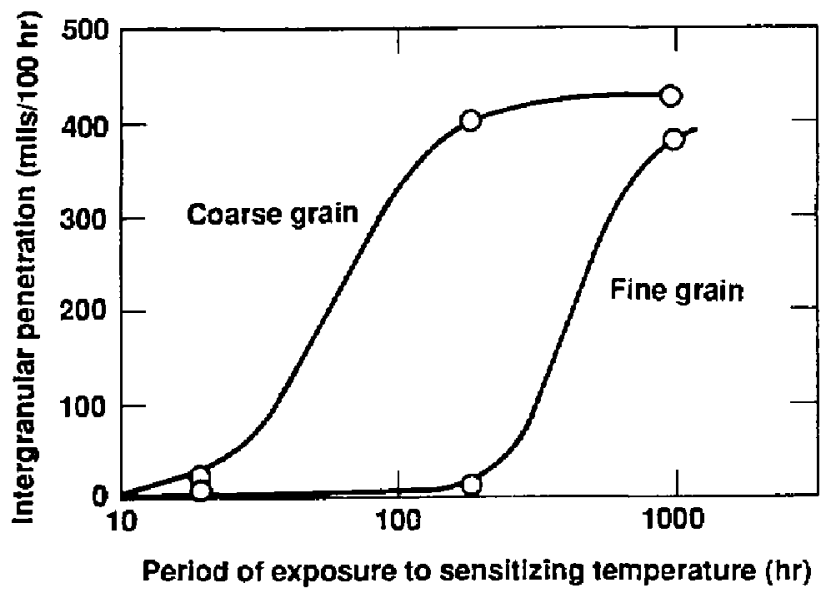

Figure 23. Relative development of sensitivity in coarse and fine-grained alloys; chromium, 17.6; nickel, 8.8; carbon, 0.05 [19].

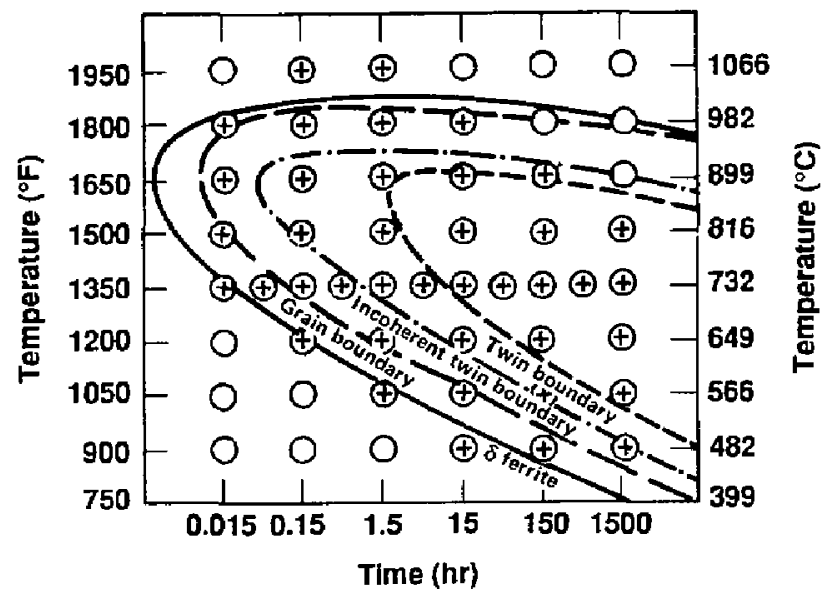

Figure 24. Time-temperalure dependence of precipitation of $\mathrm{M}_{23} \mathrm{C}_{6}$ al different sites [50].

a very fine grain in the austenite steel predis poses an alloy to a retarded sensitization. Curves of the intergranular penetration vs exposure time to the sensitizing temperature show the difference between fine-grained and coarsegrained material (Fig, 23), and suggest that the relative proportion of nomal crystalline material and grain-boundary material might exert some influence on the process of sensitization. The influence of grain size is most marked when sensitization results from relatively short-time exposures to the damaging temperatures. Material heated for long times (thousands of hours) is severely affected without regard to grain size.

The chromium carbides $\left(\mathrm{Cr}_{23} \mathrm{C}_{6}\right)$ that precipitate at grain boundaries in sensitized stainless steels have complex and varied morphologies [24]. They can be present in continuous or discontinuous modes, and their 
compositions can be variable. Up to about onefourth of the chromium can be replaced by iron [23]. Mahla and Nielsen [51] separated and isolated chromium carbides from the grain boundaries of sensitized Type 304 stainless steel. Using transmission electron microscopy (TEM), they found that the carbides nucleated in grain boundaries, but that the carbides grew into adjacent grains. The carbides initially have a dendritic or flake-like structure, but with time and temperature, these flakes transform into more regular geometric shapes, whose habit is determined by meta] lattice planes. They also found that the carbides were very thin [51]. essentially forming a two-dimensional dendritic structure.

Stickler and Vinckier [50], using the techniques developed by Mahla and Nielsen [ 51 ] observed that carbides precipitate in stages: first on the $\delta$ ferrite-austenite interface, then on the grain boundaries, next on the incoherent grain boundaries, and finally on the coherent twin boundaries. These stages are illustrated in Fig. 24, which shows the time-temperature dependence of precipitation of $\mathrm{M}_{23} \mathrm{C}_{6}$ at each site. From these observations, it can be concluded that the carbides are not present as continuous films but rather that they assume complex, thin dendritic shapes and that their morphology is highly dependent on time and temperature.

\subsubsection{Low-Temperature Sensitization}

Povich [52] observed that Type 304 stainless steel could be sensitized at temperatures well beJow the normal isothermal sensitization range if chromium carbide nuclei were present. The combination of nucleation within the conventional sensitization temperature range and subsequent growth during low-temperature heat treatments has been termed low-temperature sensitization (LTS).

A schematic illustrating LTS is shown in Fig. 25. The shaded region shows the normal isothermal TTS zone. Neither path A nor B separately result in sensitization. However, combining pains $A$ (high temperature) and $B$ (long times) into $C$ results in severe sensitization. Povich and Rao [40] postulated that LTS is a nucleation and growth phenomenon; that is, carbides are nucleated during a welding process

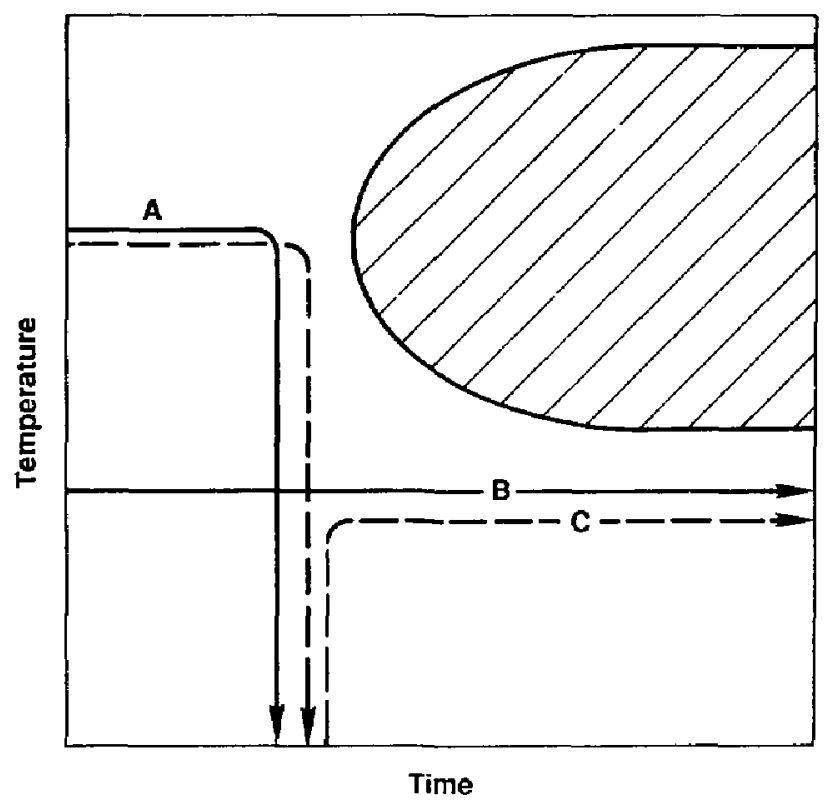

Figure 25. Schematic representation of LTS. Paths A and B do not cause sensitization. However, path $C$ causes severe sensitization. The shaded region is the normal isothermal TTS zone [52]. 


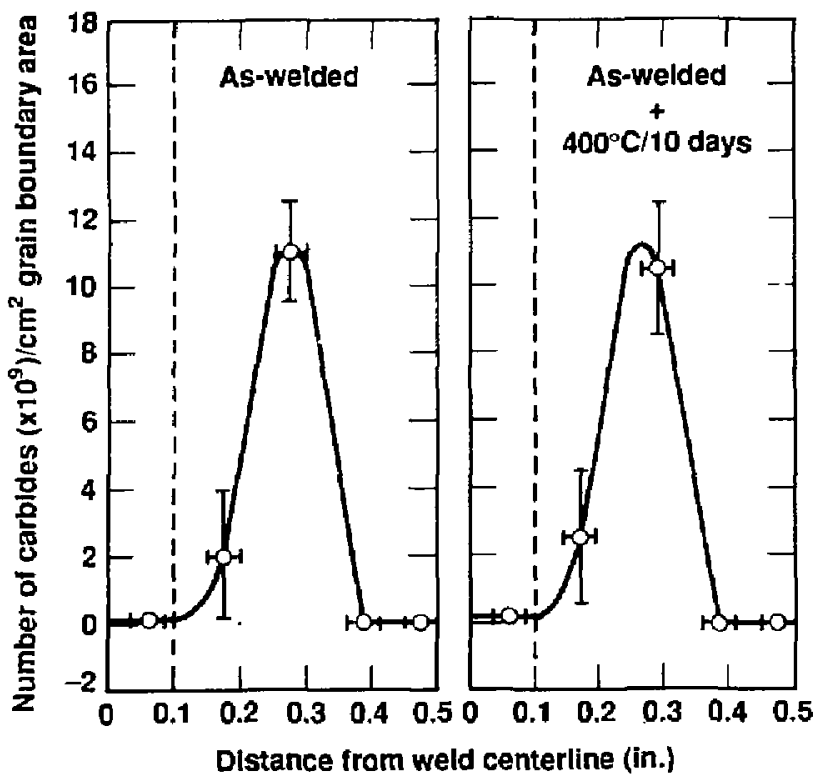

Figure 26. Number of carbides per unit grain boundary area vs distance from the weld centerline before and after the $400^{\circ} \mathrm{C}\left(752^{\circ} \mathrm{F}\right) / 10$ day LTS heat treatment [52].

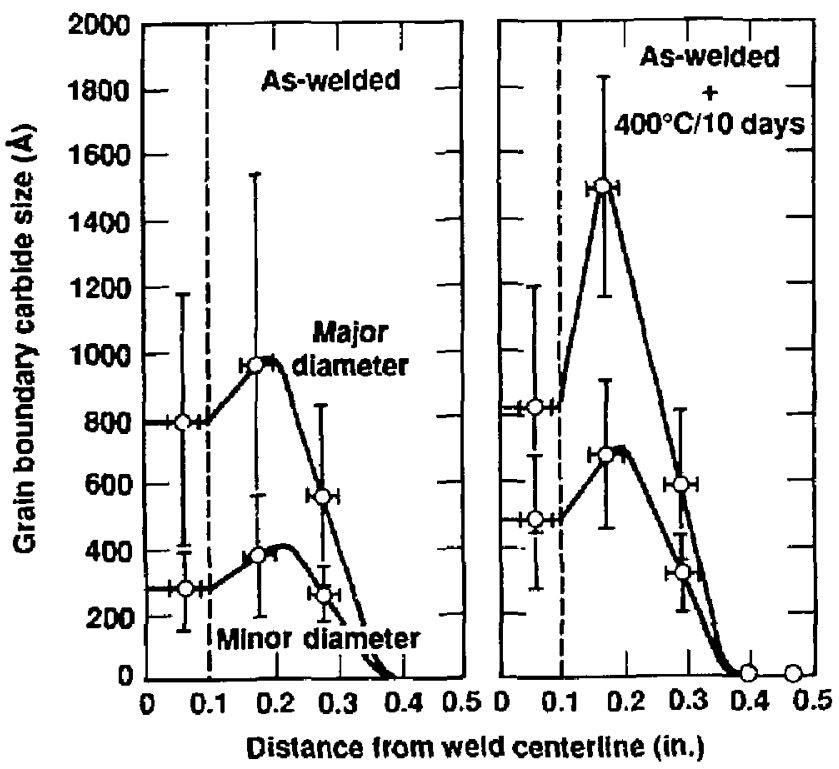

Figure 27. Plots of grain boundary carbide size as a function of distance from the weld centerline before and after the $4000^{\circ} \mathrm{C}$ $\left(752^{\circ} \mathrm{F}\right) / 10$ day LTS heat treatment [52]. 
or isothermal heat treatments, and long-term exposure to above-ambient temperatures brings about carbide growth.

Quantitative TEM studies on coupons from a pipe weld section have shown that no new carbides were nucleated during a $400^{\circ} \mathrm{C}\left(752^{\circ} \mathrm{F}\right)$ LTS heat treatment, but that carbides nucleated during welding increased in size, particularly along the direction of the grain boundary [40]. Povich and Rao [40] found an increase in the grain boundary coverage from $60 \%$ in the aswelded condition to $89 \%$ after a $400^{\circ} \mathrm{C} / 10$-day LTS heat treatment. These observations are shown in Fig. 26, which illustrates no change in the number of carbides after an LTS treatment, and Fig. 27, which shows a significant increase in the size of grain-boundary carbides after the $400^{\circ} \mathrm{C} / 10$-day LTS heat treatment.

From scanning electron microscopy (SEM) examination on welded specimens held for varying periods of time at $400^{\circ} \mathrm{C}\left(752^{\circ} \mathrm{F}\right)$, Kekkonen et al. [53] made several observations: the $\mathrm{M}_{23} \mathrm{C}_{6}$ carbides nucleate on high-angle boundaries during their short exposure to temperatures in the precipitation range. Relatively little carbide growth occurs during this stage. During the growth at low temperatures, the carbides seem to grow into one of the grains forming the boundary. After the carbides reach a certain size, retaining their geometrical shape, the grain boundary between the carbide particles starts to bow, and the carbides begin to coarsen. Both EPR and

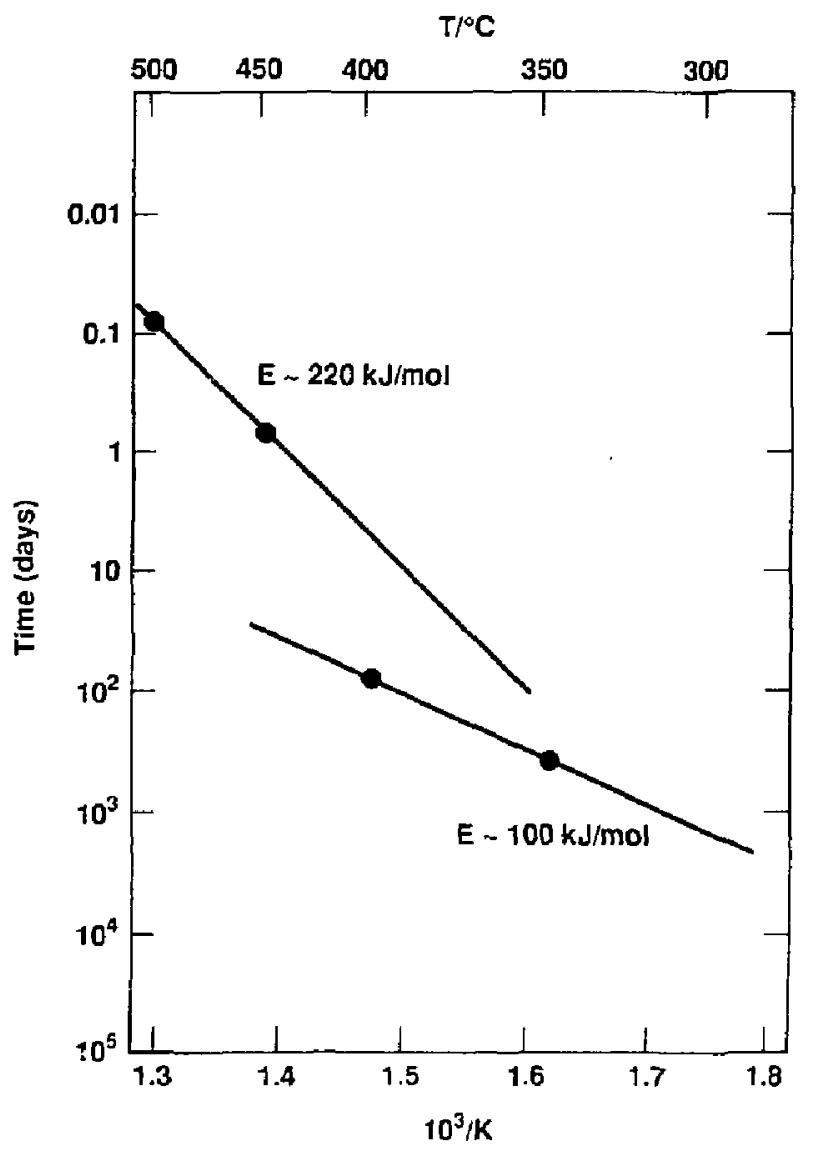

Figure 28. A temperature-time dependence for LTS based on the EPR test results [53]. 
Strauss test results indicate a change in the activation energy of LTS as the temperature decreases. The change can be explained by the pronounced effect of grain-boundary diffusion of chromium at low temperatures and the growth of $\mathrm{M}_{23} \mathrm{C}_{6}$ grain-boundary carbides involving grainboundary migration.

The change in activation energy can be seen in Fig. 28, which shows the decrease of energy with decreasing temperature. The numbers shown in the figure are close to those developed by Perkins et al. [54] for bulk diffusion

$\left(265 \mathrm{~kJ} \cdot \mathrm{mole}^{-1}\right)$ and grain-boundary diffusion: $\left(150 \mathrm{~kJ} \cdot \mathrm{mole}^{-1}\right)$ of chromium in an austenitic alloy.

In a review by Fox and McCright [55] of about 50 reports on LTS, 9 contained data pertinent to the LTS of low-carbon stainless steel. Fox and McCright concluded that Type 304L stainless steel is susceptible to LTS and that cold work has a rate effect, in that more cold work results in increased susceptibility to LTS. Hattori et al. [56] using ASTM A 262 practice E [28] as a means of characterization, concluded that Types $304 \mathrm{~L}$ and $316 \mathrm{~L}$ stainless steels are susceptible to LTS.

Type 316L stainless steel (carbon unknown) can be sensitized, and strain enhances the susceptibility to sensitization [57]. However, a prediction based on experimental data indicates that, at $300^{\circ} \mathrm{C}\left(572^{\circ} \mathrm{F}\right)$, it would take 2000 to $5000 \mathrm{yr}$ for sensitization to occur. Tsuge and Nagano [58] observed that Type 316 stainless steel was not susceptible to IGSCC even after an LTS treatment. They explained the lack of carbide growth to be the result of molybdenum relarding the diffusion of chromium and suggested that molybdenum increased the surface-film resistance. The reported activation energies for Type 304 stainless steel in these papers on LTS $[52,53,58]$, vary from 23 to $38.6 \mathrm{kcal} /$ mole. For Type 316 stainless steel, Tsuge and Nagano [58] reported a value of $42.7 \mathrm{kcal} / \mathrm{mole}$, which suggests a lower likelihood of sensitization occurring in the molybdenum-containing stainless steels.

\subsubsection{Sensitization of the Auslenitic Candidates}

Types 304L and 316L Stainless Steels. There is a considerable amount of test data on sensitization of Types 304 and 316 stainless steels; however, such is not the case for Types $304 \mathrm{~L}$ and $316 \mathrm{~L}$ stainless steels. Table 2 provides a summary of the available test data on Types 304L and 316L stainless steels. This data suggests that resistance to sensitization significantly increases as the carbon content is lowered. While the low carbon specified in Types $304 \mathrm{~L}$ and $316 \mathrm{~L}$ stainless steels (maximum 0.03 wt\% carbon) increases the resistance to sensitization in normal weld practice, the alloys are not immune from sensitization. Heat treatments in the sensitization range, as for stress relief, must still be avoided.

The compositional model for resistance to sensitization presented earlier can be used to predict the relative susceptibilities of Types $304 \mathrm{~L}$ and $316 \mathrm{~L}$ stainless steels. For purposes of comparison, the effective chromium is calculated from Eq. (3) using a carbon content of 0.03 wt $\%$ and from midspecification values for chromium, nickel, and molybdenum (Table 1). This results in a prediction that Type 316L stainless steel is more resistant to sensitization than Type 304L stainless steel, with effective chromium values of 17,8 and 16,0 , respectively. Maximum effective chromium values at $0.03 \%$ carbon (using optimized compositions) are 20.1 for Type 316L stainless steel and 17.4 for Type 304L stainless. steel. The calculated time required for sensitization at $650^{\circ} \mathrm{C}$ in these alloys was calculated from similar empirical relations by Bruemmer et al. [37]. For Types 304L and 316L stain]ess steel with $0.035 \mathrm{wt} \%$ carbon, the limes to sensitize at $650^{\circ} \mathrm{C}$ are 2.9 and $5.8 \mathrm{hr}$, respectively.

Alloy 825. Alloy 825 is an austenitic atloy containing a high percentage of nickel ( $42 w t \%)$. It also contains titanium, which partially stabilizes the carbon against chromium-rich carbide formation. There seems to be a scarcity of available data on sensitization of this alloy. Scarberry et al. [103] reported on the corrosion rate in boiling $\mathrm{HNO}_{3}$ of several stainless steel alloys after a sensitizing treatment of $1 \mathrm{hr}$ at $649^{\circ} \mathrm{C}\left(1200^{\circ} \mathrm{F}\right)$. After similar processing of Type 304 stainless steel and Alloy 825, there is a decrease by a factor of 30 with regard to the measured corrosion rates in Alloy 825.

Extrapolating Eq. (3) for the composition of Alloy 825, using the specified maximum of 0.05 wt\% carbon and midspecification values for chromium, nickel, and molybdenum, results in an effective chromium value of 15.2. However, using two actual heat chemistries supplied by INCO Alloys International, much higher values are obtained. A value of 18.0 is calculated from an actual heat chemistry of $22 \mathrm{Cr}-44 \mathrm{Ni}-2.8 \mathrm{Mo}-$ $0.02 \mathrm{C}$, and a value of 19.7 from an actual heat chemistry of $22 \mathrm{Cr}-43.5 \mathrm{Ni}-3.2 \mathrm{Mo}-0.01 \mathrm{C}$. Potential stabilization of carbon, as in Alloy 825, is not accounted for in Eq. (3). Therefore, the actual resistance to sensitization in Alloy 825 is expected 
Table 2. Summary of available test data on Types 304L and 316L stainless steels.

\begin{tabular}{|c|c|c|c|c|c|}
\hline Material & $\begin{array}{l}\text { Number of } \\
\text { specimens }\end{array}$ & Type of test & Results & Comments & Reference \\
\hline 1. $304 \mathrm{~L}$ & 4 & Isothcrmal heal treatment & $\begin{array}{l}\text { All specimens had step structure; } \\
621^{\circ} \mathrm{C} / 24 \text { hr sample was deeply } \\
\text { elched at grain boundaries }\end{array}$ & Oxalic acid screening and EPR & 38 \\
\hline 2. $304 \mathrm{LA}$ & 1 & $\begin{array}{l}\text { Isothermal heat treatment, } \\
600,650 \text {, and } 700^{\circ} \mathrm{C}\end{array}$ & Sensitized in less than $1 \mathrm{hr}$ & Strauss test & 35 \\
\hline 3. $316 \mathrm{~L}$ & 1 & Isothermal heat treatment & Sensitized in more than $1 \mathrm{hr}$ & Strauss test & 35 \\
\hline 4. $304 \mathrm{~L}$ & 9 & $\begin{array}{l}\text { Cyclic stress, } \\
\text { oxygen level } 8 \text { ppm }\end{array}$ & $\begin{array}{l}\text { No failure after } \\
2000 \text { to } 6000 \text { cycles }\end{array}$ & $\begin{array}{l}\text { Controlled nitrogen, } \\
\text { three welded + LTS }\left(500^{\circ} \mathrm{C} / 24 \mathrm{hr}\right)\end{array}$ & 34 \\
\hline 5. $316 \mathrm{~L}$ & 10 & $\begin{array}{l}\text { Cyclic stress, } \\
\text { oxygen level } 8 \text { ppm }\end{array}$ & $\begin{array}{l}\text { No failure after } \\
2000 \text { to } 6000 \text { cycles }\end{array}$ & $\begin{array}{l}\text { Pipe welds } 6 \text { of } 10 \text { LTS } \\
\left(500^{\circ} \mathrm{C} / 24 \mathrm{hr}\right)\end{array}$ & 34 \\
\hline 6. 316L & 2 & $\begin{array}{l}\text { Cyclic stress, } \\
\text { oxygen level } 8 \text { ppm }\end{array}$ & $\begin{array}{l}\text { Failure } 2885 \text { cycles } \\
\text { and } 1256 \text { cycles }\end{array}$ & $\begin{array}{l}\text { Pipe welds + LTS, transgranular } \\
\text { cracking }\end{array}$ & 34 \\
\hline 7. $304 \mathrm{~L}$ & 9 & Fatigue & $\begin{array}{l}\text { Degrees of cracking analyzed aftex } \\
772,1502,2680,5000,10,000 \text { cycles }\end{array}$ & No survival after 5000 cycles & 34 \\
\hline 8. 316L & 8 & Fatigue & $\begin{array}{l}\text { Degrees of cracking analyzed after } \\
772,1502,2680,5000,10,000 \text { cycles }\end{array}$ & No survival after 5000 cycles & 34 \\
\hline 9. $304 \mathrm{LN}$ & - & $\begin{array}{l}\text { Multiple and preheat } \\
\text { welded specimens }\end{array}$ & EPR below sensitization value & EPR tests & 17 \\
\hline 10. $304 \mathrm{~L}$ & $\begin{array}{l}\text { S heats, } \\
2 \text { specimens } \\
\text { each heat }\end{array}$ & $\begin{array}{l}\text { Isothermal heat treatments } \\
\text { at } 500,600,700 \text {, } \\
\text { and } 800^{\circ} \mathrm{C}\end{array}$ & $\begin{array}{l}\text { EPR testa, no DOS up to } 1 \mathrm{hr} \\
\text { at } 600,700 \text {, and } 800^{\circ} \mathrm{C}\end{array}$ & $\begin{array}{l}\text { Results of additional } 100 \text { Type } 304 \\
\text { tests were incorporated into plots }\end{array}$ & 33 \\
\hline 11. $316 \mathrm{~L}$ & $\begin{array}{l}4 \text { heats, } \\
2 \text { specimens } \\
\text { each heat }\end{array}$ & $\begin{array}{l}\text { Isothermal heat treatments } \\
\text { at } 500,600,700 r \\
\text { and } 800^{\circ} \mathrm{C}\end{array}$ & $\begin{array}{l}\text { EPR tests, no DOS up to } 10 \mathrm{hr} \\
\text { at } 600,700^{\text {, and }} B 00^{\circ} \mathrm{C}\end{array}$ & $\begin{array}{l}\text { Results of additional } 100 \text { Type } 304 \\
\text { tests were incorporated into plots }\end{array}$ & 33 \\
\hline 12. $304 \mathrm{~L}$ & 4 & $\begin{array}{l}\text { Corrosion weight Ioss in } \\
\text { boiling nitric acid }\end{array}$ & 304L better than 304 & $\begin{array}{l}\text { Experimental work performed } \\
\text { to validate model }\end{array}$ & 102 \\
\hline
\end{tabular}




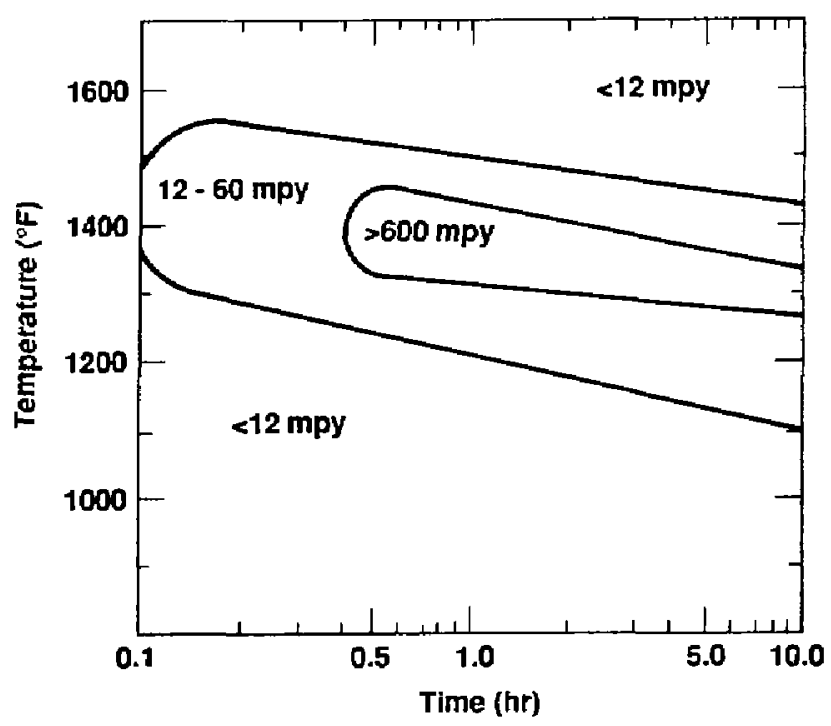

Figure 29. TTS diagram for Alloy 825 annealed at $1093^{\circ} \mathrm{C}$ $\left(2000^{\circ} \mathrm{F}\right)$ for $1 \mathrm{hr}$ prior to sensitization treatment [40].

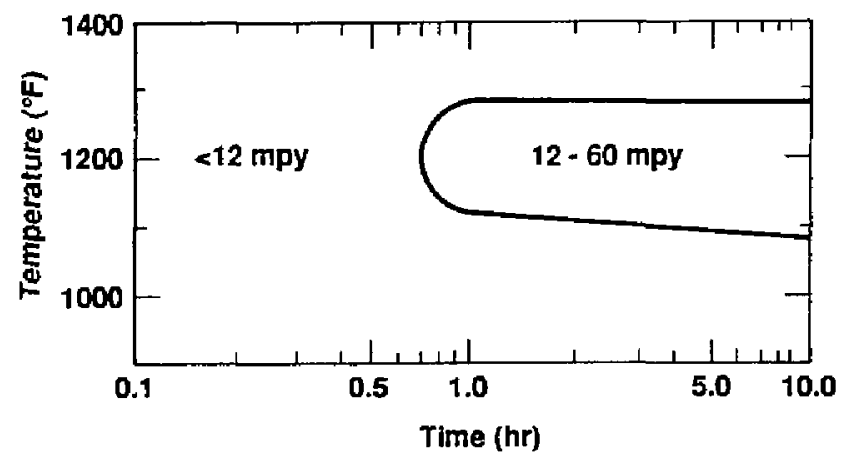

Figure 30. TTS diagram for Alloy 825 annealed at $941^{\circ} \mathrm{C}\left(1725^{\circ} \mathrm{F}\right)$ for $1 \mathrm{hr}$ prior to sensitization treatment [40].

to be higher than predictions from bulk carbon contents of unstabilized alloys.

Brown and Kirchner $[59,60]$ evaluated 15 heats of Alloy 825, using ASTM A 262, practices B and C [28]. He found a wide variation in resistance to sensitization, which he felt could not be explained by compositional differences. He believed that variations in mill processing have a larger in fluence on resistance to sensitization than variations in composition within the nominal composition.
Raymond [61] used the Huey test (ASTM A 262, practice C) [28], TEM, and compositional analysis of chemically extracted carbides to evaluate the sensitjzation behavior of Alloy 825 . He established that the alloy can be stabilized through a proper mill-annealing heat treatment. His results show that only 0.01 wto carbon is stabilized as titanium-rich carbide in a heat containing 0.99 wt\% titanium. Raymond postulated that the principal mechanism of 
stabilization for Alloy 825 is that of precipitating the $\mathrm{M}_{23} \mathrm{C}_{6}$ at a temperature at which the diffusion of chromium is sufficiently rapid to prevent chromium depletion. Optimum thermal stabilization in Alloy 825 occurs in the range of 920 to $980^{\circ} \mathrm{C}$ (approximately 1700 to $1800^{\circ} \mathrm{F}$ ). The effectiveness of higher-temperature anneals diminishes because of increased carbon remaining in solution. The carbon solubility increases from approximately $0.01 \mathrm{wt} \%$ carbon below $980^{\circ} \mathrm{C}\left(1800^{\circ} \mathrm{F}\right)$ te. ${ }^{\circ} .02 \mathrm{wt} \%$ carbon at $1095^{\circ} \mathrm{C}\left(2000^{\circ} \mathrm{F}\right)$ and 0.04 wt\% carbon at $1150^{\circ} \mathrm{C}$ $\left(2100^{\circ} \mathrm{F}\right)$ [61]. The stabilized condition is quite resistant to isothermal sensitization, as shown by the low corrosion rates subsequent to exposure within the sensitization range in Figs. 29 and 30.

It should be noted that carbon solubility in $18 \mathrm{Cr}-8 \mathrm{Ni}$ steels is reported [37] to increase more rapidly with increasing temperature than in Alloy 825, exceeding 0.06 wt\% carbon below $900^{\circ} \mathrm{C}\left(1650^{\circ} \mathrm{F}\right)$. For a thermal-stabilization mechanism dependent on the increased matrix diffusion of chromium relative to grainboundary diffusion at high temperatures, the potential for thermal stabilization in $18 \mathrm{Cr}-8 \mathrm{Ni}$ steels is much lower than in Alloy 825.
The only review to evaluate the effects of welding on corrosion rales in Alloy 825 is that by Copson et al. [62]. The alloys investigated in this work are referred to as "Ni-O-Nel". The compositions of the materjals investigated are listed in Table 3. Corrosion rates for alloy No. 12 were compared in three conditions: millannealed, isothermally aged at $650^{\circ} \mathrm{C}\left(1200^{\circ} \mathrm{F}\right)$ for $1 \mathrm{hr}$, and as-welded. The composition of alloy No. 12 is within the specifications for Alloy 825 listed in Table 1. A summary of results on corrosion rates in a wide range of media for alloy No. 12 are listed in Tables 4 and 5. Welded specisiens did not show any signs of increased attack over the annealed material.

A summary of corrosion tests performed on Alloy 825 as reported in the literature is shown in Table 6.

\subsection{SCC of the Austenitic Candidates}

SCC refers to the accelerated corrosive attack resulting in crack propagation at stresses below that required in the absence of a corrosive environment. The critical stress intensity for unstable crack growth can be significantly

Table 3. Compositions of materials used to in: :stigate the effects of welding on corrosion rates in Alloy 825 [62].

\begin{tabular}{cccccccccc}
\hline & \multicolumn{10}{c}{ Composition (\%) } \\
\cline { 2 - 11 } Alloy No. & Ni & Cr & Mo & Cu & Mn & Si & C & Ti & Fe \\
\hline 1 & 41.1 & 19.9 & 2.92 & 1.62 & 0.63 & 0.30 & 0.017 & 0.46 & Bal. \\
2 & 41.3 & 19.8 & 3.21 & 1.73 & 0.57 & 0.36 & 0.022 & 0.48 & Bal. \\
3 & 41.1 & 20.6 & 3.20 & 1.78 & 0.62 & 0.35 & 0.023 & 0.44 & Bal. \\
4 & 41.4 & 20.6 & 3.30 & 1.90 & 0.55 & 0.39 & 0.035 & 0.55 & Bal. \\
5 & 43.2 & 18.6 & 3.26 & 1.30 & 0.55 & 0.30 & 0.04 & 0.47 & Bal. \\
6 & 43.3 & 20.8 & 3.07 & 1.70 & 0.74 & 0.39 & 0.05 & 0.42 & Bal. \\
7 & 37.2 & 20.5 & 1.98 & 1.09 & 0.68 & 0.28 & 0.05 & 0.22 & Bal. \\
8 & 41.5 & 19.6 & 3.21 & 1.44 & 0.96 & 0.58 & 0.05 & 0.63 & Bal. \\
9 & 42.6 & 19.5 & 3.21 & 1.52 & 0.90 & 0.62 & 0.04 & 0.83 & Bal. \\
10 & 42.1 & 19.6 & 3.23 & 1.60 & 0.92 & 0.59 & 0.04 & 1.34 & Bal. \\
11 & 42.3 & 21.6 & 2.94 & 1.91 & 0.69 & 0.23 & 0.03 & 0.69 & Bal. \\
12 & 40.0 & 21.4 & 3.01 & 1.70 & 0.63 & 0.23 & 0.03 & 0.81 & Bal. \\
13 & 41.0 & 19.6 & 4.03 & 1.91 & 0.90 & 0.40 & 0.05 & 0.54 & Bal. \\
14 & 40.5 & 20.8 & 3.04 & 2.00 & 0.51 & 0.30 & 0.04 & 0.47 & Bal. \\
15 & 41.1 & 21.7 & 3.14 & 1.86 & 0.57 & 0.42 & 0.03 & 0.57 & Bal. \\
16 & 45.7 & 17.2 & 3.11 & 1.58 & 0.65 & 0.28 & 0.05 & 0.49 & Bal. \\
\hline
\end{tabular}


Table 4. Corrosion tests on alloy No. 12 in sulfuric acid [62].

\begin{tabular}{|c|c|c|c|c|c|}
\hline \multicolumn{3}{|c|}{ Test conditions ${ }^{\mathbf{a}}$} & \multirow{2}{*}{\multicolumn{3}{|c|}{ Corrosion rate (in./yr) }} \\
\hline & & & & & \\
\hline $\begin{array}{c}\text { concentration } \\
(\%)\end{array}$ & $\begin{array}{c}\text { Temperature } \\
\left({ }^{\circ} \mathbf{F}\right) \\
\end{array}$ & $\begin{array}{c}\text { Time } \\
\text { (hr) }\end{array}$ & $\begin{array}{c}\text { Mill- } \\
\text { annealed }\end{array}$ & $\begin{array}{l}1 \mathrm{hr} \text { at } \\
1200^{\circ} \mathrm{F}\end{array}$ & Welded \\
\hline 5 & Boiling & 4 & 0.035 & 0.064 & 0.027 \\
\hline 10 & Boiling & 4 & 0.056 & 0.087 & 0.042 \\
\hline 20 & Boiling & 4 & 0.197 & 0.082 & 0.114 \\
\hline 40 & Boiling & 4 & 0.135 & 0.167 & 0.135 \\
\hline 60 & Boiling & 4 & 0.531 & 0.645 & 0.759 \\
\hline 80 & Boiling & 4 & 17.0 & 12.1 & 11.2 \\
\hline 96 & Boiling & 4 & 0.829 & 0.861 & 0.608 \\
\hline 5 & Boiling & 20 & 0.028 & 0.046 & 0.048 \\
\hline 10 & Boiling & 20 & 0.051 & 0.062 & 0.067 \\
\hline 20 & Boiling & 20 & 0.034 & 0.058 & 0.069 \\
\hline 40 & Boiling & 20 & 0.065 & 0.078 & 0.081 \\
\hline 60 & Boiling & 20 & 0.324 & 0.351 & 0.377 \\
\hline 80 & Boiling & 20 & 4.0 & 3.8 & 4.5 \\
\hline 96 & Bailing & 20 & 0.213 & 0.296 & 0.394 \\
\hline 5 & 150 & 4 & 0.004 & 0.004 & 0.006 \\
\hline 10 & 150 & 4 & 0.005 & 0.010 & 0.007 \\
\hline 20 & 150 & 4 & 0.009 & 0.004 & 0.016 \\
\hline 40 & 150 & 4 & 0.040 & 0.024 & 0.051 \\
\hline 60 & 150 & 4 & 0.033 & 0.025 & 0.041 \\
\hline 80 & 150 & 4 & 0.053 & 0.047 & 0.056 \\
\hline 96 & 150 & 4 & 0.283 & 0.346 & 0.264 \\
\hline 5 & 150 & 20 & 0.001 & 0.001 & 0.001 \\
\hline 10 & 150 & 20 & 0.001 & 0.002 & 0.001 \\
\hline 20 & 150 & 20 & 0.001 & 0.001 & 0.001 \\
\hline 40 & 150 & 20 & 0.036 & 0.038 & 0.038 \\
\hline 60 & 150 & 20 & 0.030 & 0.029 & 0.017 \\
\hline 80 & 150 & 20 & 0.124 & 0.095 & 0.021 \\
\hline 96 & 150 & 20 & 0.246 & 0.249 & 0.138 \\
\hline
\end{tabular}

${ }^{2}$ Tests at $150^{\circ} \mathrm{F}$ were aerated, and specimens were moved at $16 \mathrm{ft} / \mathrm{min}$.

decreased under conditions of SCC. Three principal factors must coexist for the operation of SCC $[17,24,63]$ : a critical stress intensity, a critical environment, and a susceptible microstructure. SCC can be prevented by the elimination of any of these factors. Weidinginduced microstructural changes can influence the susceptibility of the austenitic candidate materials to SCC. In particular, the effects resulting in preferential corrosion in the $\mathrm{FZ}$ and sensitization in the HAZ of weldments can create SCC-susceptible microstructures.

Three microstructurally specific modes of SCC have been observed in weldments: intergranular stress corrosion cracking (1GSCC), transgranular stress corrosion cracking (TGSCC), and interdendritic SCC. The susceptibility of a weldment to any of these three modes of SCC is 
Table 5. Corrosion tests on alloy No. 12 in other acid environments [62].

\begin{tabular}{|c|c|c|c|c|c|}
\hline \multicolumn{3}{|c|}{ Test conditions ${ }^{\mathrm{a}}$} & \multicolumn{3}{|c|}{ Corrosion rate (in./yr) } \\
\hline Environment & $\begin{array}{c}\text { Temperature } \\
\text { ('F) }\end{array}$ & $\begin{array}{l}\text { Time } \\
\text { (hr) }\end{array}$ & $\begin{array}{c}\text { Mill- } \\
\text { annealed }\end{array}$ & $\begin{array}{l}1 \mathrm{hr} \text { at } \\
1200^{\circ} \mathrm{F}\end{array}$ & Welded \\
\hline Phosphoric acid, 60\% & Boiling & 20 & 0.0 .08 & 0.012 & 0.015 \\
\hline Phosphoric acid, 70\% & Boiling & 20 & 0.007 & 0.013 & 0.018 \\
\hline Phosphoric acid, $80 \%$ & Boiling & 20 & 0.051 & 0.038 & 0.052 \\
\hline $10 \% \mathrm{H}_{2} \mathrm{SO}_{4}^{\mathrm{a}}$ & 150 & 20 & 0.001 & 0.002 & 0.001 \\
\hline $10 \% \mathrm{H}_{2} \mathrm{SO}_{4}+5 \% \mathrm{HNO}_{3}{ }^{\mathrm{a}}$ & 150 & 20 & 0.002 & 0.002 & 0.002 \\
\hline $10 \% \mathrm{H}_{2} \mathrm{SO}_{4}+5 \% \mathrm{NaCl}^{\mathrm{a}}$ & 150 & 20 & 0.203 & 0.181 & 0.222 \\
\hline Acetic acid, $10 \%$ & Boiling & 120 & $<0.001$ & 0.002 & $<0.001$ \\
\hline Formic acid, $10 \%$ & Boiling & 120 & 0.003 & 0.003 & 0.003 \\
\hline Lactic acid, $10 \%$ & Boiling & 120 & $<0.001$ & $<0.001$ & $<0.001$ \\
\hline Maleic açid, 10\% & Boiling & 120 & $<0.001$ & $<0.001$ & $<0.001$ \\
\hline Oxalic acid, 10\% & Boiling & 120 & 0.020 & 0.015 & 0.016 \\
\hline Phthalic acid, 10\% & Boiling & 120 & $<0.001$ & $<0.001$ & $<0.001$ \\
\hline Aluminum chloride, ${ }^{\mathrm{a}} \mathbf{2 5 \%}$ & 86 & 168 & 0.005 & 0.005 & - \\
\hline Zinc chloride $_{s}^{\mathrm{a}} 25 \%$ & 86 & 168 & 0.0001 & 0.0062 & - \\
\hline Sodium bisulfite, ${ }^{b}$ 25\% & 86 & 168 & $<0.0001$ & 0.0002 & $<0.0001$ \\
\hline
\end{tabular}

aSolutions were aerated; specimens were moved at $16 \mathrm{ft} / \mathrm{min}$.

${ }^{b}$ No air was added to solutions; specimens were moved at $16 \mathrm{ft} / \mathrm{min}$.

Table 6. Summary of tests performed on Alloy 825.

\begin{tabular}{|c|c|c|c|c|}
\hline $\begin{array}{l}\text { Number of } \\
\text { specimens }\end{array}$ & Type of test & Results & Comments & Reference \\
\hline 2 & $\begin{array}{l}\text { Boiling } 42 \% \\
\text { magnesium chloride }\end{array}$ & $\begin{array}{l}\text { No cracking in } \\
30 \text { days }\end{array}$ & Solution heat treated & 103 \\
\hline 2 & $\begin{array}{l}\text { Boiling } 65 \% \\
\text { magnesium chloride }\end{array}$ & $\begin{array}{l}\text { Corrosion rate }= \\
36 \text { mils per yr }\end{array}$ & $\begin{array}{l}\text { Sensitized } \\
\left(649^{\circ} \mathrm{C} \text { for } 1 \mathrm{hr}\right)\end{array}$ & 103 \\
\hline$?$ & $\begin{array}{l}\text { ASTM A 262, } \\
\text { practices B and C [28] }\end{array}$ & $\begin{array}{l}\text { Corrosion rate in } \\
\text { nitric and ferric } \\
\text { showed wide heal } \\
\text { to heat variation }\end{array}$ & $\begin{array}{l}\text { Effect of sensitization } \\
\text { on various ranges of } \\
\text { compositions within } \\
\text { specifications. } 15 \\
\text { heats examined. }\end{array}$ & 60 \\
\hline$?$ & $\begin{array}{l}\text { ASTM A 262, } \\
\text { practice C [28] }\end{array}$ & $\begin{array}{l}\text { Heat treatment = } \\
\text { self-sensilization }\end{array}$ & $\begin{array}{l}\text { TTS diagrams } \\
\text { generated }\end{array}$ & 60 \\
\hline
\end{tabular}


dependent on both the composition of the alloy and thermomechanical history. IGSCC results from the development of grain-boundary sensitization in the HAZ of the weldment. TGSCC can occur in the FZ, and interdendritic SCC has been observed at the austenitic/ferritic interfaces in duplex weldmenis.

In a study of SCC in single-pass autogenous GTA weldments in Type 304L stainless steel (in boiling $42 \% \mathrm{MgCl}_{2}$ ) by Sherman et al. [14], none of the failures occurred by an intergranular mode. Carbon contents of 0.016 and $0.028 \mathrm{wt} \%$ resulted in high and low ferrite levels, respectively. In tests of transverse weldment sections, failure always initiated outside of the FZ. In the high-ferrite alloy, transgranular cracking initiated in the parent metal, while in the low-fersite alloy, transgranular cracking occurred in the grain-coarsened HAZ. The high-ferrite alloy retained ferrite in the hightemperature region of the $\mathrm{HAZ}$, significantly reducing the maximum $\mathrm{HAZ}$ grain size. In tests of all-weld-metal samples, the samples failed in an interdendritic mode following the ferriteaustenite interfaces.

Using ferrite in the $\mathrm{FZ}$ to prevent hot cracking raises the issue of the effect of a two-phase structure and its inherent corrosion problems. Stalder and Duquette [65] observed the effect of a two-phase ferrite-plus-austenite structure in a weld on its corrosion resistance as compared with a fully austenitic structure. In an SCC test, they found that fracture occurred preferentially along ferrite-austenite interfaces regardless of temperature, whereas in annealed material, fracture occurred intergranularly or transgranularly, depending on the test temperature.

Baeslack et al. [66] conducted an SCC study of Type 304 stainless steel containing welds with varying degrees of ferrite. They concluded from observations of the failure microstructure and measurements of reduction of area that the fully austenitic Type 304 stainless steel cracks in a transgranular manner and is less susceptible to SCC than is the two-phase weld metal. The crack morphology of the duplex weld metal indicates preferential dissolution of the ferrile and SCC of the austenite. In addition, they found that the ferrite content does have an effect on the susceptibility to SCC; those structures showing a continuous network of ferrite appear to be more susceptible to cracking.

Gooch et al. [67] have used potentiostatic polarization techniques to study the localized corrosion of stainless steel weld metais in aqueous environments. All steels studied were austenitic and included Types 304, 316, and 321 stainless steels. The welding processes investigated included tungsten inert gas (TIG), metal inert gas (MIG), manual metal arc (MMA), and submerged arc welding (SAW). Various filler materials were used, some containing a small percentage of niobium, a carbide-former capable of suppressing the formation of $\mathrm{Cr}_{23} \mathrm{C}_{6}$ precipitated near the weld. Most atmospheres present during the welding operation were either pure argon or argon with 2 wt\% oxygen. Most welds were made from $1 / 4$-in.-thick plates, although a few samples were made from either $1 / 8$ or $5 / 8$-in.-thick plates. Transverse cross sections were polished to a 1-mm finish with diamond paste. Active areas were defined using lacquer masks. All corrosion tests were performed with solutions consisting of $20 \mathrm{wt} \%$ sulfuric acid and $0.5 \mathrm{~g} / \mathrm{l}$ ammonium thiocyanate. In all experiments, the potential was controlled relative to the mercury/mercurous sulfate reference electrode, which has a standard half-cell voltage of $664 \mathrm{mV}$ on the hydrogen scale.

Initially, Gooch et al. [67] attempted to characterize samples with potentiodynamic polarization experiments. The potential of the working electrode (test specimen) was swept from -900 to $+1500 \mathrm{mV}$ at a rate of $300 \mathrm{mV} / \mathrm{hr}$. Polarization curves exhibited all of the qualitative characteristics expected, including active loops, activepassive transitions, passivity, and transpassive regions. These experiments demonstrated that the addition of molybdenum tends to stabilize passive films on stainless steels and make them more noble. For example Type 316 stainless steel had a lower peak current density (active loop) than did Type 304 stainless steel.

Furthermore, it was also determined that the ferrite phase in welds was preferentially attacked.

Although the potentiodynamic tests were useful, better results were obtained by anodic polarization of samples at various potential levels, followed by microscopic examination and characterization of corroded specimen surfaces. Several general types of localized corrosion were identified, including fusion-boundary attack, grain-boundary attack, and preferential attack of the ferrite phase. Deep attack of the fusion boundary occurred in specimens containing molybdenum, and those specimens polarized anodic to the potential required for breakdown of 
the passive film. Most welds will never be polarized to the extent necessary for attack of the fusion boundary. Grain-boundary attack was observed at potentials near the active-passive transition (positive side of active loop), but only in specimens containing more than $0.08 \mathrm{wt} \%$ carbon and no molybdenum. Such attack is probably due to the precipitation of $\mathrm{Cr}_{23} \mathrm{C}_{6}$ particles, which depletes chromium near grain boundaries. Localized depletion of chromium and the general lack of molybdenum could prevent formation of stable passive films in these regions. Welds maintained near the corrosion potential (negative side of active loop) suffered preferential attack of the ferrite phase. Since the potential of a metal in aqueous solution remains near the free corrosion potential, localized attack of the ferrite phase should be the predominant mode of weld-meial corrosion. The process used to make the welds had no significant effect on either overall corrosion behavior or susceptibility to preferential attack. However, in multiple-pass welds, the first-pass weld metal was more susceptible than the weld metal of subsequent passes; the reason for this difference may be related to the additional thermal cycles imposed by subsequent weld passes.

\section{Defects and Defect Tolerance}

\subsection{Hot Cracking}

The causes and prevention of hot cracking of welds in austenitic alloys are well documented [68]. In reviewing the subject of hot cracking, consideration must be given not only to hot cracking of the $\mathrm{FZ}$ but also to the HAZ. It is generally accepted [69-72] that the presence of ferrite in the weld metal will reduce or prevent the problem of hot cracking. This review presents background material on the causes of hot cracking (both in the $\mathrm{FZ}$ and $\mathrm{HAZ}$ ), and means for its control.

A review by Thomas [73] discusses the theories of hot cracking of HAZs and the effects of composition. The observation that HAZ cracks are almost always intergranular in nature has suggested that compositional segregation of some sort is responsible for hot cracking. This segregation or partitioning of alloy elements can result in localized liquation. Sulfur and phosphorus are common segregants contributing to cracking $[99,107]$. Cracking is also exacerbated in those stainless steel alloys containing niobium and titanium as stabilizers. The niobium and titanium both form low-melting eutectics with carbon.

Several theories [68] have been proposed to account for the hot cracking that occurs in stainless steel welds. Of these, the phenomenology proposed by Borland $[\mathbf{7 0}, 72]$ and Borland and Younger [71] seems to be the most generally accepted. In this view, the mechanism of hot cracking comprises four stages:

(1) Primary dendrite formation occurs, in which the solid is dispersed and the liquid is continuous, and no cracking is possible.
(2) The dendrites become interlocked, with the liquid circulating between the dendrites. If the grains are pulled apart, the cracks are refilled and healed by the interconnecting liquid.

(3) The "critical solidification range" occurs, in which cracks cannot be healed by liquid because of the lack of interconnections among liquid volumes.

(4) The remaining liquid completely solidifies and no cracking occurs.

In multicomponent systems containing potentially dangerous impurities such as phosphorus and sulfur the solidus can be severely depressed. This depression leads to a wider temperature range during stage 3 for development of thermal stress, and severe cracking susceptibility.

It has long been recognized [74] that the presence of ferrite has a positive effect on the reduction of hot cracking, and many theories have been proposed as an explanation. To understand the presence of ferrite in the solidified weld metal, it is helpful to review Fig. 3. The figure shows a vertical cross section of the ironchromium-nickel phase diagram at $63.5 \mathrm{wt} \%$ iron. Ternary alloys with compositions typical of stainless steel welds (within the broken vertical lines) should solidify as austenite plus $\delta$ ferrite. Either phase can solidify first, depending on the nickel and chromium equivalents. Most of the $\delta$ ferrite formed at high temperature transforms to austenite by a solid-state reaction. The amount of retained $\delta$ ferrite at ambient temperatures is dependent on the cooling rate as well as the composition.

There are at least five different theories explaining the beneficial effects of ferrite in 


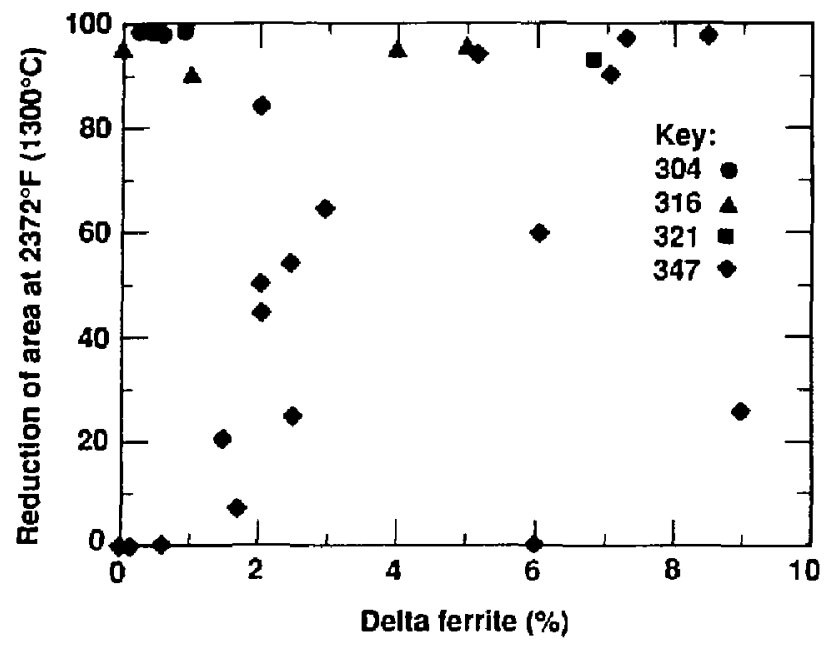

Figure 31. Hot ductility as a function of the $\delta$ ferrite tendency [69].

reducing or eliminating hot cracking. The most popular of these $[70,71]$ start with the assumption that ferrite has a greater solubility than austenite for those impurities that generally form low-melting phases. The presence of some ferrite can therefore reduce the amount of liquid films and the temperature range over which they persist by decreasing impurity segregation during the solidificalion process. Borland and Younger [71] tabulated the solubilities of various elements in austenite and ferrite and, from this, inferred that elements such as phosphorus, sulfur, silicon, and oxygen would partition to the $\delta$ ferrite. It has also been suggested that the interphase boundary between ferrite and austenite benefits as a sink for impurities [70]. Astrom et al. [75] performed an $x$-ray analysis of a welded stainless steel specimen doped with sulfur and phosphorus. They concluded that sulfur was the cause of hot cracking and that, in a fully austenitic weld, manganese remains largely in solution and is not available at the final stages of solidification to break up the sulfide films. In terms of absolute amounts, 5 wt\% ferrite [76] is considered to be a preferred value in the weld metal to prevent hot cracking.

Morishige et al. [69] conducted a statistical study of 39 commercial heats of Types 304, 316, 321 , and 347 stainless steels. Using a tungsten arc weld, they performed hot ductility tests (Fig. 31) at $1300^{\circ} \mathrm{C}\left(2372^{\circ} \mathrm{F}\right)$ on these specimens, which had 0 to $10 \% \delta$ ferrite present. The results show no correlation between the presence of ferrite and reduction of area. This work emphasizes the importance of solidification behavior vs consideration of ferrite content alone. Matsuda et al. [77] proposed from their experimental work that $\delta$ fernite prevented hot cracking by a peritectic/ eutectic reaction. They reasoned that the residual liquids were confined to liquid drops within the austenite grains. Primary $\delta$ ferrite solidification also reduces the level of impurities in the final liquid.

Schaeffler [78] and DeLong [79] examined the combined effect of alloy additions on the constitution of weld deposits. Their diagrams enable the user to design a $\mathrm{FZ}$ with any desired ferrite content (Figs. 6 and 7). However, this approach has not been completely effective since there have been instances where, predictions notwithstanding, cracking has occurred in the FZ. Lippold [108] observed that the welding process could affect the prediction of the ferrite composition in the FZ. He found fully austenitic regions in deep electron-beam welds where the DeLong diagram had predicted 2 to $3 \%$ ferrite. In laser welds made at Lawrence Livermore National Laboratory on Types 304 and 316 stainless steels, cracks occurred in fully austenitic microstructures which, by Schaeffler/DeLong predictions, should have contained 5 to 10\% of ferrite [83]. The relatively large mell 
Table 7. Compositions of Alloy 825, Alloy 800 (comparable to Alloy 825), and Alloy 625 (a weld filler material for Alloy 825).

\begin{tabular}{|c|c|c|c|}
\hline & Alloy 825a & Alloy $800^{b}$ & Alloy $625^{\circ}$ \\
\hline $\mathbf{N i}$ & $\begin{array}{l}38.0 \mathrm{~min} \\
46.0 \mathrm{max}\end{array}$ & $\begin{array}{l}30.0 \text { min } \\
35.0 \text { max }\end{array}$ & $58.0 \mathrm{~min}$ \\
\hline$C r$ & $\begin{array}{l}19.5 \mathrm{~min} \\
23.5 \mathrm{max}\end{array}$ & $\begin{array}{l}19.0 \mathrm{~min} \\
23.0 \mathrm{max}\end{array}$ & $\begin{array}{l}20.0 \mathrm{~min} \\
23.0 \mathrm{max}\end{array}$ \\
\hline $\mathbf{F e}$ & $22.0 \mathrm{~min}$ & 39.5 min & $5.0 \mathrm{max}$ \\
\hline Mn & $1.0 \max$ & $1.5 \max$ & $0.50 \max$ \\
\hline $\mathrm{C}$ & $0.05 \max$ & $0.10 \max$ & $0.10 \max$ \\
\hline $\mathrm{Cu}$ & $\begin{array}{l}1.5 \mathrm{~min} \\
3.0 \mathrm{max}\end{array}$ & 0.75 thax & - \\
\hline Si & $0.50 \max$ & $1.0 \mathrm{max}$ & $0.50 \max$ \\
\hline Ti & $\begin{array}{l}0.6 \min \\
1.2 \max \end{array}$ & $\begin{array}{l}0.15 \text { min } \\
0.60 \max \end{array}$ & $0.4 \max$ \\
\hline Mo & $\begin{array}{l}2.5 \mathrm{~min} \\
3.5 \mathrm{max}\end{array}$ & - & $\begin{array}{r}8.0 \mathrm{~min} \\
10.0 \max \end{array}$ \\
\hline$C b+T a$ & - & - & $\begin{array}{l}3.15 \min \\
4.15 \max \end{array}$ \\
\hline Al & $0.2 \max$ & $\begin{array}{l}0.15 \text { min } \\
0.60 \mathrm{max}\end{array}$ & $0.4 \max$ \\
\hline $\mathbf{P}$ & - & 一 & $0.015 \max$ \\
\hline$S$ & $0.03 \max$ & 0.015 max & $0.015 \mathrm{max}$ \\
\hline
\end{tabular}

undercooling and high cooling rates in laser and electron-beam processes can have a significant influence on solidification and retained ferrite levels.

Hot cracking is generally avoided if roughly 3 to $5 \%$ ferrite is retained in the as-solidified structure. However, the optimum resistance to cracking requires primary solidification as $\delta$ ferrite vs austenite. For this reason, Types $304 \mathrm{~L}$ and 308 fillers, which solidify as primary $\delta$ ferrite, are more resistant to weld cracking than Types 316 and $316 \mathrm{~L}$ stainless steel, which can solidify as primary austenite. Both can be welded without cracking using proper control of ferrite content and impurity levels.

Little data is available on weld cracking of the fully austenitic Alloy 825. Because of this lack of published information, much of the data in this section is derived from personal communications and from extrapolations from alloy systems similar in composition to Alloy 825 .
Although Alloy 825 has been known to hatcrack, definitive work has not yet been published. Some work has been conducted on Alloy 800 , which is similar to Alloy 825 (see Table 7). This alloy also has been known to hot-crack [80]. Lippold [80] compared four different heats of Alloy 800 , using the Varestraint lest as a measurement of cracking susceptibility. Using optical microscopy, SEM, and Auger surface analysis, he observed that the heat most susceptible to cracking contained the largest amount of silicon (in this case, $0.39 \%$ ), with the cracking occurring primarily at the grain boundaries of the FZ. Lippold observed high concentrations of silicon, titanium, and niobium at these grain boundaries, which he postulated developed as a result of partitioning during solidification. These constiluents then acted to depress the solidification temperature. The sulfur and phosphorus contents were on the order of 0.01 wt\% or less and were not evident in the region of fracture. 
Cheng [B1] stated that it was possible to weld Alloy 825 without cracks by using the TIG process and plates with thicknesses less than 0.5 in. Cheng and others interviewed solved the problem of joining thicker sections by using

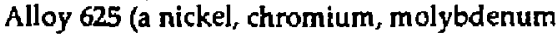
alloy) as a weld filler metal. Bishel [82] considered solidification stresses a primary cause of hot cracking. Composition is probably the most significant factor, but he could not place the blame on any one constituent. Bishel does not believe that there is a problem with the corrosion resistance of weld metal Alloy 625 and base metal Alloy 825 because the weld is the more noble of the two compositions.

Witherell [83], responsible for much of the developmental work on weld filler metals for Alloy 625, supports the above comments on the use of Alloy 625 for welding. He also points out that an attempt to modify the composition of Alloy 825 so as to reduce or eliminate the fissuring essentially changes the alloy to such an extent that it can no longer be considered to be Alloy 825. Witherell thinks oxygen and nitrogen lock in the grain boundaries during solidification, and the thermal strain (which cannot be acrommodated) then causes cracking.

Alloy 625 has more molybdenum than Alloy 825 and therefore creates a more passive film. Consequently, Alloy 625 is more resistant to crevice corrosion and pitting than Alloy 825 [84]. Lingenfelter [85] stated the following:

Alloy 825 was developed in the $195 \mathrm{ks}$ and was originally marketed as NIONEL, prior to the adoption of the current alloy numbering system by its producer, INCO Alloys International. It has been used hislorically in aqueous corrosion environments, particularly where pitting and crevice corrosion are a problem and in oxidizing acids where intergranular attack is the problem.

Most of the early applications were for pickling hooks and other hardware which did not require nuclear quality weldments, i.e., weldments free or virtually free of porosity, fissuring and other linear defects. A matching composition filler wire for use with GMAW and GTAW (Filler Metal 65) as well as a coated electrode (Welding Electrode 135) were developed and markeled for a number of years. Weldments produced with these prod- ucts exhibited microfissuring to the extent that they would not consistently meet the high-quality standards demanded by the Navy Nuclear Code $\{86\}$ or Section 8 of the ASME Boiler Code [87]. It should be noted that these codes require a full one-inch-thick butt joint for qualification of a welding product. The same fully austenitic alloys (such as Alloy 825 represents) will frequently have adequate cracking resistance to produce crack-free welds up to one-quarter-inch or perhaps one-half-inch thickness. These same materials will not meet the standands at oneinch thickness due to the higher levels of restraint imposed by the added thickness.

In conclusion, on the basis of the information available on Alloy 825 , there are two observations that should be made: (1) if Alloy 825 is to be a viable candidate, it is important that the causes of hot cracking be understood so that whichever technique is chosen for joining the potentiat problems will have been considered and addressed, and (2) because hot cracking is the result of a melting and solidification process, th possible use of friction welding as a joining method is very attractive since it does not involve melting.

\subsection{Toughness}

While the toughness of as-welded austenitic alloys is generally excellent, there are several areas of concern. Weld thermal cycles and high service temperalures can cause precipitation of carbides such as $\mathrm{M}_{23} \mathrm{C}_{6}$ and intermetallics such as $\sigma$ phase. The presence of ferrite is of some concern regarding the cryogenic toughness, but more important, it can increase the extent of degradation of toughness due to $\sigma$ formation. The presence of weld discontinuities such as microfissures can potentially limit operational stresses.

The effect of aging treatments within the sensitization range on the loughness of Types 304 and 308 stainless steels with Types 308 and 16-8-2 stainless steel welds was measured by Mills [88]. The fracture toughness was measured by multiple-specimen $J_{R}$-curve techniques after $10,000-\mathrm{hr}$ thermal exposures at temperalures of 427 to $538^{\circ} \mathrm{C}\left(800\right.$ to $\left.1000^{\circ} \mathrm{F}\right)$. Thermal aging at $427^{\circ} \mathrm{C}$ resulted in no loss in toughness in either 
the parent materials or the weld metal. Thermal aging at $538^{\circ} \mathrm{C}$ resulted in a 10 to $20 \%$ reduction in fracture toughness $J_{C}$ for both the parent materials and the weld metal. These toughness levels are high enough to preclude any possibility of nonductile fracture. The aging treatments caused a partial transformation of the residual ferrite into carbides and o phase, which lowered values of toughness by providing microvoid nucleation sites.

Lefebvre et al. [89] measured the influence of severe thermal cycles on the notch toughness of Type 316 stainless steel filler metals. Composjtions ranged from 17.7 to $19.4 \mathrm{wt} \%$ chromium and 3 to $10 \% \delta$ ferrite. After an isothermal aging treatment of $100 \mathrm{hr}$ at $750^{\circ} \mathrm{C}\left(1382^{\circ} \mathrm{F}\right)$, values of Charpy V-Notch impact strength at $20^{\circ} \mathrm{C}$ were maintained above $15 \mathrm{~J}$ for all compositions. The impact values decreased with increasing chromium and ferrite contents. An optimized chromium level of $18.3 \%$ and a ferrite content of $4 \%$ resulted in aged impact strength values of 25 to $30 \mathrm{~J}$. After the aging treatment, the residual ferrite had obviously fully decomposed, and o phase is believed to be primarily responsible for the decrease in impact values.

Alloy systems based on transition metals iron and nickel that also contain titanium, vanadium, or chromium can form a number of intermetallic phases. The austenitic atloys can form $\sigma, \chi$ and Laves phases that are thermodynamically stable. The compositions of these phases may adhere strictly to the prescribed stoichiometric ratios, or the phases may exist over a range of compositions. The o phase, which has a tetragonal structure, can range in composition from $B_{4} A$ to $A_{4} B$. The $\chi$ phase has a bec- $\alpha \mathrm{Mn}$ structure with the formula (FeNi) ${ }_{36} \mathrm{Cr}_{12} \mathrm{Mo}_{10}$ [90], and the Laves phase has a hexagonal structure with the formula $\mathrm{Fe}_{2} \mathrm{Mo}$ [91]. The occurrence of these phases can be correlated with the electron/atom ratio, atomic size, and atomic compressibility. The conditions under which these phases form are quite complex, and this complexity is compounded by the fact that these phases do not form independently. They generally precipitate over the lemperature range $600^{\circ} \mathrm{C}<\mathrm{T}<1150^{\circ} \mathrm{C}\left(1112^{\circ} \mathrm{F}<T<2102^{\circ} \mathrm{F}\right)$.

The o phase has been extensively studied because it occurs in alloys used at elevated temperatures. Sigma is a hard, brittle, nonmagnetic phase in stainless steel that was first noted by Bain and Griffiths [92] in 1927. In Type 304 stainless steel, the formation of $\sigma$ is promoted by the presence of silicon, which appears to broaden the composition range in which o is stable. The addition of molybdenum, as in Type 316 stainless steels, tends to further broaden the range of stability of o phase. Phase equilibrium diagrams for a $70 \mathrm{wt} \%$ iron alloy containing molybdenum, nickel, and chromium were determined by Bechtoldt and Vacher [9]] and are presented in Fig. 32. Note that, in the region near the composition of Type 3161 stainless steel (16-18 Cr. 10-14 $\mathrm{Ni}, 2-3 \mathrm{Mo}$ ), the equilibrium phases change from $\alpha+\gamma$ at $1204^{\circ} \mathrm{C}\left(2200^{\circ} \mathrm{F}\right)$ to $\alpha+\gamma+\chi+$ Laves at $815^{\circ} \mathrm{C}\left(1500^{\circ} \mathrm{F}\right)$. The formation of the $\sigma$ and $\chi$ phases can result in equilibrium $\chi$ and Laves phases as molybdenum content increases.

The formation of o phase in austenitic alloys generally leads to a reduction in fracture toughness. This reduction in toughness is most pronounced at ambient temperatures, as shown in Fig. 33. This figure indicates a dramatic decrease in fracture toughness with increasing o content in high-nickel, high-chromium austenitic alloys. Although precipitation will not be as pronounced in Type 316L stainless steels, the formation of even a small amount of o phase can have a significant impact on the mechanical properties. Sigma-phase formation is primarily a concern at temperatures below about $600^{\circ} \mathrm{C}\left(1110^{\circ} \mathrm{F}\right)$ [93]. Intergranular corrosion of alloys containing o phase has been observed in oxidizing environments [94]. Sigma is not resistant to strong oxidizing media such as hot concentrated nitric acid, which leads to intergranular atfack when the $\sigma$ phase is distributed along grain boundaries. Recognizing that $\sigma$ phases can potentially develop, it is equally important that the kinetics of the reaction be evaluated $[95,96]$.

Willingham and Gooch [95] present data on o formation in Type 316L stainless steel in times as short as $2 \mathrm{~min}$ at a temperature of $850^{\circ} \mathrm{C}$ $\left(1562^{\circ} \mathrm{F}\right)$. It has generally been accepted that the formation of $\sigma$ requires times considerably longer than that suggested above. Nevertheless, once initiated, $\sigma$ formation might be rapid, should the bulk material structure promote further transformation. Blenkinsop and Nutting [96] examined $\sigma$ and carbide formation and concluded that carbide $\mathrm{M}_{23} \mathrm{C}_{6}$ does not nucleate a phase. They also suggested that cold work could produce o nucleation sites and that, the greater the deformation, the more extensive the effect. 

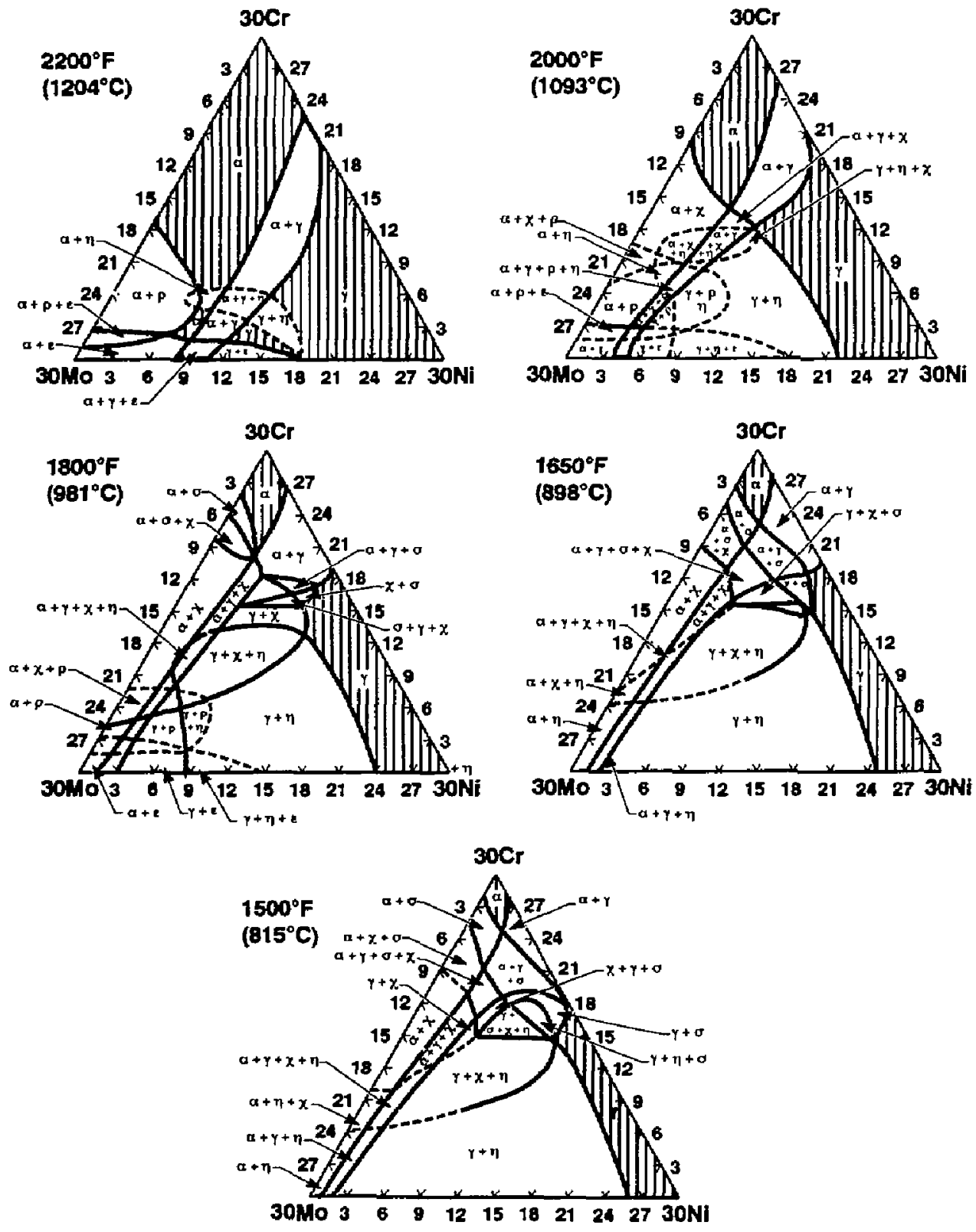

Figure 32. Phase equilibrium diagrams for high-purity iron-chromium-nickel alloys containing 70 wt\% iron [91]. 


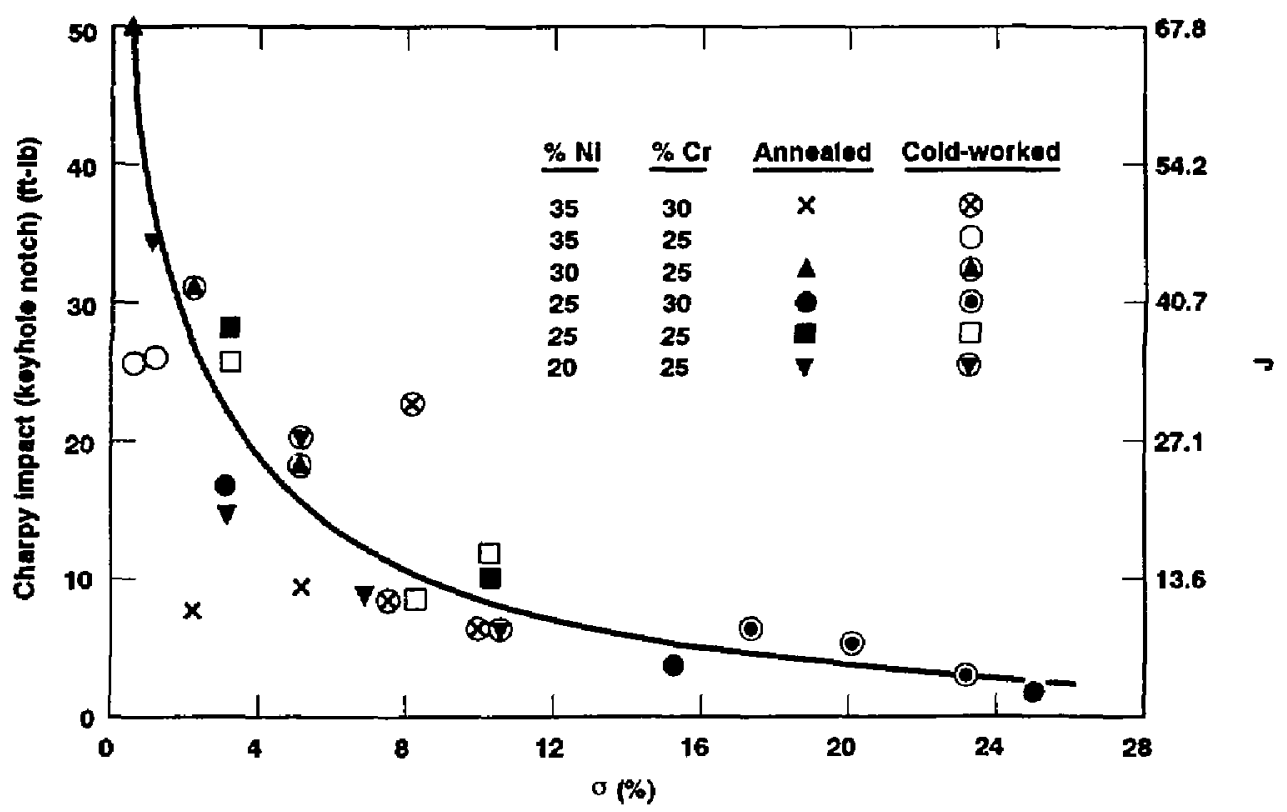

Figure 33. Effect of $\sigma$ phase formation on room-temperature impact strength of iron-chromium-nickel alloys [93].

In terms of potential $\sigma$ formation, Alloy 825 has to be treated differently from Type 316L stainless steel since it is an austenite-stable material throughout the temperature range (from the solidus to room temperature). Figure 4 shows a cross section of the iron-chromium-nickel phase diagram as a function of temperature and alloy content. Note that Alloy 825 would correspond to an iron content of approximately $30 \%$, which is beyond the left side of this figure. Type 316L stainless steel contains between 60 and $70 \%$ iron and could be considered a metastable austenitic alloy as shown in Fig. 3. Below about $70 \%$ iron, the $\gamma$ pilese is stable throughout the entire temperature range. This points out the unlikelihood of $\sigma-, x-$, o l aves-phase formation in Alloy 825; $\mathrm{n} n$ data have been identified that document the formation of these phases. This information agrees well with the equilibrium phase diagram for the iron-chromium-nickel ternary system shown in Fig. 5. Investigation of the stability of a potential filler metal (Alloy 625) for Alloy 825 indicated no intermetallic formation following extended heat treatment in the temperature range of 593 to $927^{\circ} \mathrm{C}\left(1100\right.$ to $\left.1700^{\circ} \mathrm{F}\right)$ [97].
The presence of microfissures is another concern with respect to the toughness of weldments. In a review [68], Lundin notes that despite the known presence of fissure-like discontinuities in austenitic alloy weldments, no documented evidence exists linking these defects to failures. On the contrary, investigators have found little if any consequence of microfissures on the mechanical properties of austenitic alloys. Static tests show no influence on the tensile strength of weld joints unless the microcracked area exceeds $5 \%$ of the weld cross section. In toughness and impact testing of Types 316 and 310 stainless steels containing microcracks, no unstable crack propagation occurred from $+18^{\circ} \mathrm{C}$ to $-196^{\circ} \mathrm{C}$. Microcracks had no influence on fatigue life in the same weldments. Fatigue-crack initiation sites were distributed between microfissures, specimen corners, and acceptable discontinuities such as inclusions, with no dominance of one type over another. Basically, the critical flaw size in austenitic alloys is much larger than the sizes of any microcracks normally found. 


\section{Summary}

The complexity of the fusion-welding process gives rise to several concerns regarding potential degradation modes in austenitic weldments. The principal concerns are: (i) resistance to sensitization and SCC, (2) weld cracking, and (3) brittle intermetallic formation. None of the three auslenitic candidates dominates in its resistance to all of these concerns. Therefore, priority is placed on the material- and service-dependent concerns of corrosion and embrittlement. Weld cracking is a fabrication concern amenable to control by the proper selection of filler-metal chemistry and welding procedures.

Compositional models relate increased resistance to sensitization to increases in chromium and molybdenum contents and decreases in carbon and nickel additions. From such analysis, and from available data, the resistance of Type $316 \mathrm{~L}$ stainless steel to sensitization is rated superior to that of Type 304L stainless steel. Extension to actual heat chemistries of Alloy 825 predicts further improvement in resistance to sensitization. The degree of sensitization (DOS) is most effectively lowered by reductions in carbon content. Excellent resistance to sensitization can be achieved by stabilization of the carbon otherwise available for sensitization in a form that does not result in nonpassivating chromium-depleted regions. While Alloy 825 is partially stabilized by titanium and is amenable to thermal stabilization, specification of low carbon content is recommended.
Susceptibility to IGSCC is expected to be related to the DOS. In as-welded (unsensitized) stainless steels containing ferrite, however, SCC can aiso occur by preferential interphase attack or by TGSCC outside the FZ. Alloy 825 is predicted to be immune from TGSCC in the parent metal because of its high nickel content.

The principal concern regarding the cracking of weldments in the austenitic candidates is microfissuring. Considerable doubt exists with respect to the significance of these typically small cracks on the mechanical behavior of ductile materials such as the austenitic alloys. However, it is well documented that the presence of $\delta$ ferrite in the FZ will severely limit microfissuring. At equivalent $\delta$ ferrite levels, Type $304 \mathrm{~L}$ stainless steel is more resistant to microfissuring than Type $316 \mathrm{~L}$ stainless steel. Prevention of fissuring in fully austenitic steels requires special control of impurity levels and may require fabrication constraints. Substitution of Alloy 625 filler metal may be the best method of ensuring proper resistance to cracking in Alloy 825 . This filler metal is noble with respect to Alloy 825 and is also resistant to intermetallic formation.

The ranking of these austenitic candidates in terms of resistance to welding-induced degradation is: Alloy 825 (best) > Type 316L stainless steel > Type 304L stainless steel (worst).

\section{Acknowledgments}

This work was performed under the auspices of the U.S. Department of Energy by Lawrence Livermore National Laboratory under contract No. W-7405-ENG-48, and was supported by the Yucca Mountain Project. 


\section{References}

1. "Disposal of High-Level Radioactive Wastes in Geologic Repositories, Technical Criteria," 10 CFR Part 60, Nuclear Regulatory Agency, Federal Register, Rules and Regulations, Vol. 48, No. 120, Tuesday, June 21, 1983, pp. 28194-28229. HQ2.870302.4901, HQ2.870302.5242

2. "Environmental Standards for the Management and Disposal of Spent Nuclear Fuel, High-Level and Transuranic Radioactive Wastes," 40 CFR Part 191, Environmental Protection Agency, Federal Register, Rules and Regulations, Vol. 50, No. 192, Thursday, September 19, 1985, pp. 38066-38089. HQ2.870228.0724

3. W. F. Savage, "Solidification, Segregation, and Weld Defects," in Weldments: Physical Melallurgy and Failure Phemomena, Proceedings of the Fifth Bolton Landing Conference, August 1978, General Electric Co., pp. 1-18. NNA.890928.0002

4. P. Patriarca, "Effects of Minor Elements on the Weldability of High-Nickel Alloys," in Effects of Minor Elements on the Weldability of High-Nickel Alloys, Welding Research Council (July 1969). NNA.890928.0003

5. C. J. Novak, "Structure and Constitution of Wrought Auslenitic Stainless Steels," Handbook of Stainless Steels, Peckner and Bernstein, Eds., McGraw-Hill Book Co., New York, 1977, Chapter 4. NNA.891009.0002

6. P. Marshall, Austenitic Stainless Steels: Microstructure and Mechanical Properlies, Elsevier Publishers, London, 1984.

7. W. Betteridge, Nickel and Jis Alloys, Halsted, New York, 1984.

8. M. Hansen, K. Anderko, Constitution of Binary Alloys, Second ed., MoGraw-Hill Book Co., New York, 1958, p. 687. NNA.891009.0004

9. S. D. Kaiser, "Welding High-Nickel Alloys: Different but Not Difficult," Welding Journal, October 1988, pp. 55-57. NNA.890928.0004

10. A. Garner, "The Effect of Autogenous Welding on Chloride Pitting Corrosion in Austenitic Stainless Sleels," Corrosion, Vol. 35, No. 3, March 1979, pp. 108-114. NNA.890928.0005

11. S. A. David, G. M. Goodwin, D. N. Braski, "Solidification Behavior of Austenitic Stainless Stcel Filler Metals," Welding Journal, Vol. 58, No. 11, November 1979, pp. 330s-336s. NNA.890928.0006

12. A. Garner, 'Titting Corrosion of High Alloy Stainless Steel Weldments in Oxidizing Environments," Welding Journal, Vol. 62, No. 1, January 1983, pp. 27-34. NNA.890928.0007

13. D. E. Hetzel, "Intergranular Stress Corrosion Cracking in Welded, Unstabilized Austenitic Stainless," Metal Progress, March 1984, pp. 73-78. NNA.890928.0008

14. D. H. Sherman, D. J. Duquette, W. F. Savage, "Stress Corrosion Cracking Behavior of Duplex Stainless Stcel Weldments in Boiling $\mathrm{MgCl}_{2}$ " Corrosion, Vol. 31, No. 10, October 1975, pp. 376-380. NNA.890928.0009

15. R. G. Ellis, G. Pollard, "Technical Note: The Observation of Sigma Phase after Short Aging Times in a Duplex Steel," Journal of the Iron and Steel Institute, August 1970, pp. 783-784. NNA.890928.0010

16. R. A. Farrar, "Influence of Microsegregation on Phase Transformations and Properties of Type 316L Weld Metals at Elevated Temperatures," in Stainless Steel "84 Conference, University of Technology, Goteberg, Sweden, 3-4 Sept. 1984, The Institute of Metals, 1985, pp. 336-342. NNA.890928.0011

17. C. D. Lundin, C. H. Lee, R. Menon, E. E. Stansbury, Sensitization of Austenitic Stainless Steels; Effect of Welding Variables on HAZ Sensitization of AISI 304 and HAZ Behavior of BWR Alternative Alloys 316 NG and 347, Welding Research Council Bulletin 319 (November 1986). NNA.890928.0012

18. A. Garner, "How Stainless Steel Welds Corrode," Metal Progress, April 1985, pp. 31-36. NNA. 890928.0013

19. E. C. Bain, R. H. Aborn, J. J. B. Rutherford, "The Nature and Prevention of Intergranular Corrosion in Austenitic Stainless Stcels," Transactions of American Society for Steel Treating, Vol. 21, June 1933, pp. 481-509. NNA.890928.0014

20. R. Stickler, A. Vinckier, "Electron Microscope Investigation of the Intergranular Corrosion Fracture Surfaces in a Sensitized Austenitic Stainless Steel, " Corrosion Science, Vol. 3, 1963, pp. 1-8. NNA.890928.0015 
21. K. T. Aust, "Intergranular Corrosion of Austenitic Stain]ess Steel," Transactions of the Metallurgical Society of ALME, Vol. 245, October 1969, pp. 2117-2126. NNA.890928.0016

22. A. Joshi, D. F. Stein, "Chemistry of Grain Boundaries and Its Relation to Intergranular Corrosion of Austenitic Stainless Steel," Corrosion, Vol. 28, No. 9, September 1972, pp. 321-330. NNA.890928.0017

23. C. Stawstrom, M. Hillert, "An Improved Depleted-Zone Theory of Intergranular Corrosion of 18-8 Stainless Steel," Journal of Iron and Steel Institute, January 1969, pp. 77-85. NNA.891005.0144

24. R. L. Cowan, C. S. Tedmon, "Intergranular Corrosion of Iron-Nickel-Chromium Alloys," Advances in Corrosion Science and Techrology, Vol. 3, M. G. Fontana, R. W. Staehle, Eds., 1973, pp. 293-401. NNA.890921.0111

25. C. S. Tedmon, D. A. Vermilyea, J. H. Rosolowski, "Intergranular Corrosion of Austenitic Stainless Steel," Journal of the Electrochemical Society, Vol. 118, No. 2, February 1971, pp. 192-202. NNA.891005.0145

26. C. Wagner, Thermodynamics of Alloys, Addison-Wesley, Reading, Massachusetts (1952), p. 51.

27. C. L. Briant, R. A. Mulford, E. L. Hall, "Sensitization of Austenitic Stainless Steels, I. Controlled Purity Alloys," Corrosion, Vol. 38, No. 9, September 1982, pp. 468-477. NNA.891005.0155

28. ASTM Designation: A 262-86, "Standard Practices for Delecting Susceptibility to Intergranular Attack in Austenitic Stainless Steels," Annual Book of ASTM Standards, Vol. 01.05, pp. 62-79, American Society for Testing and Materials, Philadelphia, Pennsylvania, 1988. NNA.890928.0018

29. W. O. Binder, C. M. Brown, R. Franks, "Resistance to Sensitization of Austenitic Chromium-Nickel Steels of 0.03\% Max. Carbon Content," Transactions of the American Society for Metals, Vol. 41, 1949, pp. 1301-1370. NNA.890928.0019

30. E. L. Hall, R. A. Mulford, C. L. Briant, An Investigation of the Comparative Corrosion Behavior and Grain Boundary Structure of Low Carbon, High Nitrogen Stainless Steels, Electnic Power Research Institute, Palo Alto, California, EPRI NP-2671 (October 1982), Appendix G.

31. V. Cihal, "Factors Determining Resistance to Intergranular Corrosion; Importance of Chemical Composition," in Inlergranular Corrosion of Steels and Alloys, Materials Science Monographs, 18, Elsevier, New York, 1984, Chapter 4.1, pp. 130-141. NNA.890928.0020

32. R. Fullman, "A Thermodynamic Model of the Effects of Composition on the Susceptibility of Austenitic Stainless Steels to Intergranular Stress Corrosion Cracking," Acta Metallurgica, Vol. 30, 1982, pp. 1407-1415. NNA.891005.0146

33. S. M. Bruemmer, "Composition-Based Correlations to Predict Sensitization Resistance of Austenitic Stainless Steels," Corrosion, Vol. 42, No. 1, January 1986, Pp. 27-35. NNA.891005.0149

34. J. N. Kass, J. C. Lemaire, R. B. Davis, J. E. Alexander, J. C. Danko, "Comparative Stress Corrosion Behavior of Welded Austenitic Stainless Steel Pipe in High Temperature High Purity Oxygenated Water," Corrosion, Vol. 36, No. 12, December 1980, pp. 686-698. NNA.890928.0021

35. R. A. Mulford, E. L. Hall, C. L. Briant, "Sensitization of Austenitic Stainless Steels, Il. Commercial Purity Alloys," Corrosion, Vol. 39, No. 4, April 1983, pp. 132-143. NNA.891005.0154

36. H. Erhart, H. J. Grabke, "Site Compelition in Grain Boundary Segregation of Phosphorus and Nitrogen in Iron," Scripta Metallurgica, Vol. 15, 1981, pp. 531-534. NNA.890928.0022

37. S. M. Bruemmer, L. A. Charlot, D. G. Atteridge, Evaluation of Welded and Repair-Welded Stainless Steel for Light Water Reactor (LWR) Service: Compositional Effects on the Sensitization of Austenitic Stainless Steels, Nuclear Regulatory Commission, Washington, D.C., NUREG/CR-3918 (1984). NNA.890928.0023

38. A. P. Majidi, M. A. Streicher, "Totentiodynamic Reactivation Method for Detecting Sensitization in AISI 304 and 304L Stainless Steels," Corrosion, Vol. 40, No. 8, August 1984, pp. 393-408. NNA.890921.0115

39. W. L. Clarke, R. L. Cowan, W. L. Walker, "Comparat' :e" thods for Measuring Degree of Sensitization in Stainless Steel," in Intergranular Corrost , $n$ of Stainless Alloys, American Society for Testing and Materials, ASTM STT 656 (1978), pp. 99-132. NNA.890928.0024

40. M. J. Povich, P. Rao, "Low Temperature Sensitization of Welded Type 304 Stainless Steel," Corrosion, Vol. 34, No. 8, August 1978, pp. 269-275. NNA.891005.0159

41. H. D. Solomon, "Continuous Cooling Sensitization of Type 304 Stainless Steel," Corrosion, Vol. 34, No. 6, June 1978, pp. 183-193. NNA.890928.0025 
42. A. A. Wells, "The Mechanics of Notch Brittle Fracture," Welding Research, Vol. 7, 1953, pp. 34r-56r. NNA.890928.0026

43. H. D. Solomon, "Variables Influencing Weld Sensitization of Austenitic Stainless Steel," Weldments: Physical Metallurgy and Failure Phenomena, Proceedings of the Fifth Bolton Landing Conference, R. J. Christoffel, E. F. Nippes, H. D. Solomon, Eds., General Electric Company, August 1978, pp. 149-163.

44. H. D. Solomon, D. C. Lord, "Influence of Strain During Cooling on the Sensitization of Type 304 Stainless Steel, "Corrosion, Vol. 36, No. 8, August 1980, pp. 395-399. NNA.890928.0027

45. A. Cigada, B. Mazza, P. Pedeferri, G. Salvaga, D. Sinigaglia, G. Zanini, "Stress Corrosion Cracking of Cold Worked Austenitic Stainless Steels," Corrosion Science, Vol. 22, No. 6, 1982, pp. 559-578. NNA.890928.0028

46. C. L. Briant, A. M. Ritter, "The Effect of Cold Work on the Sensitization of 304 Stainless Steel," Scripta Metallurgica, Vol. 13, 1979, pp. 177-181. NNA.890928.0029

47. C. L. Briant, "Sensitization of Partially Martensitic Stainless Steel at Very Low Temperatures," Corrosion, Vol. 38, No. 11, November 1982, pp. 596-597. NNA.890928.0030

48. C. L. Briant, A. M. Ritler, "The Effects of Deformation Induced Martensite on the Sensitization of Austenitic Stainless Steels," Metallurgical Transactions $A_{r}$ Vol. 11A, No. 12, 1980, pp. 2009-2017. NNA.890928.0031

49. C. L. Briant, A. M. Ritter, "The Ef ect of Martensite on the Sensilization of Low Carbon 304 Stainless Steel," Metallurgical Transactions ,Vol. 11A, No. 5, May 1981, pp. 910-913. NNA.890928.0032

50. R. Stickler, A. Vinckier, "Morphc logy of Grain Boundary Carbides and Its Influence on Intergranular Cortosion of 304 Stainless," Transactions of the American Society for Metals, Vol. 54, 1961, pp. 362-380. NNA.891009.1023

51. E. M. Mahla, N. A. Nielsen, "Car! ide Precipitation in Type 304 Stainless Steel-An Electron Microscope Study," Transactions of the American Society for Metals, Vol. 43, 1951, pp. 290-322. NNA.890928.0033

52. M. J. Povich, "Low Temperature Sensitization of Type 304 Stainless Steel," Corrosion, Vol. 34, No. 2, February 1978, pp. 60-65. NNA. 991005.0160

53. T. Kekkonen, P. Aaltonen, H. Hai ninen, "Metallurgical Effects on the Corrosion Resistance of a Low Temperature Sensitized Welded AISI Type 304 Stainless Steel," Corrosion Science, Vol. 25, No. 8/9, pp. 821-836. NNA.891C 35.0152

54. R. A. Perkins, R. A. Padgett, N. K Tunali, "Tracer Diffusion of ${ }^{59} \mathrm{Fe}$ and ${ }^{51} \mathrm{Cr}$ in Fe-17 Wt. Pct. Cr-12 Wt. Pct. Ni Austenitic Alloy," Me. allurgical Transactions, Vol. 4, November 1973, pp. 2535-2540. NNA.890928.0034

55. M. J. Fox, R. D. MCCright, An Overview of Low Temperature Sensitization, Lawrenc Livermore National Laboratory, Livermore, California, UCRL-15619 (1983). SRX.840824.0356, HQS.880517.2438

56. S. Hattori, T. Yokosuka, Y. Uraya na, Y. Mori, "Study on Low Temperature Sensitization in Austenitic Stainless Steel Pipe Wulds," Paper No. 6, International Workshop on Low Temperature Sensitization, Electric Power Research Institute, Palo Alto, Calif, January 1982. NNA.890928.0035

57. T. Kawakubo, H. Nakada, M. Hishida, "Effect of Strain and Sensitization of Type 316 S.S.," personal communication, 1978.

58. H. Tsuge, H. Nagano, "Low Tem perature Sensitization Behavior of Austenitic Stainless Steel," Transactions of the Iron and Steel Ir. stitute of Japan, Vol. 24, No. 7, 1984, B-235. NNA.890928.0036

59. M. H. Brown, R. W. Kirchner, "Sensitization of Wrought High Nickel Alloys," Corrosion, Vol. 29, No. 12, December 1973, pp. 470-471. NNA.891009.0031

60. M. H. Brown, "The Relationship of Heat Treatment to the Corrosion Resistance of Stainless Alloys," Corrosion, Vol. 25, No. 10, October 1969, pp. 438-443. NNA.891009.0032

61. E. L. Raymond, "Mechanisms of Sensitization and Stabilization of Incoloy Nickel-Iron-Chromium Alloy 825," Corrosion, Vol. 24, Nc. 6, June 1968, pp. 180-188. NNA.831009.0034

62. H. R. Copson, B. E. Hopkinson, F. S. Lang, "Behavior of Ni-O-Nel Nickel-Iron-Chromium Alloy in Intergranular Corrosion Evaluat on Tests," ASTM Proceedings, Vol.61, 1961, pp. 879-888. NNA.891009.0033 
63. W. L. Clarke, D. C. Carlson, "Nondestructive Measurement of Sensitization of Stainless Steel Reaction to High Temperature Stress Corrosion Behavior," Materials Performance, Vol. 19, No. 3, March 1980, pp. 16-23. NNA.890928.0037

64. S. Pednekar, S. Smialowska, "The Effect of Prior Cold Work on the Degree of Sensitization in Type 304 Stainless Steel," Corrosion, Vol. 36, No. 10, October 1980, pp. 565-577. NNA.890928.0038

65. F. Stalder, D. J. Duquette, "Slow Strain Rate Stress Corrosion Cracking of Type 304 Stainless Steels," Corrosion, Vol. 33, No. 2, February 1977, pp. 67-72. NNA.890928.0039

66. W. A. Baeslack, D. J. Duquette, W. F. Savage, "The Effect of Ferrite Content On Stress Corrosion Cracking in Duplex Stainless Steel Weld Metals at Room Temperature," Corrusion, Vol. 35, No. 2, February 1979, pp. 45-54. NNA.890928.0040

67. T, G. Gooch, J. Honeycombe, P. Walker, "Totentiostatic Study of the Corrosion Behaviour of Austenitic Stainless Steel Weld Metal," British Corrosion Journal, Vol. 6, July 1971, Pp. 148-154. NNA.890928.0041

68. C. D. Lundin, C. P. D. Chow, Hot Cracking Susceptibility of Austenitic Stainless Steel Weld Metals, Welding Research Council Bulletin No. 289 (1983). NNA.890928.0042

69. N. Morishige, M. Kuribayashi, H. Okabashi, Effects of Chemical Composition of Base Metal On Susceptibility To Hot Cracking In Austenitic Stainless Steel Welds, IIW Document DX-1114-79, 1979.

70. J. C. Borland, "Generalized Theory of Super-Solidus Cracking in Welds (and Castings)," British Welding Journal, Vol. 7, No. 1, January 1960, pp. 508-512. NNA.890928.0043

71. J. C. Borland, R. N. Younger, "Some Aspects of Cracking in Welded Cr-Ni Austenitic Steels," British Welding Journal, Vol. 7, No. 1, January 1960, pp. 22-59. NNA.890928.0044

72. J. C. Borland, "Suggested Explanation of Hot Cracking in Mild and Low Alloy Steel Welds," British Welding Journal, Vol. 8, No. 11, November 1961, pp. 526-540. NNA.890928.0045

73. R. D. Thomas, "HAZ Cracking in Thick Sections of Austenitic Stainless Steels-Part 11," Welding Journal, Vol. 63, No. 12, December 1984, pp. 355s-368s. NNA.890928.0046

74. F. C. Hull, "Effect of Delta Ferrite on the Hot Cracking of Stainless Steel," Welding Journal, Vol.46, No. 9, September 1967, pp. 399s-409s. NNA.890928.0047

75. H. Astrom, B. Loberg, B. Bengtsson, K. E. Easterling, "Hot Cracking and Micro-Segregation in 18-8 Stainless Steel Welds," Metal Science, July 1976, pp. 225-234. NNA.890928.0048

76. J. C. Lippold, Weld-Cracking Mechanisms in Austeritic Stainless Steels, Sandia National Laboratories, SAND 82-8238 (September 1982). NNA.890928.0049

77. F. Matsuda, H. Nakagawa, T. Uehara, S. Katayama, Y. Arata, "A New Explanation for Role of Delta Ferrite Improving Weld Solidification Crack Susceptibility in Austenitic Stainless Steel," Transactions JWRI, Vol. 8, No. 1, 1977.

78. A. L. Schaeffer, "Constitution Diagram for Stainless Steel Weld Metal," Metal Progress, Vol. 56, No. 5, November 1949, pp. 680-680-B. NNA.890928.0050

79. W. T. DeLong, "A Modified Phase Diagram for Stainless Steel Weld Metals," Metal Progress, Vol. 77. No. 2, February 1960, pp. 98-100.

80. J. C. Lippold, "An Investigation of Weld Hot Cracking in Alloy 800," Welding Journal, Vol. 63, No. 3 , March 1984, pp. 915-1035. NNA.890928.0051

81. P. Cheng, FPD, personal communication (1988).

82. R. Bishel, International Nickel Company, Huntington, West Virginia, personal communication (1988).

83. C. E. Witherell, Lawrence Livermore National Laboratory, Livermore, California, personal communication (1988). NNA.890928.0052

84. A. I. Asphahani, "Effects of Acids on the Stress Corrosion Cracking of Stainless Materials in Dilute Chloride Solutions," Materials Performance, Vol. 19, No. 11, November 1980, pp. 9-14. NNA.890831.0066

85. A. G. Lingenfelter, Lawrence Livermore National Laboratory, Livermore, California, personal communication (May 1988).

86. "Electrodes and Rods-Welding Bare Nickel Alloys," U.S. Department of Defense, Naval Publications and Forms Center, Philadelphia, Pennsylvania, Mil-E-21562 (September 29, 1982).

87. "Boiler and Pressure Vessel Code," BPV 1986, Section 2, Part C, American Society of Mechanical Engineering, New York (also, AWS B-30, American Welding Society). 
88. W. J. Mills, "Fracture Toughness of Aged Stainless Steel Primary Piping and Reactor Vessel Materials," Journal of Pressure Vessel Technology, Transactions ASME, Vol. 109, No. 11, November 1987, pp. 440-448. NNA.890928.0053

89. J. Lefebvre, R. Daeman, M. Niset, "Welding Consumables for AISI 316 High Temperature Weldments," Stainless Steel '84 Conference, University of Technology, Goteberg, Sweden, 3-4 September, 1984, The Institute of Metals, 1984, pp. 330-335. NNA.890928.0054

90. B. Weiss, R. Stickler, "Thase Instabilities during High Temperature Exposure of 316 Austenitic Stainless Steel," Metallurgical Transactions, Vol. 3, April 1972, pp. 851-866.

91. C. J. Bechtoldt, H. C. Vacher, "Thase-Diagram Study of Alloys in the Iron-ChromiumMolybdenum-Nickel System,' Journal of Research, National Bureau of Standards, Vol. 58, No. 1, January 1957, pp. 7-19. NNA.891009.0027

92. E. C. Bain, W. E. Griffiths, "An Introduction to the lron-Chromium-Nickel Alloys," Transactions of the AIME, Vol. 75, 1927, pp. 166-213. NNA.891009.0028

93. A. M. Talbot, D. E. Furman, "Sigma Formation and Its Effect on the Impact Properties of IronNickel-Chromium Alloys," Transactions of the A.S.M., Vol. 45, 1942, p. 429 . NNA.891009.0029

94. M. Henthorne, "Intergranular Ccrosion in Iron and Nickel Base Alloys," in Localized CorrosionCause of Metal Failure, ASTM Special Technical Publication 516, 1972, pp. 66-119. NNA.890928.0055

95. D. C. Willingham, T. G. Gooch, "Sigma Formation in Austenitic Stainless Steel Weld Metal," The Welding Institute Research Bulletin, Vol. 12, No. 8, August 1971. NNA.890928.0056

96. P. A. Blenkinsop, J. Nutting, "Trecipitation of the Sigma Phase in an Austenitic Steel," Journal of the Iron and Steet Institute, September 1967, pp. 953-958. NNA.890928.0057

97. W. Z. Friend, "Corrosion in Nickel and Nickel-Base Alloys," Chapter 8.7, Weldability in Austenitic Alloys, John Wiley and Sons, New York, 1980. NNA.890831.0072

98. K. E. Easterling, Introduction to Physical Metallurgy of Welding, Butterworths, London, 1983.

99. J. C. Lippold, W. F. Savage, "Solidification of Austenitic Stainless Steel Weldments: Part lII-The Effect of Solidification Behavior on Hot Cracking Susceptibility," Welding Journal, Vol. 61, No. 12, December 1982, pp. 388s-396s. NNA.890928,0058

100. T. M. Devine, B. J. Drummon, "Use of Accelerated Intergranular Corrosion Tests to Detect Sensitization and Susceptibility to Intergranular Stress Corrosion Cracking in High Temperature Water of D:slex 308 Stainless Steel," Corrosion, Vol. 37, No. 2, February 1981, pp. 104-115. NNA.890928.0059

101. J. W. Pugh, J. D. Nisbet, "Iron-Chromium-Nickel Ternary System," Transactions AIME, Journal of Metals, Vol. 188, February 1950, pp. 268-276. NNA.891009.0005

102. K. T. Aust, J. S. Armijo, E. F. Koch, J. H. Westbrook, "Intergranular Corrosion and Electron Microscopic Shudies of Austenitic Stainless Steel," Transactions of the American Saciely for Metals, Vol. 60, 1967, pp. 360-372. NNA.890928.0060

103. R. C. Scarberry, D. L. Graver, C. D. Stephens, "Alloying For Corrosion Control," Materials Protection, Vol.5, No.6, June 1967, pp. 54-57. NNA.890920.0233

104. ASTM Designation: B 424-87, "Standard Specification for Ni-Fe-Cr-Mo-Cu Alloy (UNS N08825 and UNS N08221) Plate, Sheet, and Strip," Annual Book of ASTM Standards, Vol. 02.04, pp. 251-257, American Society for Testing and Materials, Philadelphia, Pennsylvania, 1988. NNA.890928.0061

105. ASTM Designation: B 409-87, "Standard Specification for Nickel-Iron-Chromium Alloy Plate, Sheet, and Strip," Annual Book of ASTM Standards, Vol. 02.04, pp. 234-241, American Society for Testing and Malerials, Philadelphia, Pennsylvania, 1988. NNA.890928.0062

106. ASTM Designation: B 444-84, "Standard Specification for Nickel-Chromium-MolybdenumColumbium Alloy (UNS N06625) Pipe and Tube," Annual Book of ASTM Standards, Vol. 02.04, pp. 280-284, American Society for Testing and Materials, Philadelphia, Pennsylvania, 1984. NNA.890928.0063

107. V.P. Kujanpaa, "Effects of Steel Type and Impurities in Solidification Cracking of Austenitic Stainless Steel Welds," Metal Construction, January 1985, pp. 40R-46R. NNA.890928.0064

108. J. C. Lippold, "Centerline Cracking in Deep Penetration Electron Beam Welds in Type 304L Stainless Steel," Welding Journal, Vol. 64, No. 5, May 1985, pp. 127s-136s. NNA.890928.0065 
The following number is for Office of Civilian Radioactive Waste Management Records Management purposes only and should not be used when ordering this document:

Accession Number. NNA.891222.0312 